\title{
Climate Change Impacts and Vulnerability Assessment of Selected Municipalities and Agroecosystems to Support Development of Resilient Communities and Livelihoods in Nueva Ecija, Philippines
}

\author{
Annie Melinda Paz-Alberto ${ }^{1 *}$, Ma. Johanna J. de Dios ${ }^{1}$, Roann P. Alberto², \\ Charles Hans Emmanuel A. De Guzman1 \\ ${ }^{1}$ Institute for Climate Change and Environmental Management, Central Luzon State University, Muñoz, Philippines \\ ${ }^{2}$ College of Business Administration and Accountancy, Central Luzon State University, Muñoz, Philippines \\ Email: *melindapaz@gmail.com, mjdedios1970@gmail.com, chyltale.rpa111712@gmail.com, ched150307@gmail.com
}

How to cite this paper: Paz-Alberto, A.M., de Dios, M.J.J., Alberto, R.P. and De Guzman, C.H.E.A. (2018) Climate Change Impacts and Vulnerability Assessment of Selected Municipalities and Agroecosystems to Support Development of Resilient Communities and Livelihoods in Nueva Ecija, Philippines. American Journal of Climate Change, 7, 295-335.

https://doi.org/10.4236/ajcc.2018.72019

Received: January 30, 2018

Accepted: June 25, 2018

Published: June 28, 2018

Copyright $\odot 2018$ by authors and Scientific Research Publishing Inc. This work is licensed under the Creative Commons Attribution International License (CC BY 4.0).

http://creativecommons.org/licenses/by/4.0/

\section{(c) (i) Open Access}

\begin{abstract}
In the last decade, the Philippines had been hit severely by natural disasters brought about by climate change which caused great damages to agriculture. The objectives of the study were to assess climate change impacts and vulnerability of Bongabon, Gabaldon and Cabanatuan City, Nueva Ecija; to assess the vulnerability and suitability of growing various crops, goats and chicken; to generate vulnerability and suitability maps; and to validate the maps produced. A comprehensive scoping, profiling, vulnerability assessment and crop, chicken and goat suitability assessment of the municipalities and agroecosystems of the study sites was done. Generation and validation of the vulnerability and suitability maps were also conducted. Results revealed that Bongabon obtained moderate vulnerability to floods and typhoon while low vulnerability to drought and soil erosion. Gabaldon had moderate vulnerability to floods, soil erosion and drought while low vulnerability to typhoon. Cabanatuan City attained moderate vulnerability to floods and drought while low vulnerability to typhoon. There were four crops suitable to grow in the current condition with flood and landslide hazards and in the two projected future scenarios (RCP 4.5 with good conditions and RCP 8.5 with the worst conditions). Only three crops are highly suitable to grow in Gabaldon for the future conditions while in Cabanatuan City four crops are very suitable for the
\end{abstract}


three situations. Native chicken and goats are highly suitable to raise in the three study sites for the three conditions. There were 16 vulnerability maps developed and generated in Bongabon, 16 in Gabaldon and only 12 in Cabanatuan City. Furthermore, 21 crop, chicken and goat suitability maps were produced in Bongabon, 27 maps in Gabaldon and 21 maps in Cabanatuan City. Overall, validation of the maps in the study sites had high accuracy.

\section{Keywords}

Climate Change, Impact, Hazard Maps, Vulnerability, Crop Suitability, Assessment

\section{Introduction}

In the last decade, the Philippines had been hit severely by natural disasters. The Philippines is prone to about 18 - 21 typhoons per year. In 2005 alone, Central Luzon was hit by both a drought, which sharply curtailed hydroelectric power, and by a typhoon that flooded practically all of the low-lying areas. Its provinces are: Aurora, Bataan, Bulacan, Nueva Ecija, Pampanga, Tarlac, and Zambales. These provinces are also hit by natural disasters yearly. Nueva Ecija is largest province in Central Luzon, covering a total area of 5751.33 square kilometres (2220.60 sq mi). Nueva Ecija is considered the main rice growing province of the Philippines and the leading producer of onions in the municipality of Bongabon in South East Asia. It is currently the ninth richest province in the country. But it is not spared from the devastating effects of extreme weather events brought about by climate change.

Signals of changing climate are already evident in the Philippines as shown in the increasing temperature trends, sea level rise [1] [2] and extreme climate event occurrences [3]. Torrential and intense rainfall, severe storm occurrences and strong typhoons have occurred and being experienced which caused massive landslides and excessive flooding in various parts of the country [3] [4] [5] [6]. It was also during the past 15 years that the Philippines was hit by the strongest typhoon ever recorded, the most destructive, the deadliest, and that registered the highest recorded 24-hour rainfall [3].

Climate change is concurrent with increasing demand for food, feed, fiber and fuel. This phenomenon has the potential to irreversibly damage the natural resource base on which agriculture depends, with significant consequences for food insecurity [7]. The relationship between climate change and agriculture is two-way; agriculture contributes to climate change in several major ways and climate change in general adversely affects agriculture. Agriculture is thus at a crossroad. It has to find ways to feed the world while being environmentally, socially and economically sustainable.

Climate change studies in the Philippines are emerging fast, focusing on different fields of sciences. Several climate change and Vulnerability Assessment 
(VA) studies [3] [8] [9] [10] [11] had in fact been conducted in the Philippines. A lot of studies on the effects of climate change had been done in various ecosystems such as climate variability in lakes [12] (Nzoiwu et al. 2017), climate change impacts in crops and croplands in agro ecosystems [13] [14] as well as influence of climate change in land cover dynamics within the river basins which include mangrove, forest, beach, tidal areas, lagoon, river, settlements, barren salt areas and findings revealed that climate change is intensified by rapid urbanization in these ecosystems [14]. The current study did not in any way duplicate these earlier studies and would in fact use the results of recent studies including those cited above to validate the climate change risks and suitability of selected agri-aqua commodities as climate resilient livelihood options for selected communities in the country.

It is in this context that the knowledge, research and development on climate change and disaster risk reduction management are very imperative. The increasing incidence and intensity of natural hazards and climate change have distinct impacts on the environment and all sectors of the society must make a move to prevent and reduce disaster impacts. Thus, preparedness in the natural hazards or calamities such as fire, earthquake, flood, typhoon, landslide, drought, active volcanoes, tsunamis and tornados that cause damage and harm to environment and human life should be addressed.

There are already many technologies and methodologies recommended for building resilience to climate changes which are not entirely new. Years of farmers' field schools, technology demonstrations and similar initiatives have ensured that farmers "know" about these technologies. However, a system that is site-specific, impact focused and thus workable and responsive to the user's capacities, resources and necessities have not been adequately developed or demonstrated. Hence, this study was conducted to address these needs. This study aimed to assess climate change impacts and vulnerability of Bongabon, Gabaldon and Cabanatuan City, Nueva Ecija; to assess the risk exposure, vulnerability and suitability of growing various commodities (crops, goat and chicken) using the developed vulnerability assessment tool from the present agro-climatic data, results of previous studies and potential climate risk, and climate change hazards in the selected study areas; to generate vulnerability maps and crop suitability maps as affected by climate change impacts, risks and hazards in Bongabon, Gabaldon and Cabanatuan City, Nueva Ecija; and to validate hazard maps and crop suitability maps produced.

\section{Materials and Methods}

\subsection{Scoping}

A comprehensive scoping and profiling of the selected study sites particularly in Gabaldon, Bongabon and Cabanatuan City in Nueva Ecija, Philippines were done. The activity not only guides the detailed activities but also provided the necessary baselines or benchmark data that were useful in monitoring project 
impact and outcomes. The scoping and profiles that were gathered covered both the environmental and socio-demographic characteristics of the study sites.

Among the initial site selection criteria utilized were 1) willingness and commitment of the communities and respective Local Government Units (LGUs) to participate in the study; 2) relevant climate hazards/risk faced to ensure all possible hazards are covered within the context of the various study sites; 3) municipalities with watershed and ecosystems are represented 4) presence of an impacted fisheries and agricultural system; 5) potential and actual contribution of agriculture and fisheries sectors to the local economy; 6) availability of an approved or draft Comprehensive Land Use Plan (CLUP); 7) presence of champions and line agencies; 8) replicability of the study; 9) accessibility of data and related studies on climate change covering the sites and 10) presence of ordinances that could address resource management.

\subsection{Vulnerability Assessment}

Vulnerability assessment was conducted in the whole municipality with various ecosystems of each study site which focused on the exposure and sensitivity of the ecosystems on the climate change hazards such as extreme temperatures (high temperature), very strong and intense rainfall, very strong typhoons (cyclones), and frequent typhoons and occurrence of floods, landslides, etc. A climate change vulnerability assessment checklist was also prepared and was utilized to assess the vulnerability of the selected ecosystems in the three selected study areas.

As in any vulnerability assessment, the bio-geophysical impacts of the climate hazards were identified and quantified. This involved delineating areas, resources, population, and capital at risk. A qualitative assessment of the vulnerability of the communities to climate hazards was also done. The general approach undertaken was implementing a preliminary vulnerability assessment through a community-based participatory approach. This hopes to build a more in-depth understanding of the potential socio-economic impacts of the climate hazards as well as verify the existence of important non-geophysical issues related to climate hazards from the perspective of those who are directly affected i.e. communities.

Focus Group Discussion (FGD) with the representative members of the community for the various sectors of the society was conducted for this activity identified relevant issues related to climate change and their impacts. The FGD helped refine the Key Informant Interview (KII) instrument that was used for a more detailed profiling of the sites. Potential toolkits were used for the VA, which include 1) historical timeline analysis and 2) hazard maps validation/verification and analysis if there are available hazard maps present in the ecosystems. The hazard maps were obtained from National Mapping and Resource Information Authority (NAMRIA), Department of Environment and Natural Resources (DENR), Nueva Ecija Disaster Risk Reduction and Manage- 
ment Office and Light Detection and Ranging (LiDAR) Maps.

\subsection{Risk Exposure and Hazard Mapping}

The municipalities of Bongabon, Gabaldon and Cabanatuan City, Nueva Ecija were selected as the study areas based on the selection criteria. Each municipality was mapped for climate hazards, such as typhoon, flood, drought and landslide in terms of sensitivity maps, exposure maps, climate change adaptation maps and vulnerability map.

Table 1 shows the scale for sensitivity, exposure and vulnerability index for each hazard such as flooding, drought, typhoon or storms and soil erosion while Table 2 presents the scale for Adaptive Capacity for each hazard.

Table 1. Scale for sensitivity, exposure and vulnerability indices.

\begin{tabular}{ccc}
\hline Indicators & Categories & Scale Range \\
\hline VERY LOW & Very Low 1 & $0.20-0.25$ \\
LOW & Very Low 2 & $0.26-0.30$. \\
& Low 1 & $0.31-0.40$ \\
MODERATE 2 & $0.41-0.50$ \\
& Moderate 1 & $0.51-0.60$ \\
HIGH & Moderate 2 & $0.61-0.70$ \\
& High 1 & $0.71-0.80$ \\
VERY HIGH & High 2 & $0.81-0.90$ \\
& Very High 1 & $0.91-0.95$ \\
& Very High 2 & $0.96-1.0$
\end{tabular}

Table 2. Scale for adaptive capacity.

\begin{tabular}{ccc}
\hline Indicators & Categories & Scale Range \\
\hline VERY LOW & Very Low 1 & $0.96-1.00$ \\
LOW & Very Low 2 & $0.91-0.95$ \\
& Low 1 & $0.81-0.90$ \\
MODERATE & Low 2 & $0.71-0.80$ \\
& Moderate 1 & $0.61-0.70$ \\
HIGH & Moderate 2 & $0.51-0.60$ \\
& High 1 & $0.41-0.50$ \\
VERY HIGH & High 2 & $0.31-0.40$ \\
& Very High 1 & $0.26-0.30$ \\
& Very High 2 & $0.20-0.25$ \\
\hline
\end{tabular}


The various sensitivity maps, exposure maps, climate change adaptation maps and vulnerability maps for the three study sites were validated by the local communities which include rice farmers, barangay officials, municipal/city agricultural officers and personnel, etc. in each study site.

\subsection{Crop, Chicken and Goat Suitability Assessment}

Crop, chicken and goat suitability assessment was conducted for each site. The suitability of various commodities (crops, goat and chicken) was determined based on existing data and on potential climate risks using weather and climate projections from Philippine Atmospheric, Geophysical and Astronomical Services Administration (PAGASA). The project used results of available data on hazard risks in the selected areas and other available hazard maps in the municipality, province and region to determine the suitability of the sites in producing specific commodities amidst the hazards and other climate risks prevalent in the area. The data generated from the suitability assessment were based from six indicators and these indicators are temperature, rainfall, soil texture, elevation, slope and land cover. The generation of suitability maps used five different steps. First is the generation of baseline maps that produced the factor maps for the different crops for the province and municipality. Second is the generation of factor maps which was based from the crop requirements and its suitability for the province down to municipality level. Third, it is the identification of crop growth requirements. Fourth, it is the proper generation of criteria and weights to be used in determining the suitability requirement of various crops and when all these steps are combined the suitability maps of various crops in provincial and municipal level was generated. The methodology used for this study were suitability assessment guided by geographic information systems (GIS) and Institutional Analysis and Design (IAD) which consist of 4 steps: 1) secondary data analysis, 2) reconnaissance survey or video tagging of various crops in the municipality, 3) field data or FGD, and 4) community stakeholder validation. Geographic Information System (GIS) was also used in assessing the suitability of crops for the municipality using different criteria and weights which best describe the characteristics of a certain crop. For example, GIS can differentiate and generate slope, temperature, soil class, land cover and elevation which can distinguish the suitable areas for a particular crop.

The rating scales used for the suitability assessment of various crops like rice, bitter gourd (ampalaya), onion, corn, squash, tomato, string bean (sitao), pepper, eggplant, mango and calamansi ranges from 0) restricted, 1) very low, 2) low, 3) moderate, 4) high, 5) very high. The scales were based on the source layer that was used during the generation of suitability maps and these layers are temperature, rainfall, soil texture, elevation, slope and land cover. The weights that were assigned depend on the requirement that is most suitable for a particular crop.

The suitability of crops, goat and chicken for year 2050 was also projected us- 
ing the RCP 4.5 situation which focus on low energy intensity, strong reforestation programs, decreasing use of croplands and grasslands due to yield increases and dietary changes, stringent climate policies, stable methane emissions, and only slight increase of carbon dioxide emissions. Moreover, suitability of crops, goat and chicken were also projected in year 2050 in RCP 8.5 scenario where the situation is three times of today's carbon dioxide emissions, rapid increase in methane emission, increase use of croplands and grasslands which is driven by an increase in population, world population of 12 billion, low rate of technology development, heavy reliance on fossil fuels, heavy energy intensity and no climate change policies implementation. Lastly, the suitability of crops, goat and chicken were also predicted for baseline condition where the current situation and hazards are included such as landslide and flood were taken into consideration in Bongabon and Gabaldon, Nueva Ecija while only flood was involved in Cabanatuan City.

The crop suitability mapping relied heavily on the maps that were generated from the vulnerability assessments that were conducted for the three study sites.

\section{Results and Discussion}

\subsection{Vulnerability Assessment and Mapping}

\subsubsection{Bongabon}

The municipality of Bongabon comprises 28 barangays and 22 barangays are agricultural barangays which grow various crops like: onion, rice, corn and vegetables that have a total agricultural area of 10,219 hectares. The municipality experienced climate change impacts mainly from flooding, drought or heat stress and strong typhoons or storms. Results of vulnerability assessment of climate change impacts in the Municipality of Bongabon, Nueva Ecija revealed that it was affected by the consequences of climate change such as flooding, drought or heat stress and strong typhoons or storms.

\section{1) Flood}

Results of the vulnerability assessment of climate change impacts conducted in Bongabon showed that it is moderately sensitive to flooding with an average of 0.67 ; moderate exposure to flooding with a value of 0.63 . On the other hand, the adaptive capacity to flood is moderate with a value of 0.53 . Bongabon has moderate vulnerability to flooding for it got a value of 0.63 . All barangays in Bongabon, Nueva Ecija have moderate vulnerability to flooding because they have the capacity to adapt and with moderate exposure to hazards (Figure 1).

\section{2) Drought}

Results of the vulnerability assessment for drought of Bongabon, Nueva Ecija is shown in Figure 2. Bongabon has low sensitivity to drought for it got a total average of 0.46 and has very low exposure to drought for it obtained only 0.28 . Bongabon has also low adaptive capacity to cope up with drought for it got an average value of 0.73 . Lastly, it obtained an average vulnerability index of 0.48 which indicates low vulnerability to drought. Almost all barangays have the 


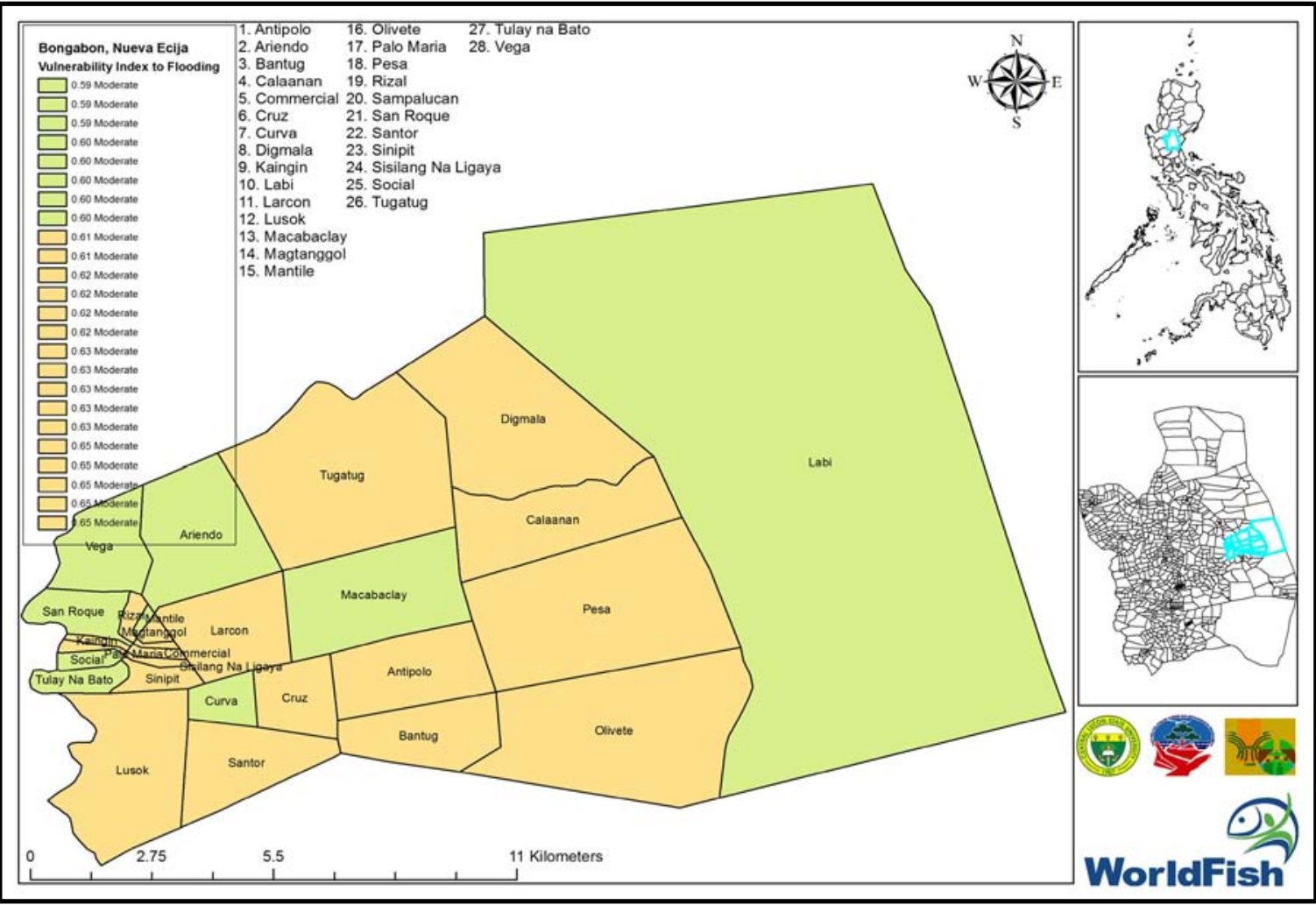

Figure 1. Flood vulnerability map of Bongabon, Nueva Ecija.

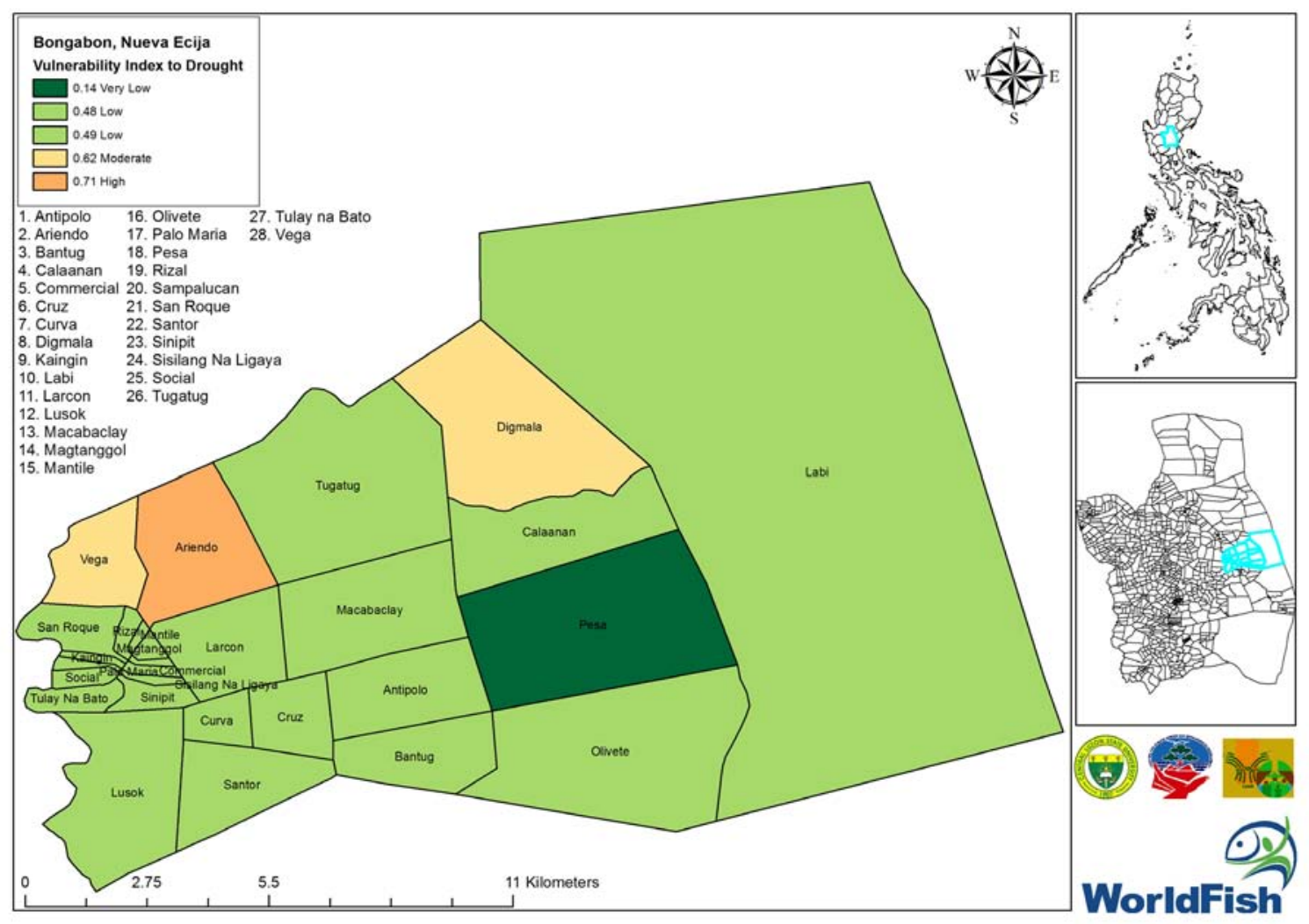

Figure 2. Drought vulnerability map of Bongabon, Nueva Ecija. 
same vulnerability indices for the reason that drought had only a few devastating impacts to agriculture and less economic losses.

All barangays in the municipality of Bongabon, Nueva Ecija have low adaptive capacity to drought for all of the barangays obtained values of 0.73 because only a few barangays used water pump as source of water. Some of the farmers adjusted their planting time and only a few of them could access the drought forecasting information but early warning system was available and accessible to most of them. Thus, farmers can easily adjust in their planting season and crops to be planted.

\section{3) Typhoon}

The results of the VA of Bongabon, Nueva Ecija in terms of typhoons or storms showed that it is highly sensitive to typhoon for it got an average of 0.73 . However, it has moderate exposure to typhoon with an average value of 0.59 . It has very high adaptive capacity to strong typhoons and storms for it obtained an average value of 0.28 . Based on the three parameters which are sensitivity, exposure, and adaptive capacity Bongabon, Nueva Ecija had a total average of 0.51 which indicates that it has a moderate vulnerability index because certain agricultural areas were affected by the frequency of typhoon hence, crop yields decreased resulting in income loss (Figure 3). All barangays have very high adaptive capacity to typhoon because access to typhoon forecasting information and early warning systems are present. This is further helped by the presence of evacuation shelters for farm-based families, access to planting calendar, relevant information, readiness for typhoon and resilient irrigation facilities in Bongabon, Nueva Ecija.

\section{4) Soil Erosion}

The results of VA in terms of soil erosion are moderately sensitive for it got an average of 0.6 , while it is very low in exposure to soil erosion with an average value of 0.20 . It has high adaptive capacity to soil erosion since it obtained a value of 0.46 . Based from the results gained in the (3) parameters the findings indicated that Bongabon has low vulnerability index with regard to soil erosion which got a total average of 0.42 (Figure 4 ).

\subsubsection{Gabaldon}

The municipality of Gabaldon, Nueva Ecija has a total of 16 barangays in which 15 are agricultural based and grow various crops that are almost the same as nearby municipalities. The crops grown in the area are corn, vegetables, sugarcane and onion. Majority of the agricultural areas in Gabaldon are irrigated due to various rivers and streams that surround the municipality which is composed of about 1586.5 hectares.

\section{1) Flood}

Results of the flood vulnerability assessment in Gabaldon showed that the average value of sensitivity to flood is 0.66 which indicates moderate sensitivity to flood. It has also moderate exposure to flood for it got an average of 0.56 while it has moderate adaptive capacity for typhoons. In terms of vulnerability 


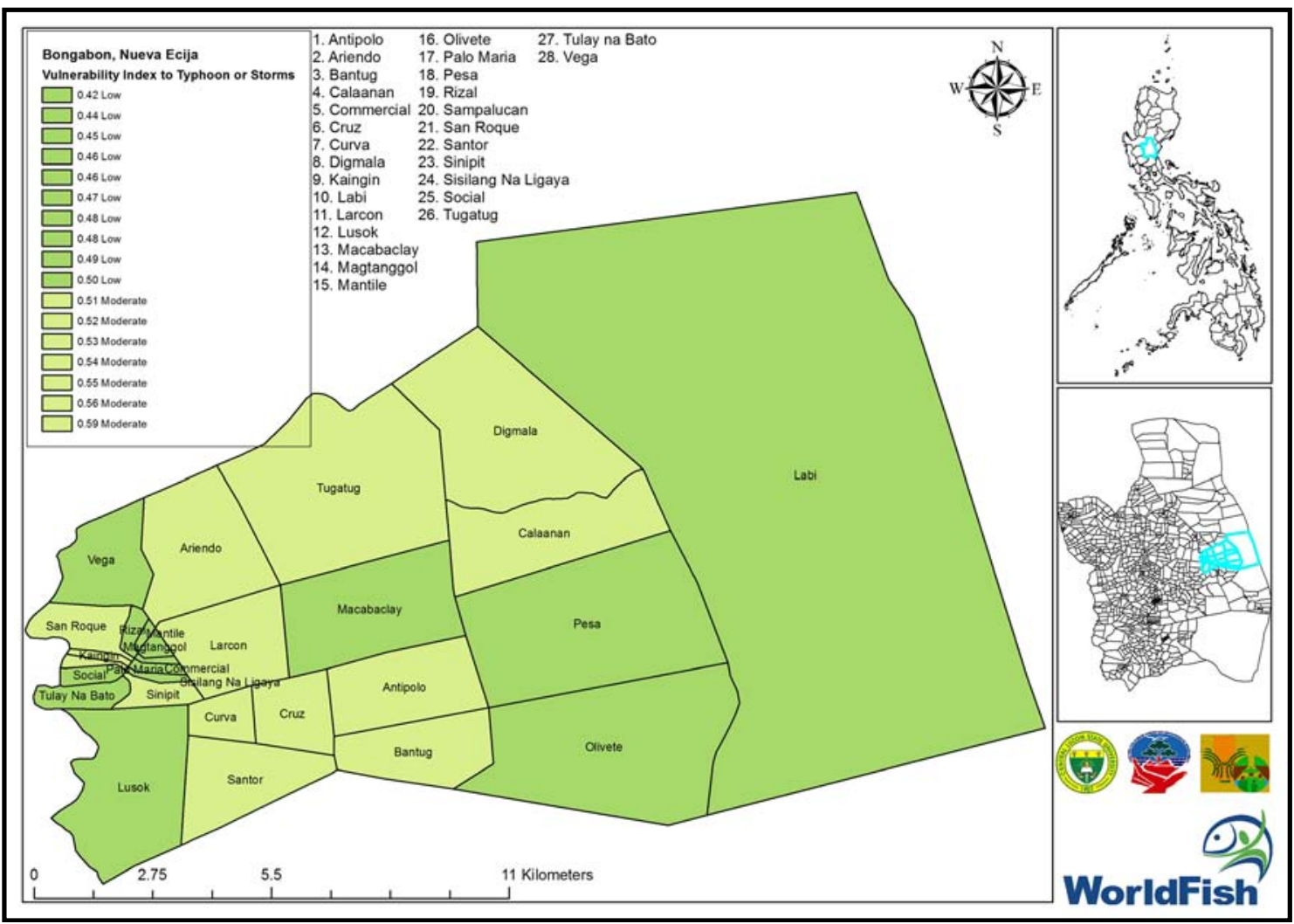

Figure 3. Typhoon vulnerability map of Bongabon, Nueva Ecija.

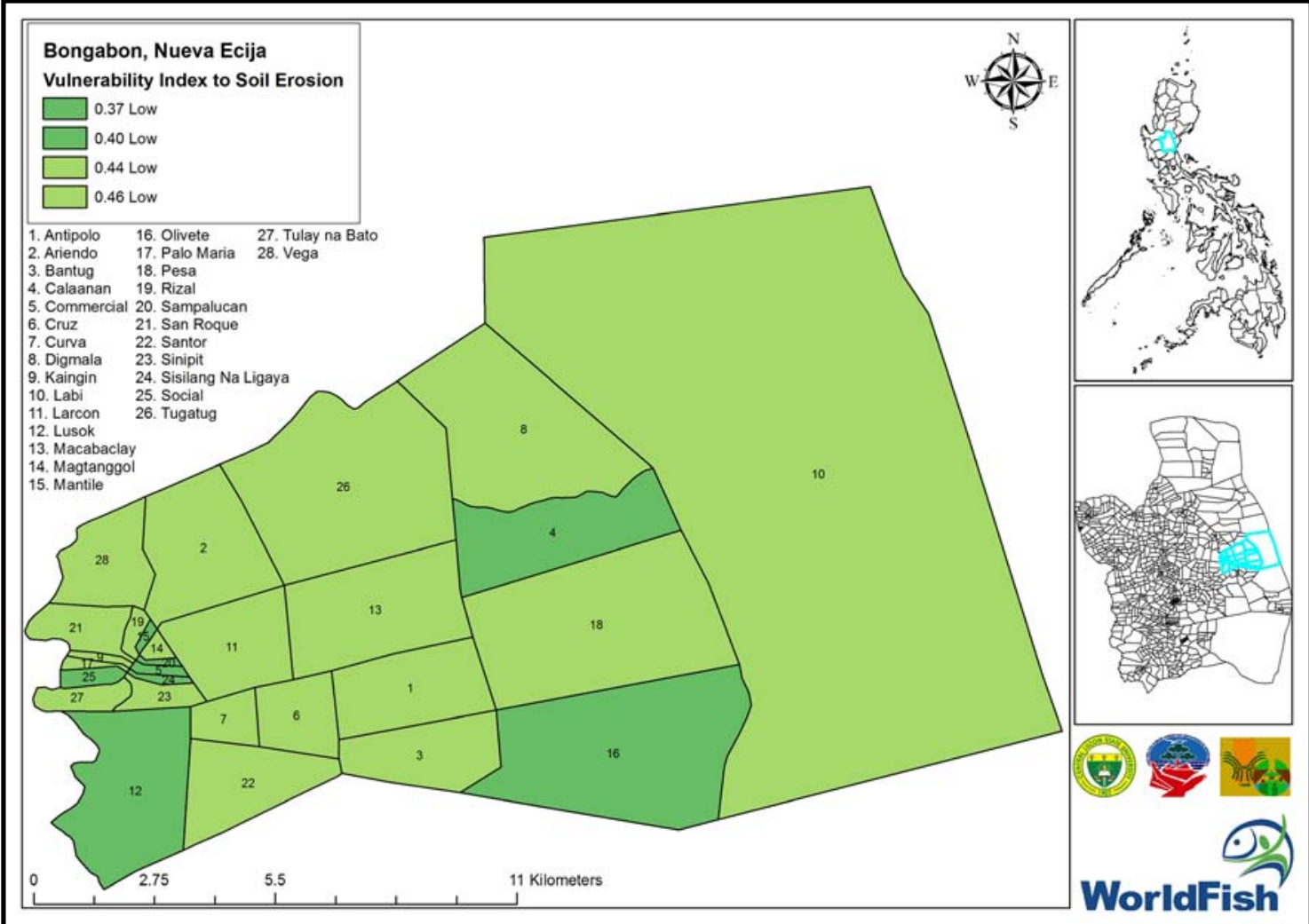

Figure 4. Soil erosion vulnerability index map of Bongabon, Nueva Ecija. 
to typhoon, it obtained an average vulnerability index value of 0.60 which indicates that it has a moderate vulnerability to flooding. The vulnerability index map for floods is shown in Figure 5. All barangays in Gabaldon have moderate vulnerability to flooding.

\section{2) Drought}

The results of the drought vulnerability assessment of Gabaldon, Nueva Ecija indicated that Gabaldon has low sensitivity to drought for it got an average value of 0.50 while it has very low exposure to drought with an average value of 0.20 . However, Gabaldon has low adaptive capacity to drought with an average of 0.80 . The average vulnerability index value is 0.52 which means that the whole municipality of Gabaldon has moderate vulnerability to drought. Gabaldon is occasionally affected by drought and only a few barangays are prone to drought or are sensitive to drought. The map of vulnerability to drought for the municipality of Gabaldon is shown in Figure 6.

\section{3) Typhoon}

Results of the typhoon vulnerability assessment in Gabaldon showed that it is moderately sensitive to typhoon with an average of 0.68 but low exposure to typhoons with an average of 0.47 . However, it has a very high adaptive capacity for typhoons because it got an average of 0.25 . Overall, Gabaldon has low vulnerability to typhoon with an average of 0.44 . The typhoon vulnerability map is shown in Figure 7.

\section{4) Soil Erosion}

Results of vulnerability assessment to soil erosion of Gabaldon revealed that it is moderately sensitive because it got a value of 0.56. Similarly, Gabaldon obtained an overall value of 0.50 for exposure to soil erosion which indicates low exposure because some barangays such as Bagong Sikat, Macasandal, Pantoc, Bitulok, Camachile, Cuyapa, Pinamalisan and Tagumpay have very low exposure to soil erosion with values of only 0.20 . Gabaldon also has moderate adaptive capacity for it had an average of 0.58 . Overall, the vulnerability index for soil erosion is 0.57 which means that Gabaldon has moderate exposure to soil erosion due to its location to mountainous area particularly Mt. Sawing Baliti which is a part of the Sierra Mountain Ranges (Figure 8).

\subsubsection{Cabanatuan City}

Cabanatuan City has a total of 89 barangays and 54 of these barangays are agricultural based growing various crops like rice, corn and vegetables. It is greatly affected by the effects of climate change such as flooding which submerges various crops of the city. The flood resides for about 3 - 5 days in the farms that brought millions of damages in the city especially to those agricultural barangays that greatly contribute to the total agricultural production of Nueva Ecija.

\section{1) Flood}

The results of flood vulnerability assessment of Cabanatuan City revealed that in terms of sensitivity to flood, Cabanatuan City has moderate sensitivity to flood and moderate exposure to flood since it got values of 0.66 and 0.75 , respectively. 


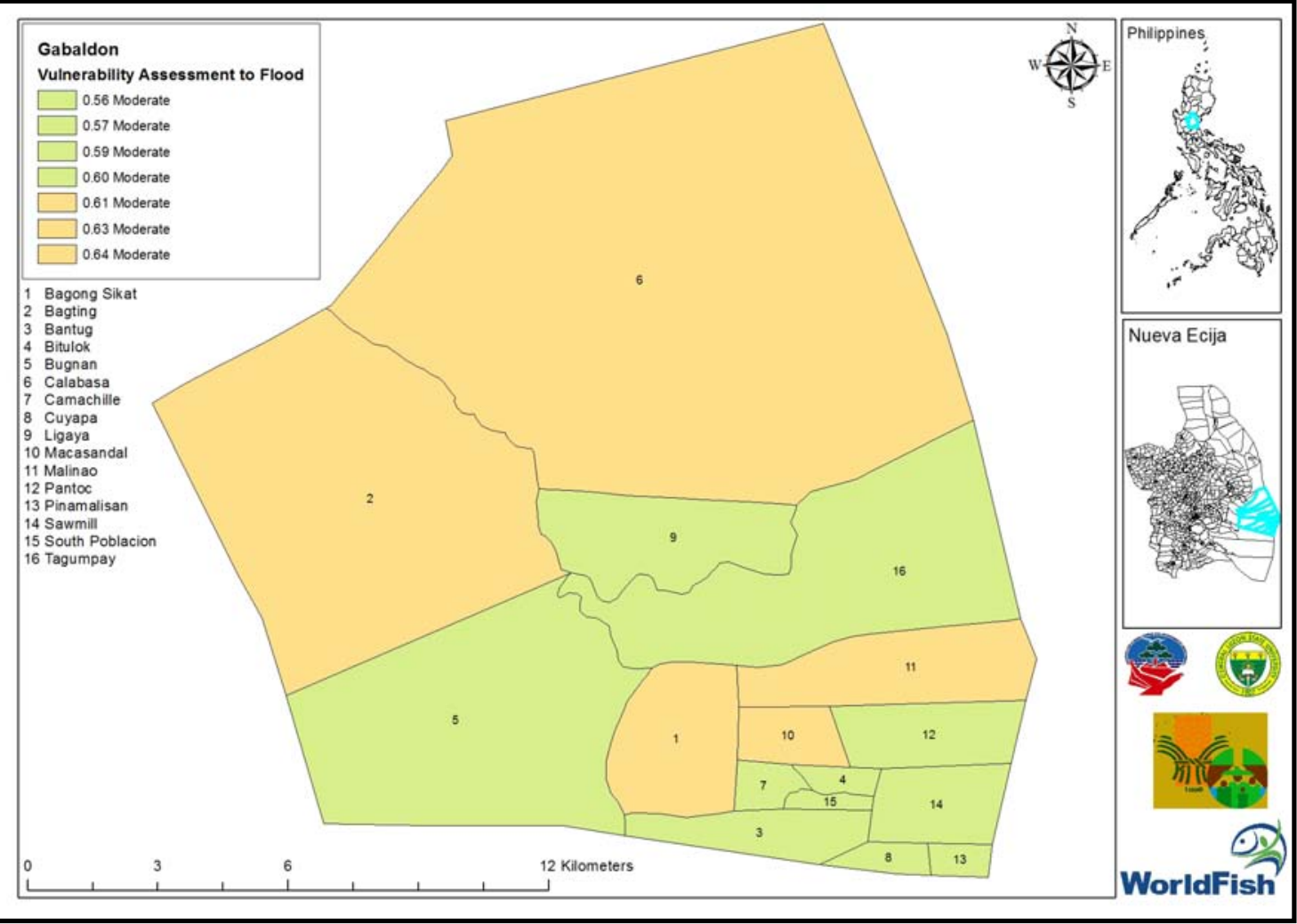

Figure 5. Flood vulnerability map of Gabaldon, Nueva Ecija.

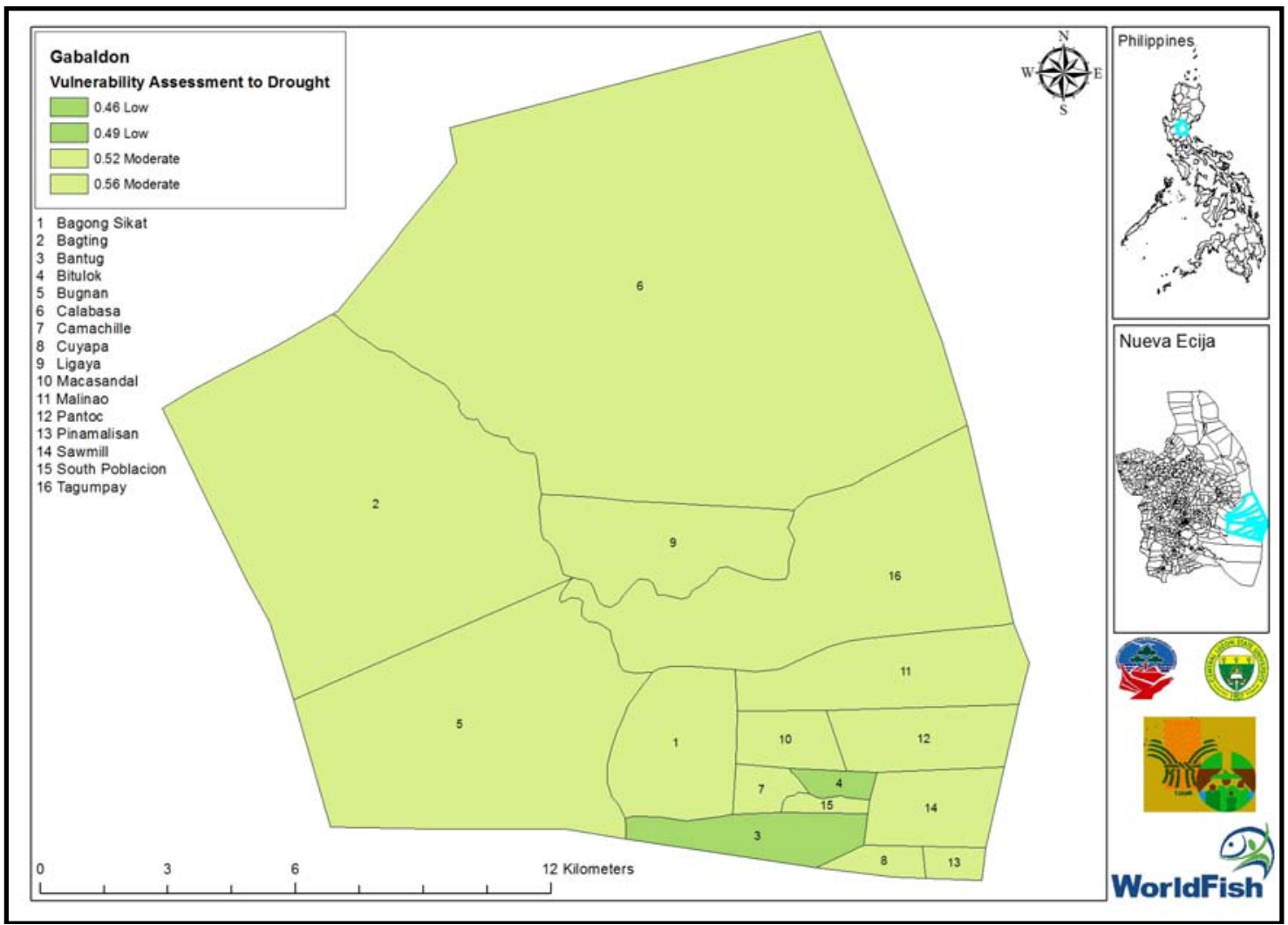

Figure 6. Vulnerability to drought of various barangays in Gabaldon, Nueva Ecija. 


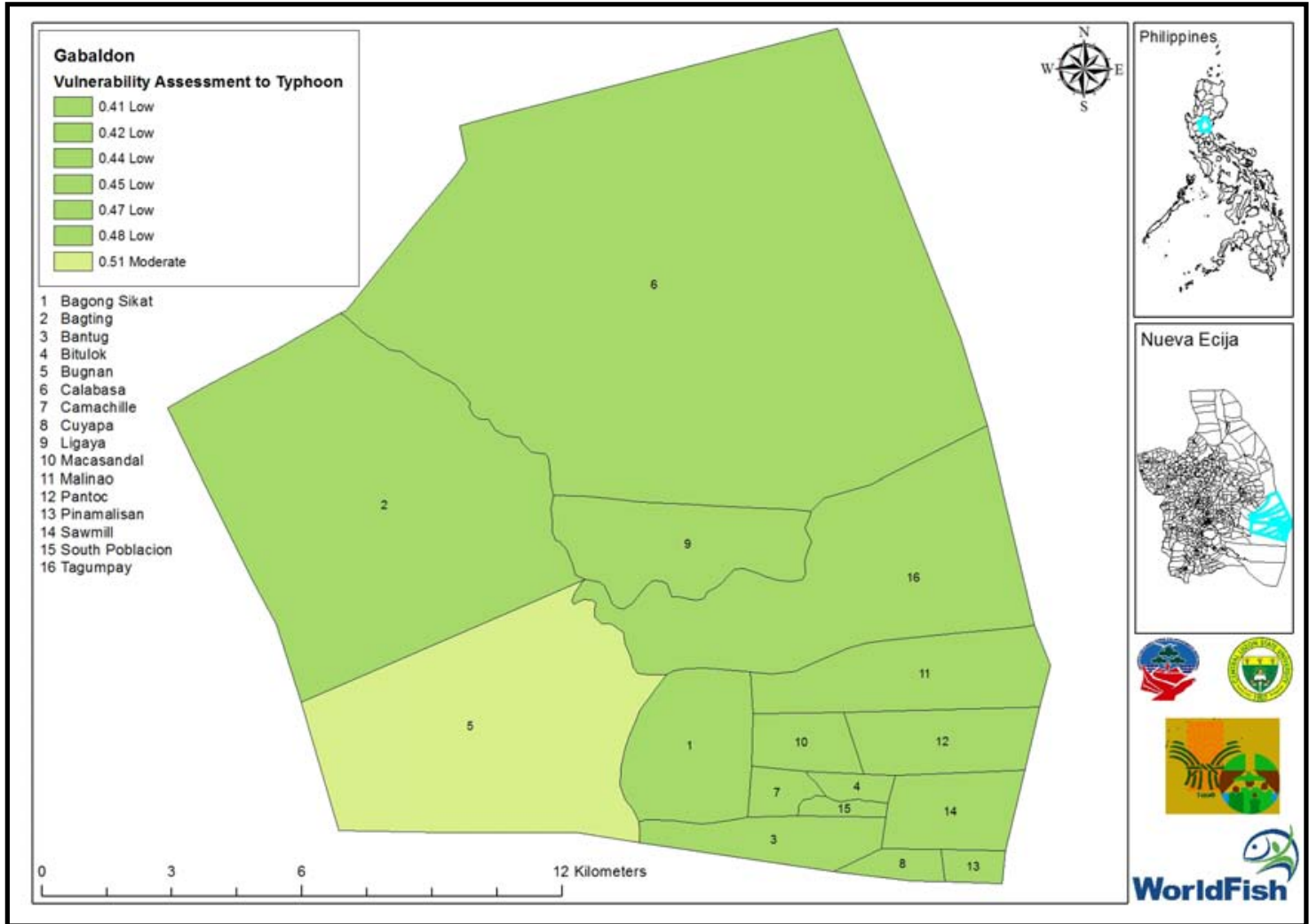

Figure 7. Typhoon vulnerability map in Gabaldon, Nueva Ecija.

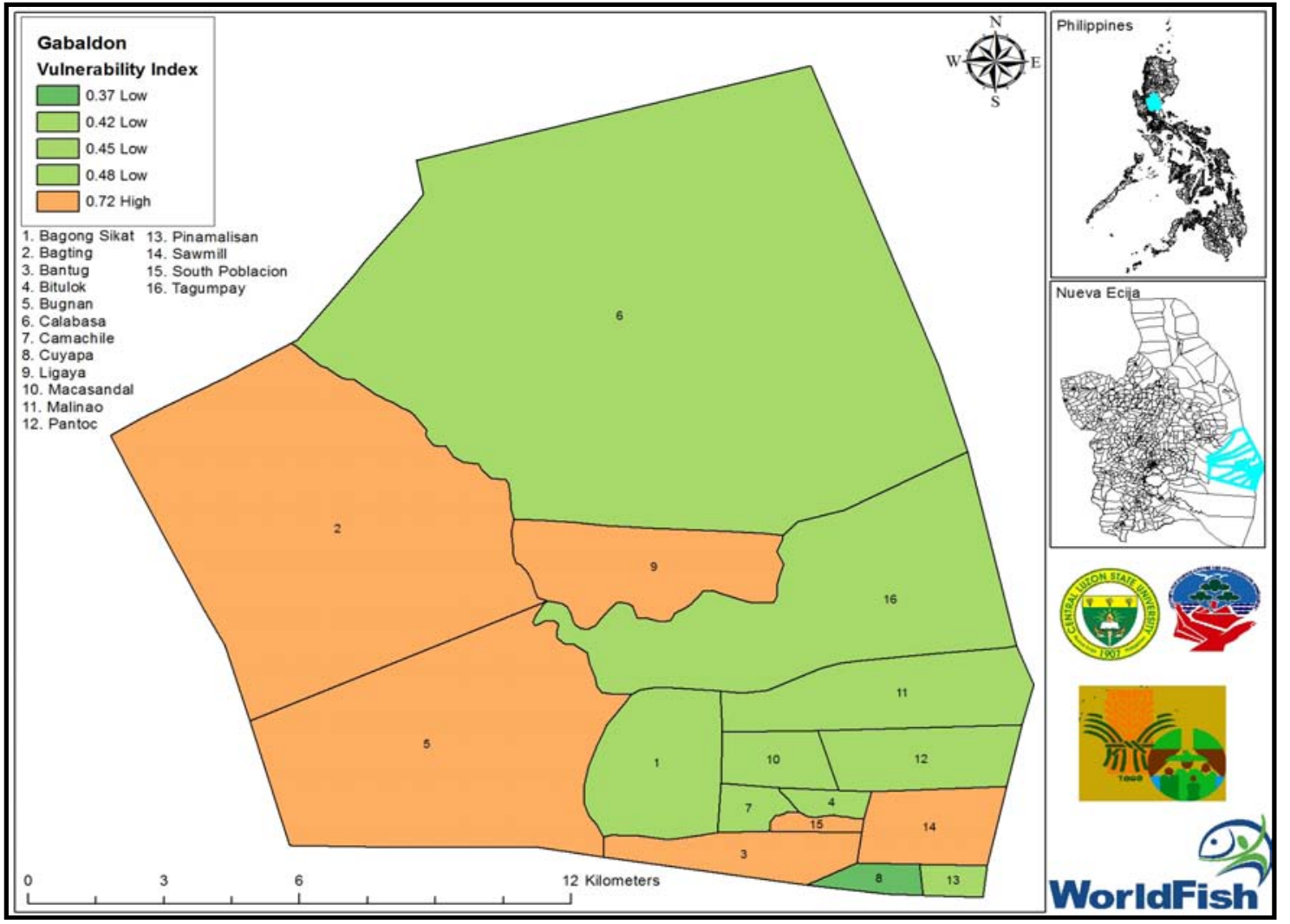

Figure 8. Soil erosion vulnerability map in Gabaldon, Nueva Ecija. 
Likewise, it also has moderate adaptive capacity to flood for the average value it obtained is 0.49 . Overall, the typhoon vulnerability index value of Cabanatuan City is 0.60 which means that it has moderate vulnerability to flood (Figure 9).

\section{2) Drought}

Cabanatuan City has low sensitivity to drought for it got an average value of 0.50. However, it has very high exposure to drought because it obtained an average value of 1.0. Majority of barangays in Cabanatuan City acquired ratings of 1.0 which is indicative of very high exposure to drought.

However, it has moderate adaptive capacity for drought since it had an average value of 0.52 . The vulnerability index value of Cabanatuan City for drought is 0.66 which means it has moderate vulnerability to drought. All barangays in Cabanatuan City have moderate vulnerability to drought since their ratings ranged from 0.64 - 0.68 (Figure 10).

\section{3) Typhoon}

The typhoon vulnerability map of Cabanatuan City is shown in Figure 11. Results showed that the city has moderate sensitivity and moderate exposure to typhoons with average values of 0.70 and 0.65 , respectively. Similarly, it has moderate adaptive capacity to climate change with an average of 0.63 . Overall, Cabanatuan City has low vulnerability to typhoon with an average of 0.40

\subsection{Crop, Chicken and Goat Suitability Assessment}

\subsubsection{Bongabon}

Results revealed that the crops present and being planted such as rice, corn, squash, onion, tomato, eggplant and ampalaya in Bongabon are highly suitable in the baseline condition with the inclusion of the occurrence of floods and landslide in the municipality. However, the suitability of those crops decrease in RCP 4.5 which is the best case scenario and RCP 8.5 which is the worst case scenario for year 2050 .

In terms of rice suitability in the municipality, it can be seen in the baseline map that it is highly suitable for the whole municipality except for the mountainous areas (Figure 12). While RCP 4.5 and RCP 8.5 showed significant decrease in the suitability of rice in the agroecosystems of the municipality which can be seen that from very high suitability in the baseline condition it becomes moderately suitable in RCP 4.5 and RCP 8.5.

The corn suitability assessment was also assessed and results revealed that it highly suitable in Bongabon except in some parts of Barangay Labi and Olivete and in mountainous areas where corn cannot be planted due to frequent landslides in the areas (Figure 13). The RCP 4.5 scenario indicated that corn is moderately suitable except for Barangays Curva and Cruz which remained highly suitable for corn. RCP 8.5 has the same outcome as in RCP 4.5.

Squash suitability assessment map is shown in Figure 14 and in the baseline condition this crop is highly suitable in areas of Barangays Digmala, Tugatug, Macabaclay, Antipolo, Bantug, Larcon and Ariendo. In the RCP 4.5 and RCP 8.5 


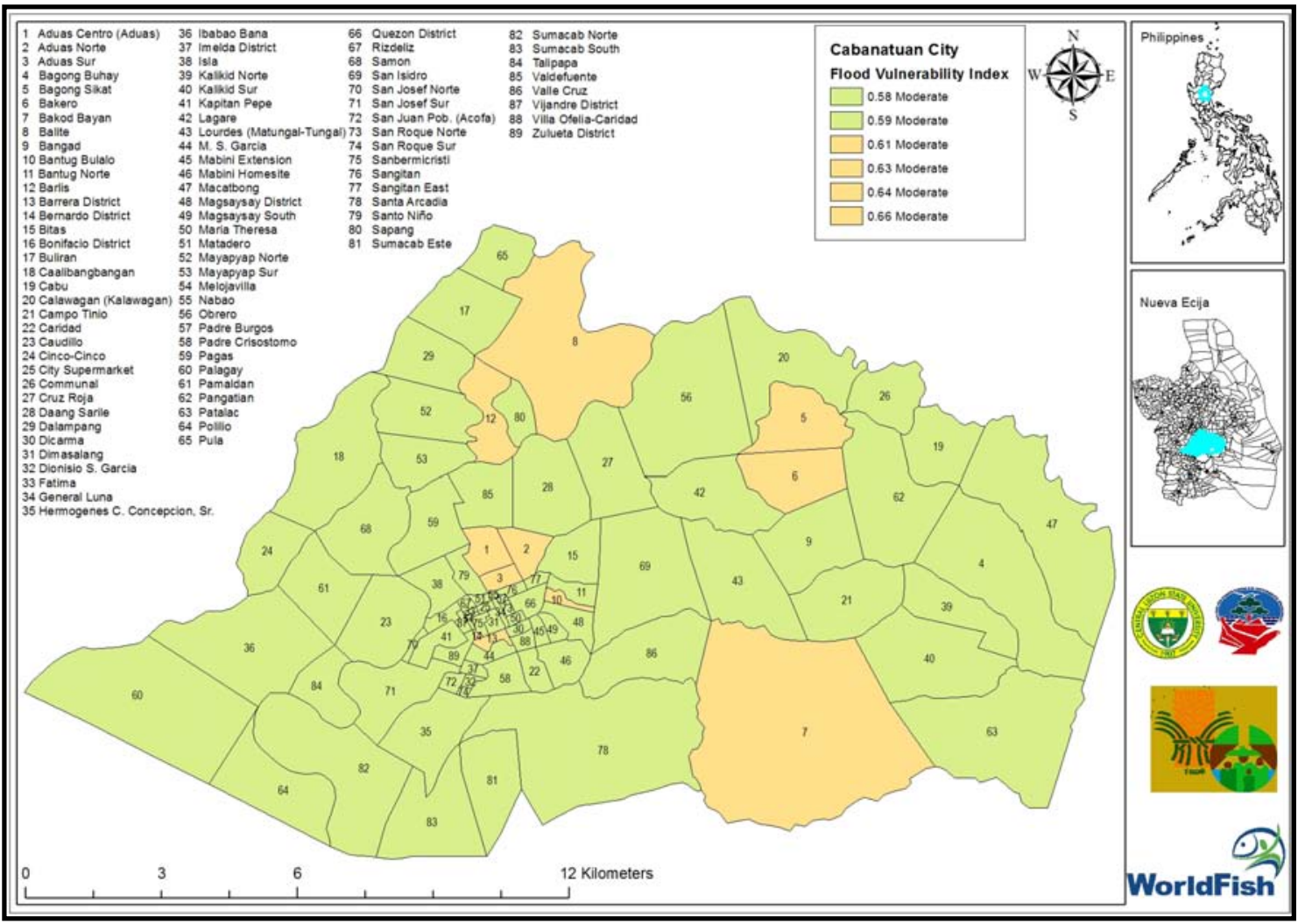

Figure 9. Flood vulnerability map in Cabanatuan City, Nueva Ecija.

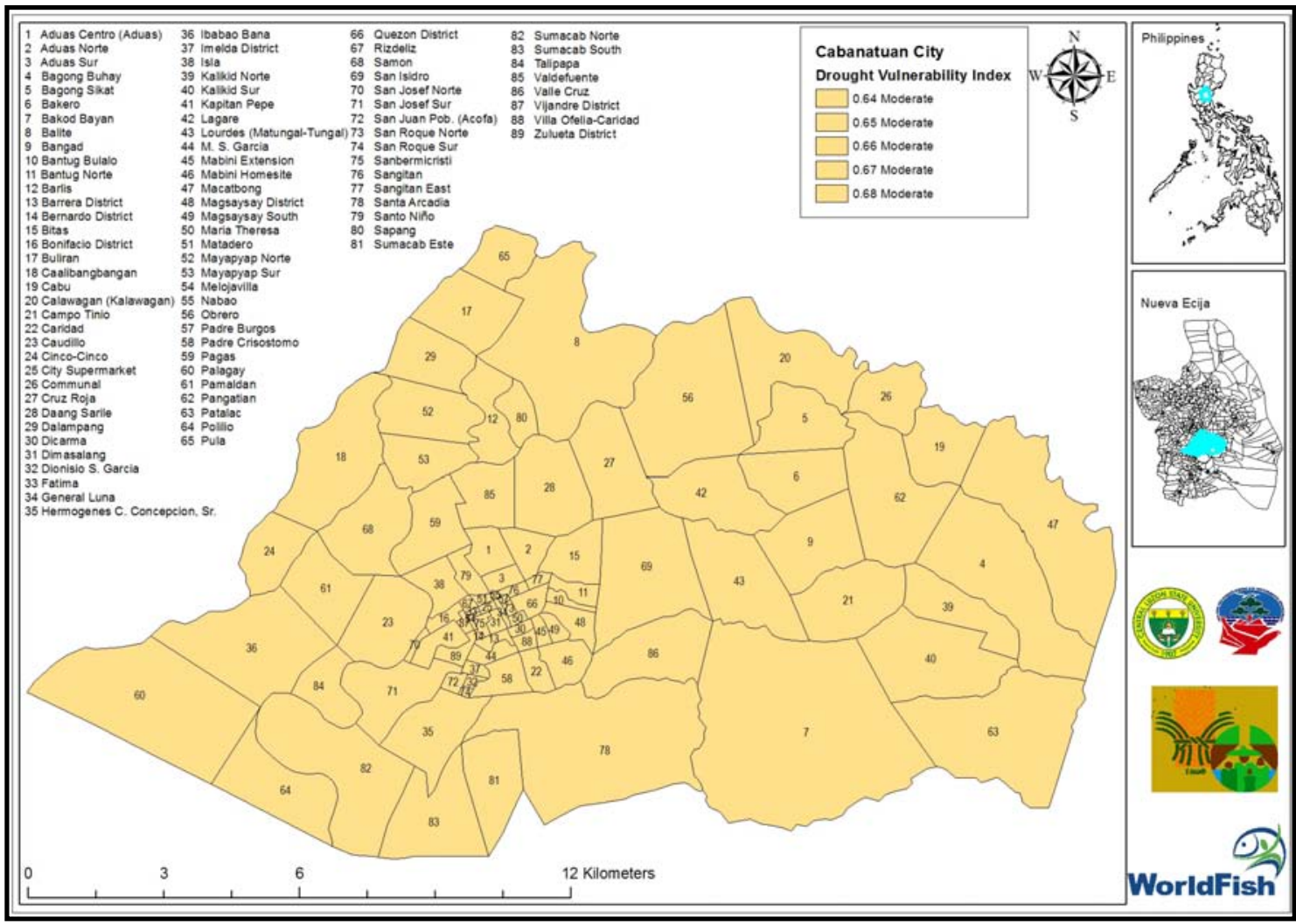

Figure 10. Vulnerability to drought of various barangays in Cabanatuan City, Nueva Ecija. 


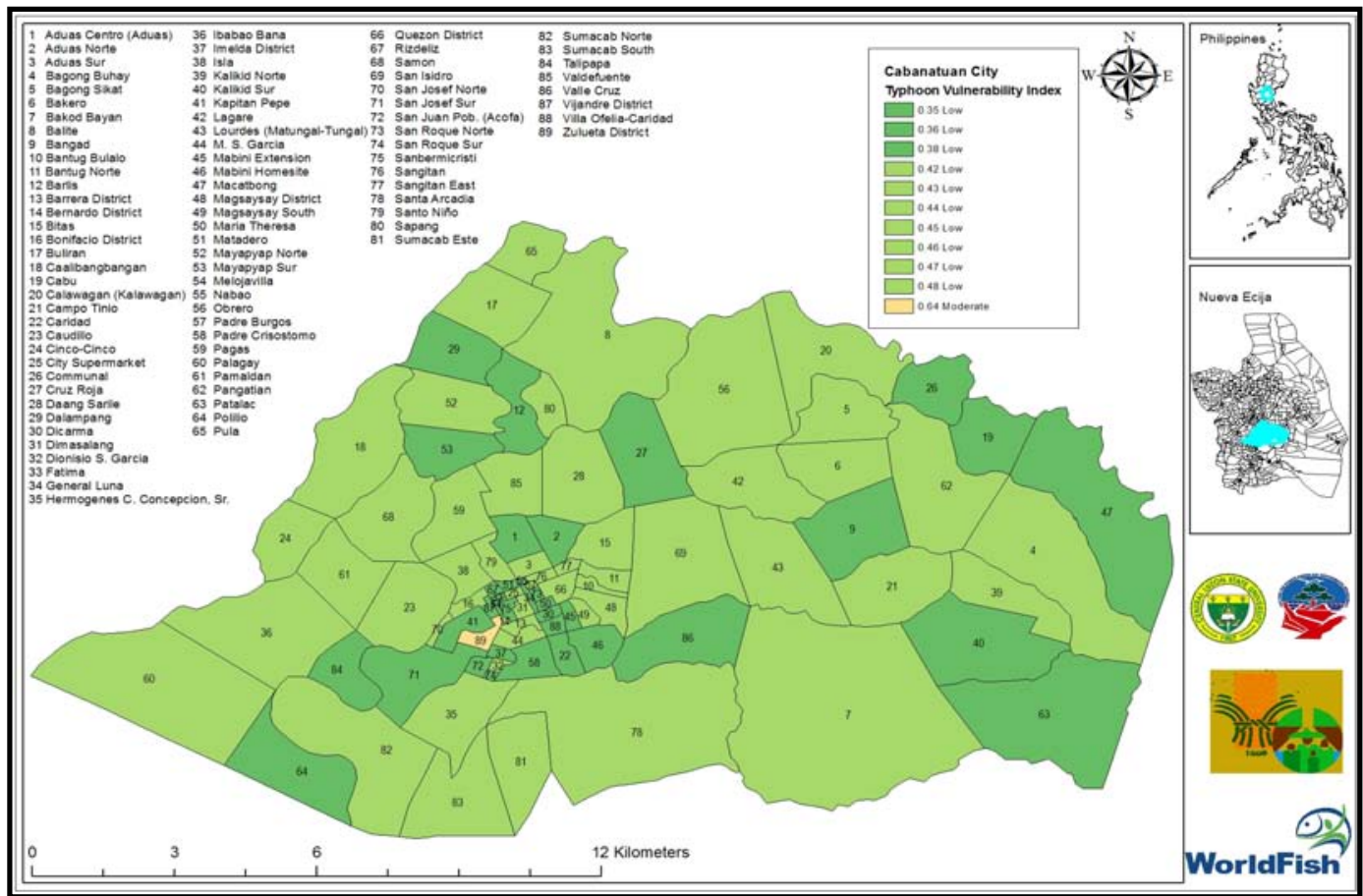

Figure 11. Typhoon vulnerability map in Cabanatuan City, Nueva Ecija.

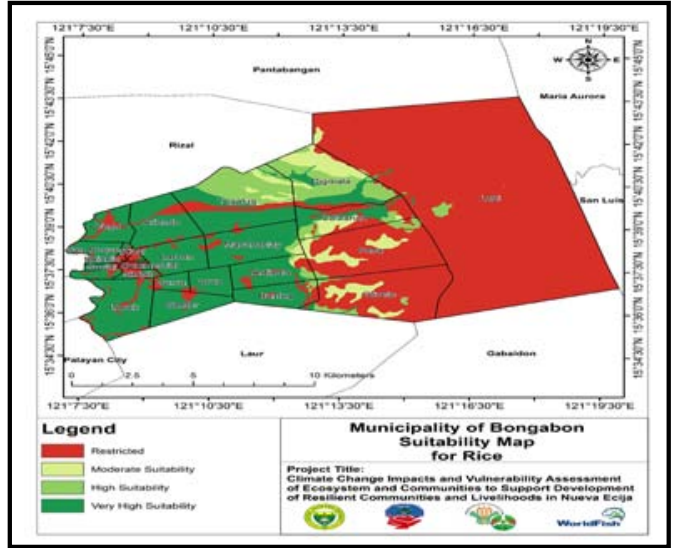

BASELINE

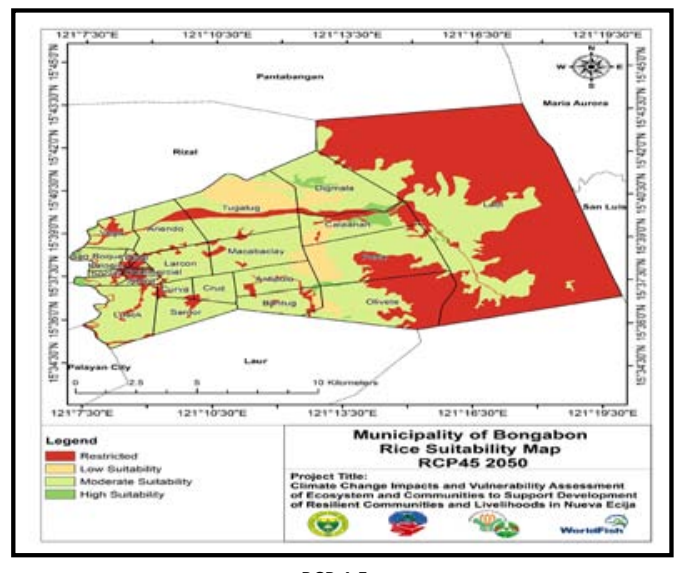

RCP 4.5

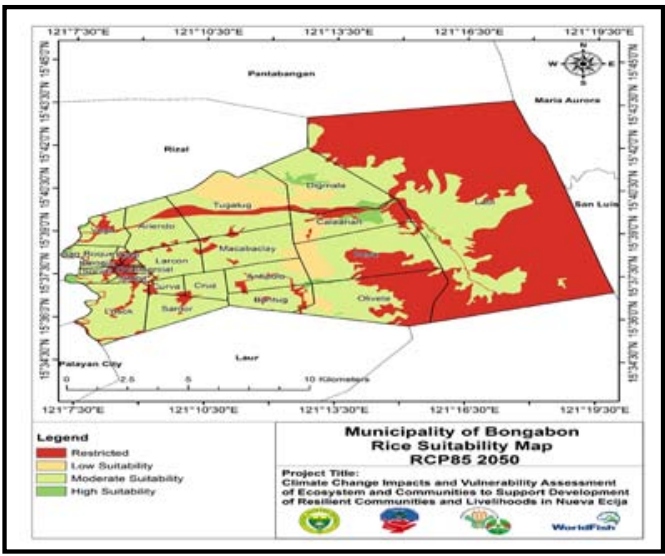

RCP 8.5

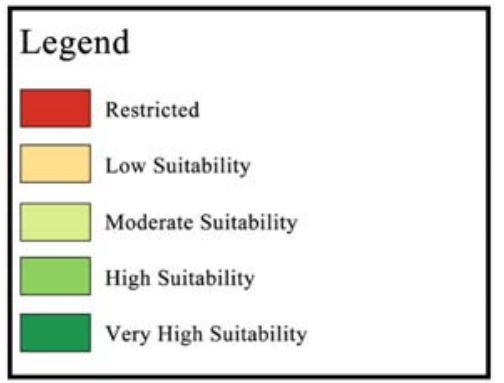

Figure 12. Rice suitability maps in Bongabon, Nueva Ecijaforthe 3 conditions. 


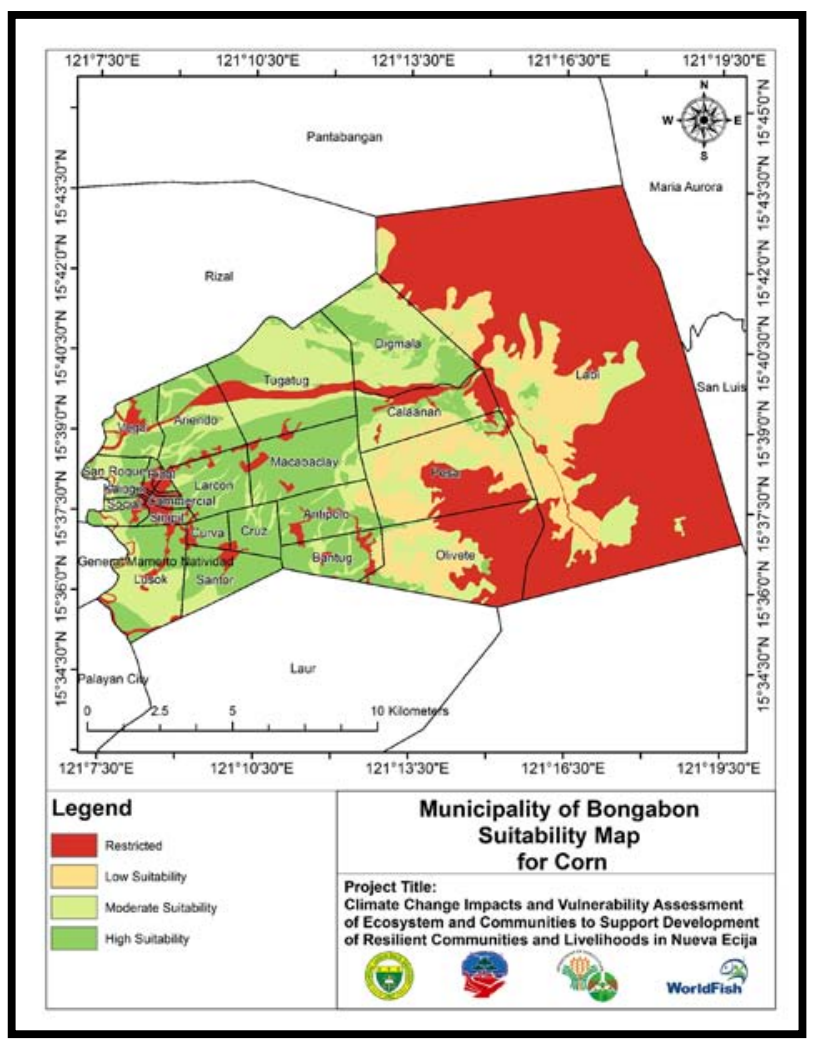

BASELINE

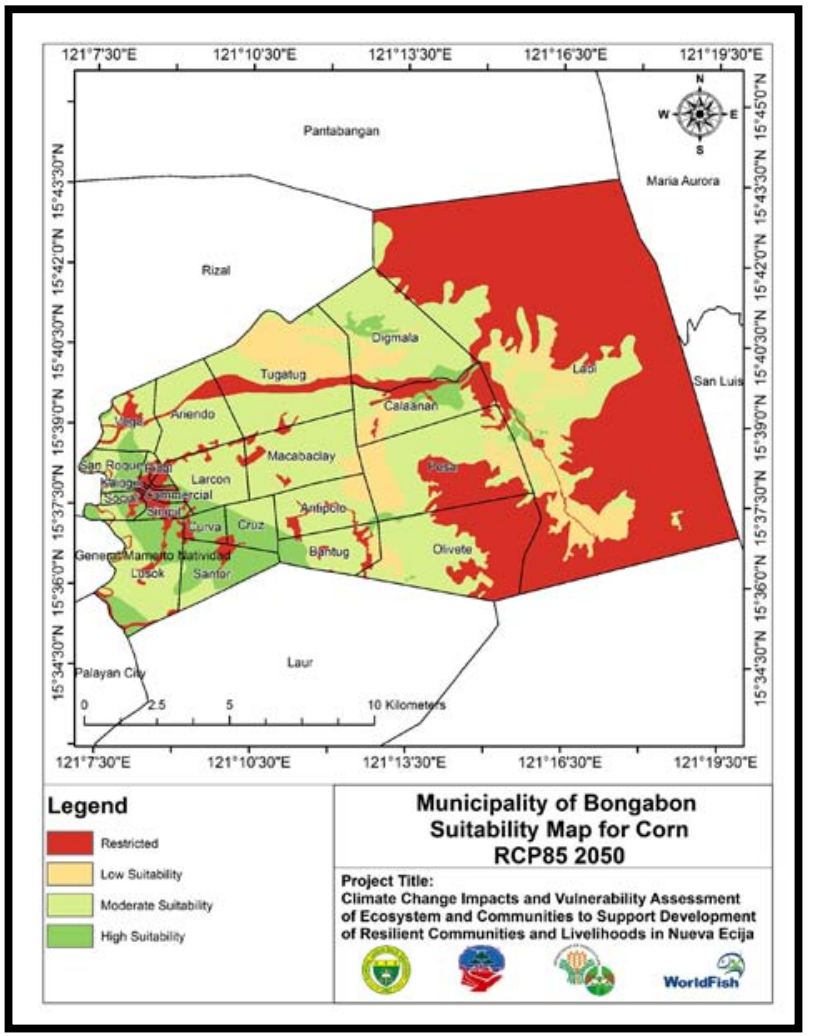

RCP 8.5

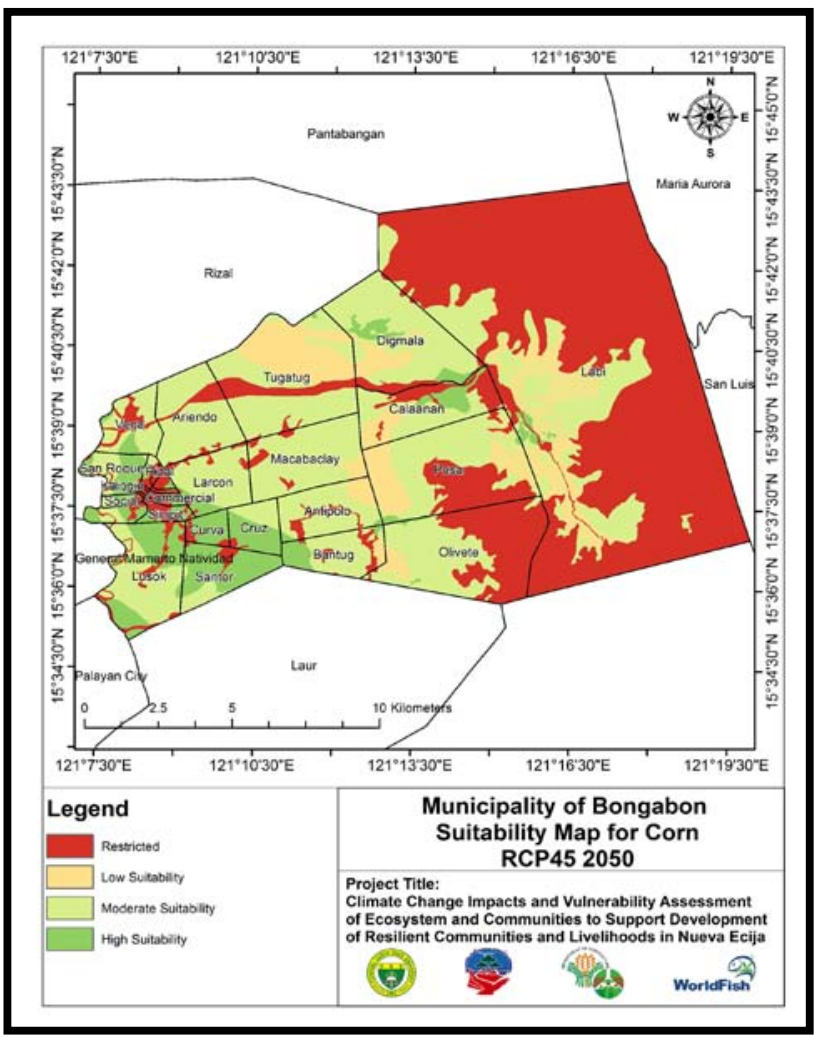

RCP 4.5

\section{Legend}
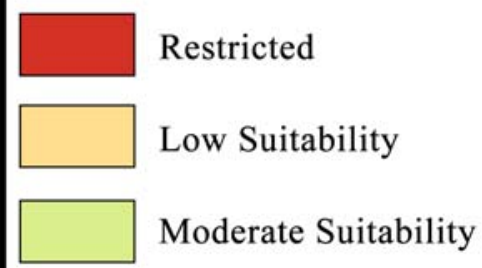

High Suitability

Very High Suitability

Figure 13. Corn suitability maps in Bongabon, Nueva Ecijafor the 3 conditions. 


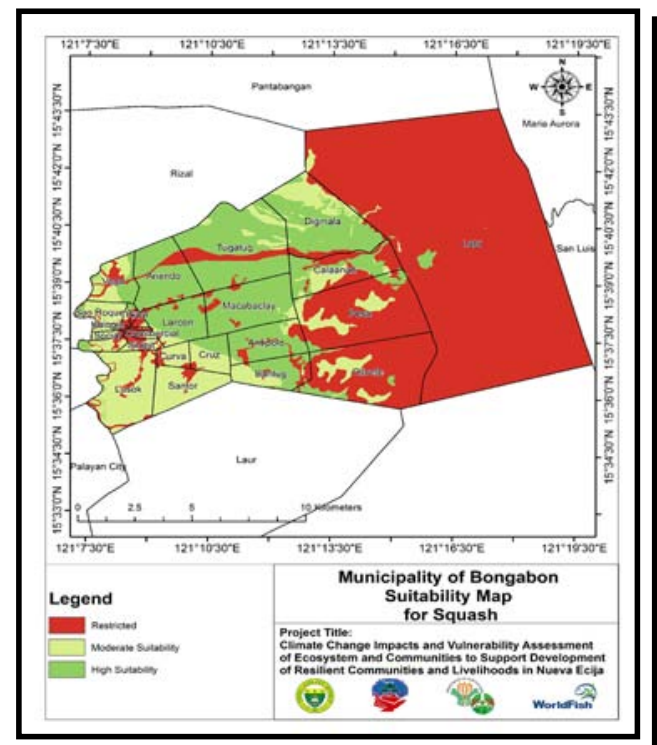

BASELINE

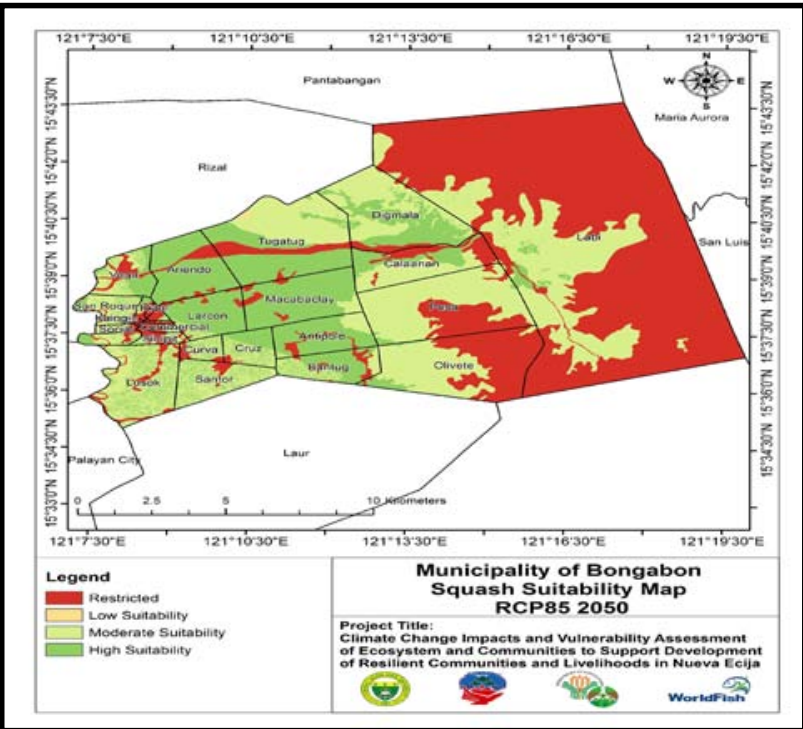

RCP 8.5

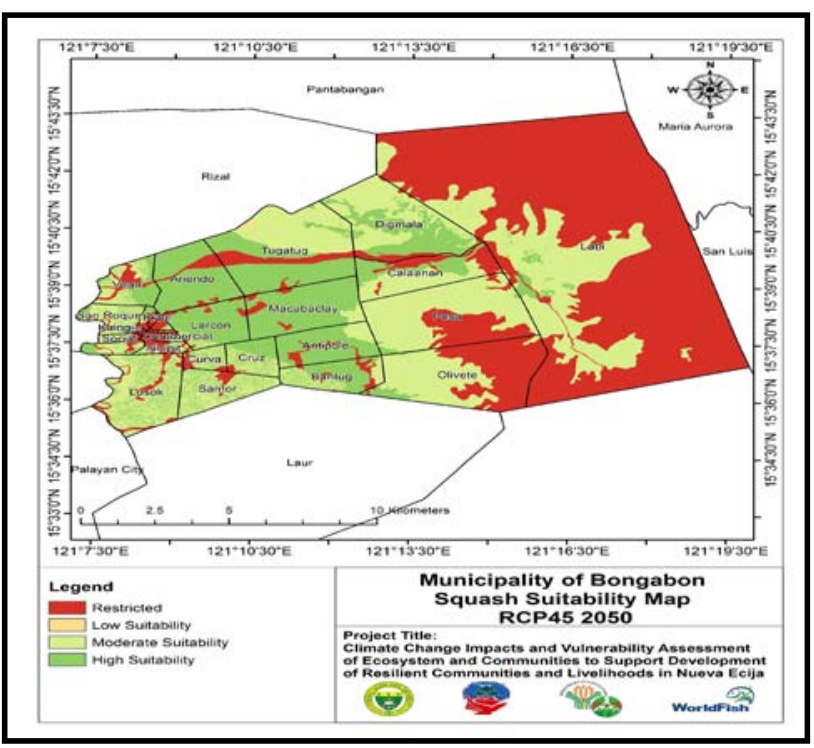

RCP 4.5

\section{Legend}
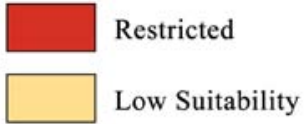

Moderate Suitability

High Suitability

Very High Suitability

Figure 14. Squash suitability maps in Bongabon, Nueva Ecija for the 3 conditions.

situations, results showed that squash is highly suitable for all barangays except for the mountainous areas. Findings of the study revealed that squash is highly suitable in Bongabon in the 3 future conditions.

The suitability of onion in the baseline condition in Bongabon also revealed that onion is highly suitable in the majority of barangays except for Barangays Labi, Olivete, Pesa and some parts of Calaanan where frequent landslides occur (Figure 15). Some barangays in the town proper are also not suitable for onion especially in Barangays Commercial, Sinipit, Rizal, Kaingin and Social because these barangays are affected by flood. In 2015 these barangays were flooded that brought millions of pesos in damage when Typhoon Kabayan hit the province especially the municipality of Bongabon. Results for RCP 4.5 revealed that onion 


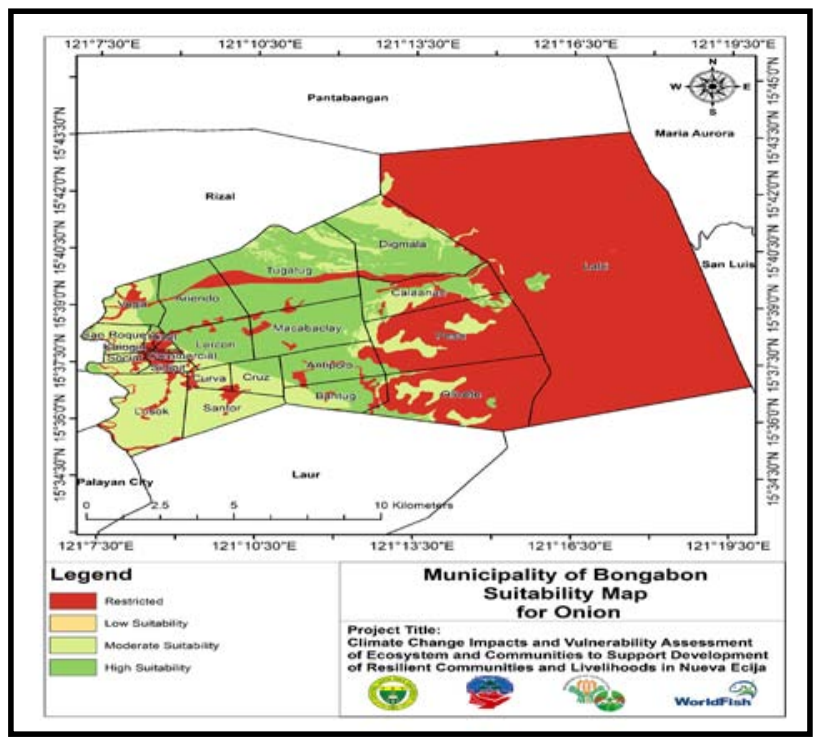

BASELINE

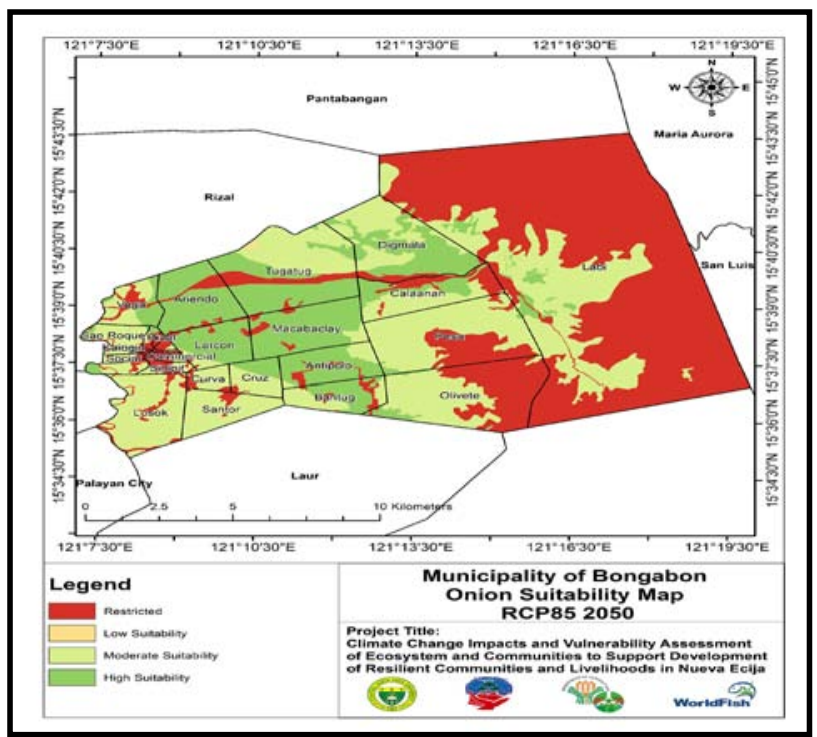

RCP 8.5

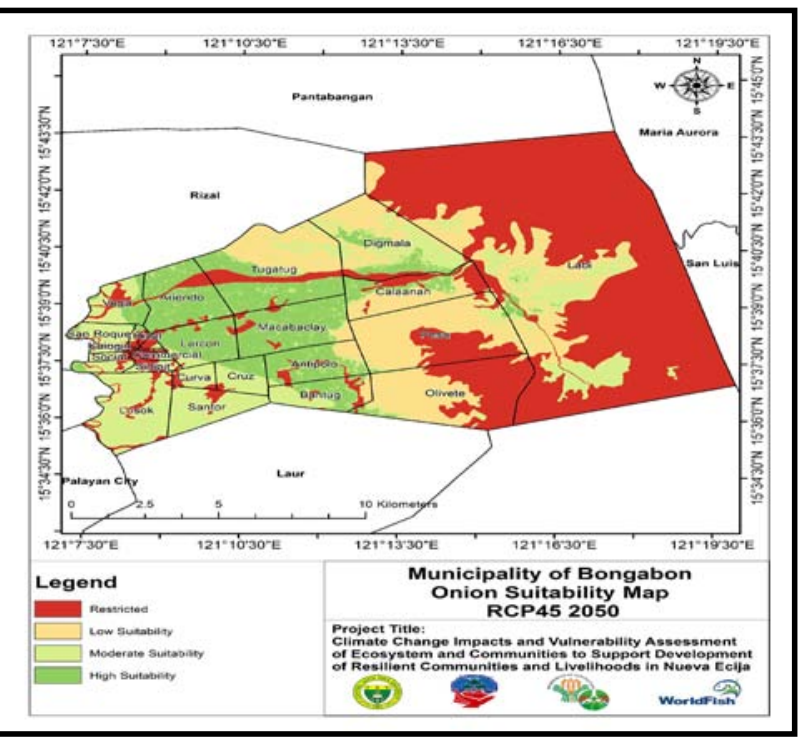

RCP 4.5

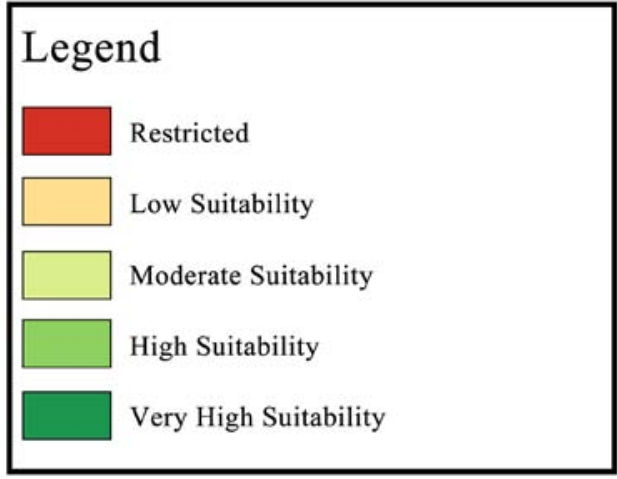

Figure 15. Onion suitability maps in Bongabon, Nueva Ecija for the 3 conditions.

is highly suitable for Barangays Macabaclay, Tugatug, Ariendo, Antipolo but has low suitability for the rest of the barangays. Similarly, onion also has high suitability in RCP 8.5. Results indicated that onion will still be suitable in Bongabon, Nueva Ecija in 2050 for the 3 future conditions.

The suitability of ampalaya in Bongabon, Nueva Ecija is shown in Figure 16 and results in the baseline condition indicated that it is not suitable for many areas of the municipality particularly those areas that are restricted for growing ampalaya like open and closed forest, inland water and even built-up areas. Ampalaya is highly suitable in RCP 4.5 for almost all barangays of the municipality except for barangays Digmala, Labi, Pesa and Olivete while for RCP 8.5 ampalaya is highly suitable in all barangays because this crop is well adapted to 


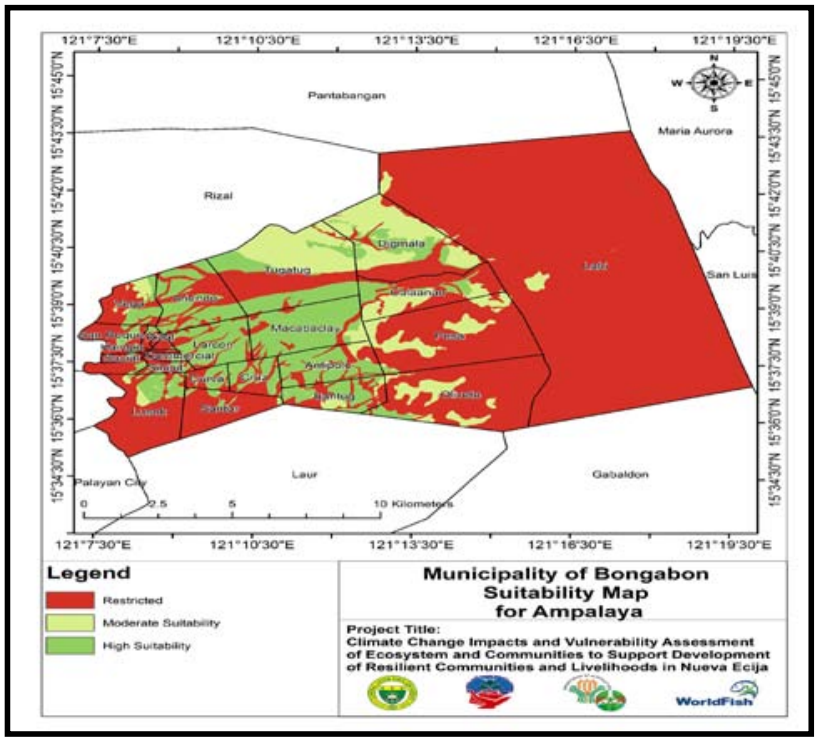

BASELINE

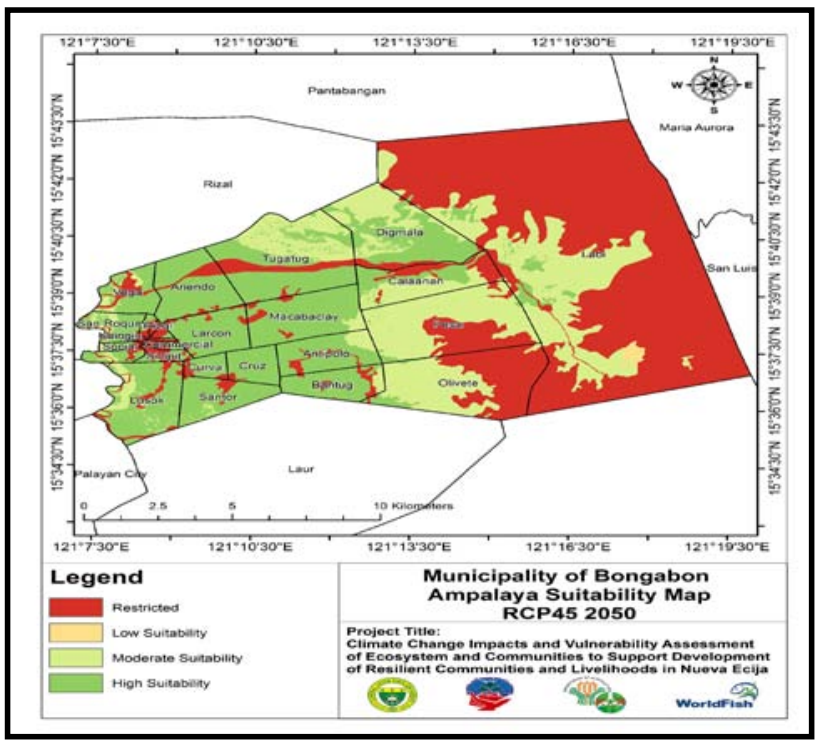

RCP 8.5

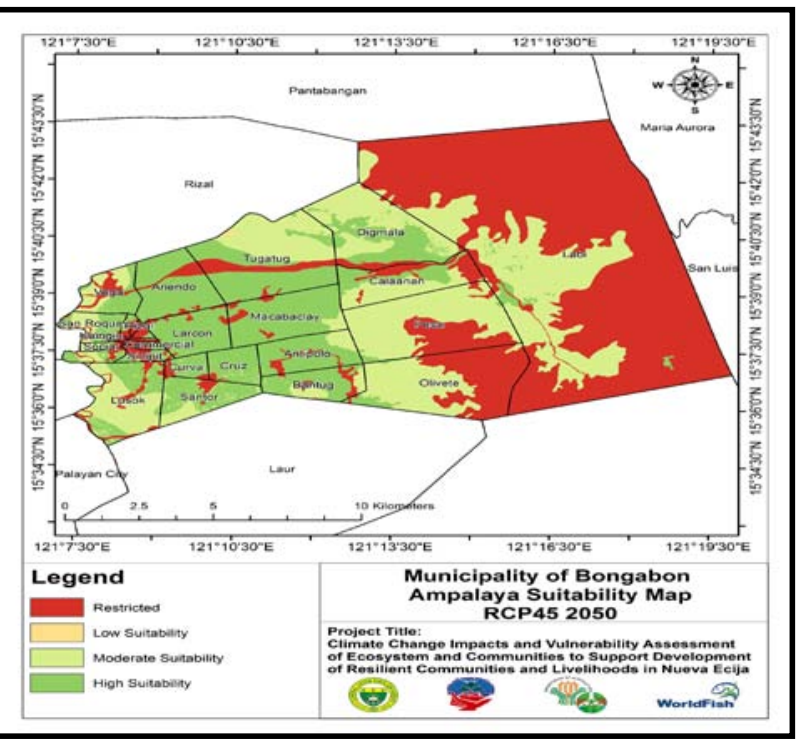

RCP 4.5

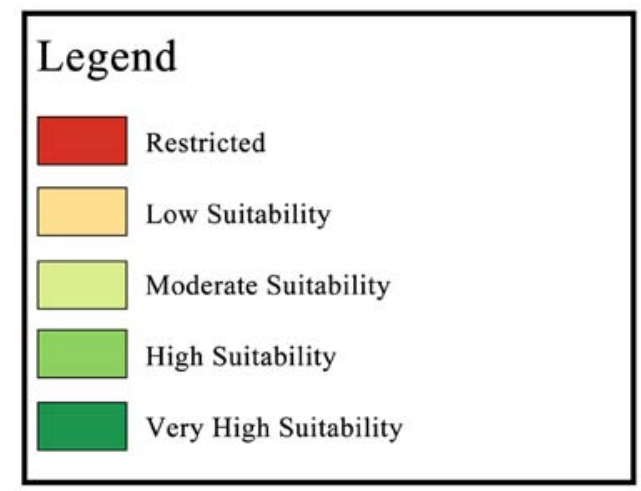

Figure 16. Ampalaya suitability maps in Bongabon, Nueva Ecija for the 3 conditions.

high temperature.

In terms of chicken suitability in Bongabon, Nueva Ecija results showed that chicken is highly suitable in the municipality for the baseline condition especially in Barangays Digmala, Tugatug and some parts of Calaanan, Pesa, Olivete and Labi but some parts of Barangay Labi are still restricted from raising chicken because of the possible effects of landslide (Figure 17). Chicken is very suitable in almost all barangays of Bongabon for RCP 4.5 condition. But for RCP 8.5 scenario chicken is also very suitable in almost all barangays. Results showed that chicken is highly suitable in the 3 future conditions and raising chicken will not be a problem in Bongabon, Nueva Ecija in the occurrence of any future situation. 


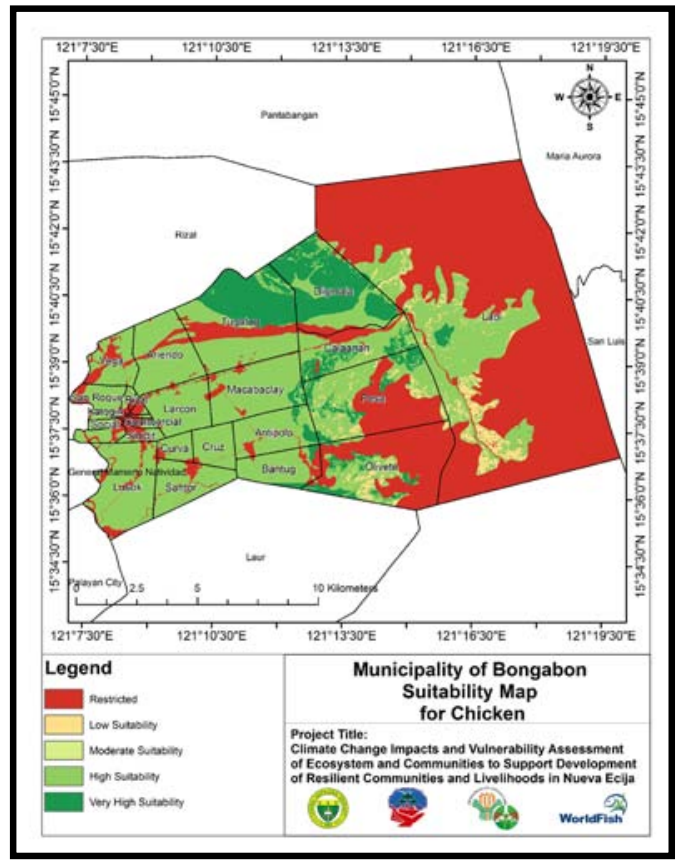

BASELINE

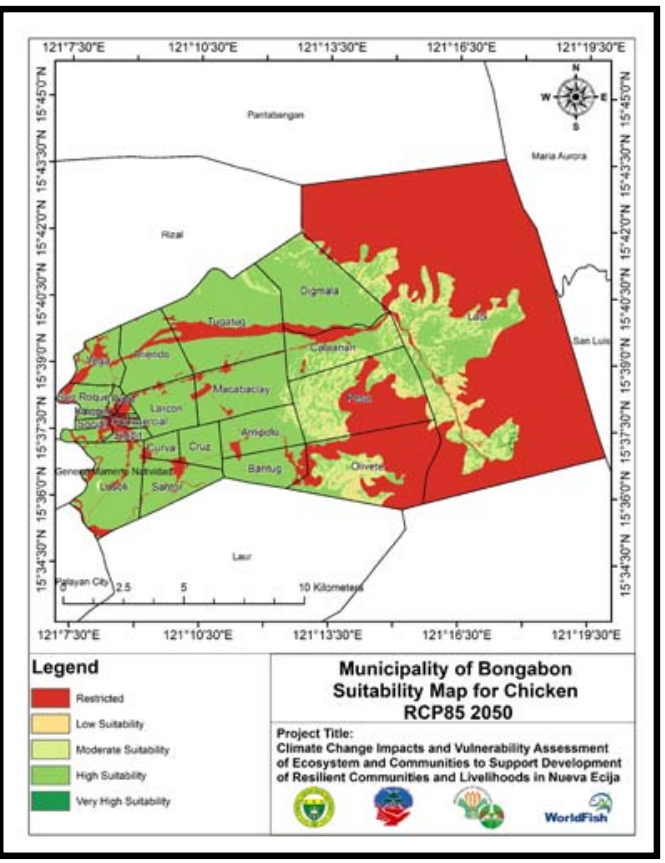

RCP 8.5

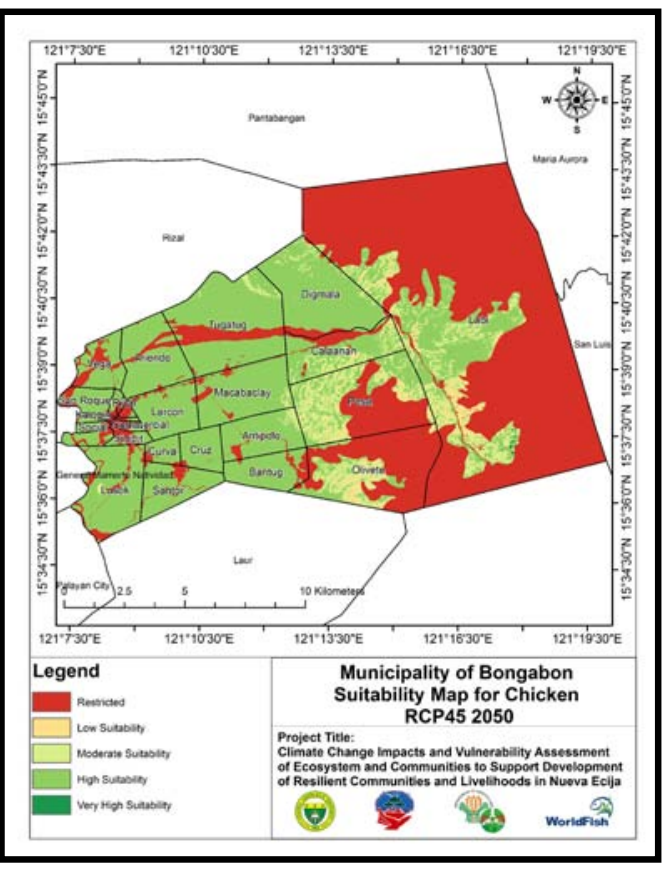

RCP 4.5

\section{Legend}

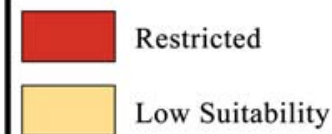

Moderate Suitability

High Suitability

Very High Suitability

Figure 17. Chicken suitability maps in Bongabon, Nueva Ecija for the 3 conditions.

Figure 18 shows that goats in the baseline condition are highly suitable in Bongabon especially in Barangays Tugatug and Digmala where grassland is widely distributed in these barangays which is the main source of food for this kind of animal. RCP 4.5 and RCP 8.5 scenarios indicated that goats are also highly suitable in all barangays. Raising goat is very suitable in Bongabon in the baseline and in the 2 future conditions. 


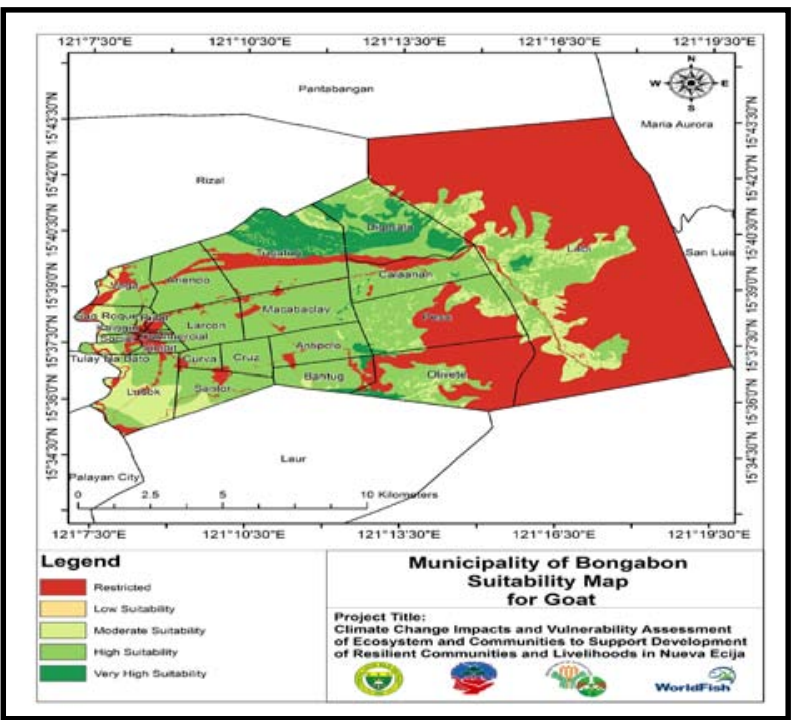

BASELINE

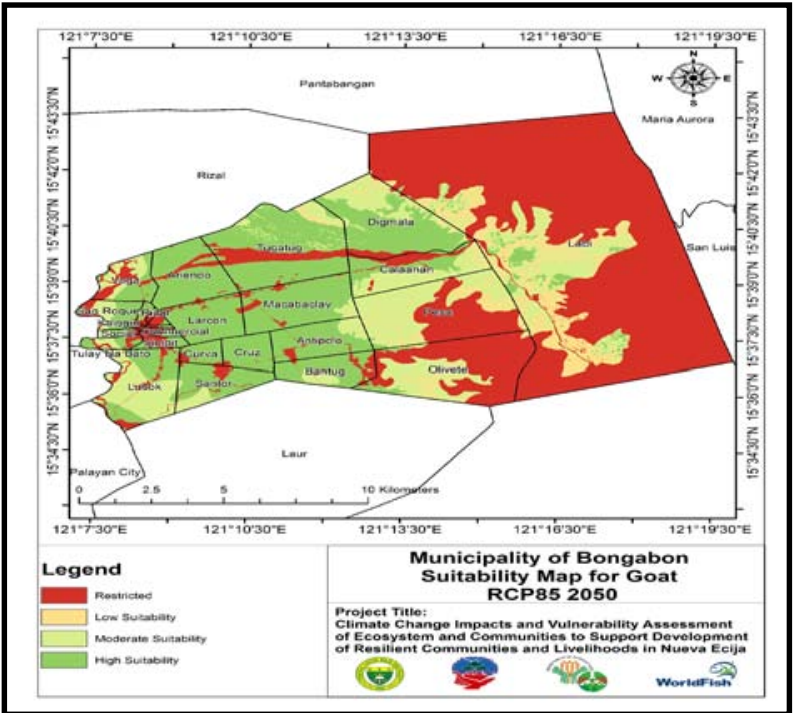

RCP 8.5

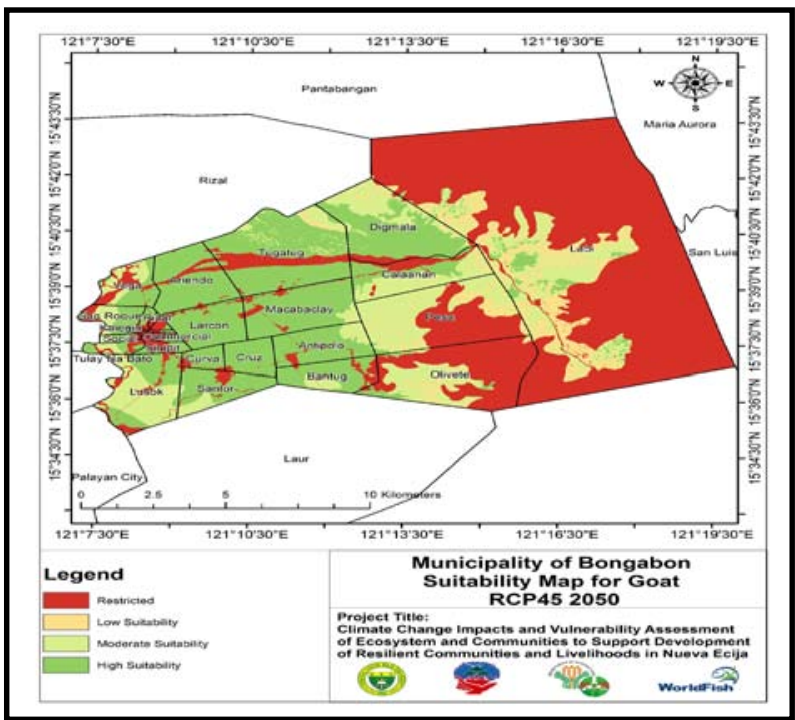

RCP 4.5

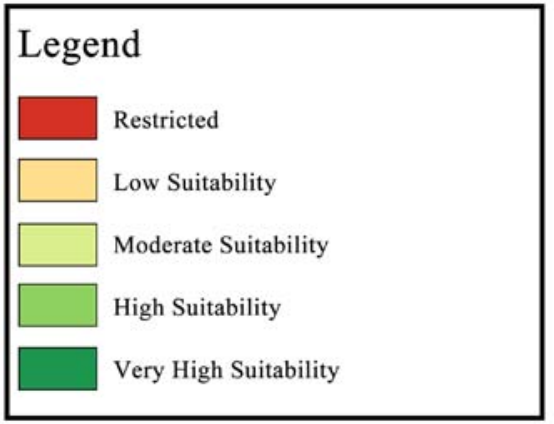

Figure 18. Goat suitability maps in Bongabon, Nueva Ecija for the 3 conditions.

\subsubsection{Gabaldon}

Results revealed that the common crops such as ampalaya, eggplant, onion, sitao, rice, tomato, chili being planted as well as the goats and native chicken being raised in Gabaldon, Nueva Ecija are highly suitable in the municipality but the various commodities become moderately suitable in the 3 future scenarios (baseline with hazard, RCP 4.5 and RCP 8.5).

Figure 19 shows the ampalaya suitability in the baseline condition in Gabaldon, Nueva Ecija. Result revealed that this kind of crop is highly suitable to grow only in the town proper where the majority of the land is flat while ampalaya is moderately suitable to grow also in some parts of the municipality especially in the mountainous areas. In RCP 4.5 situation ampalaya is highly suitable in some areas in Gabaldon while there was a decrease in the areas suitable for ampalaya 


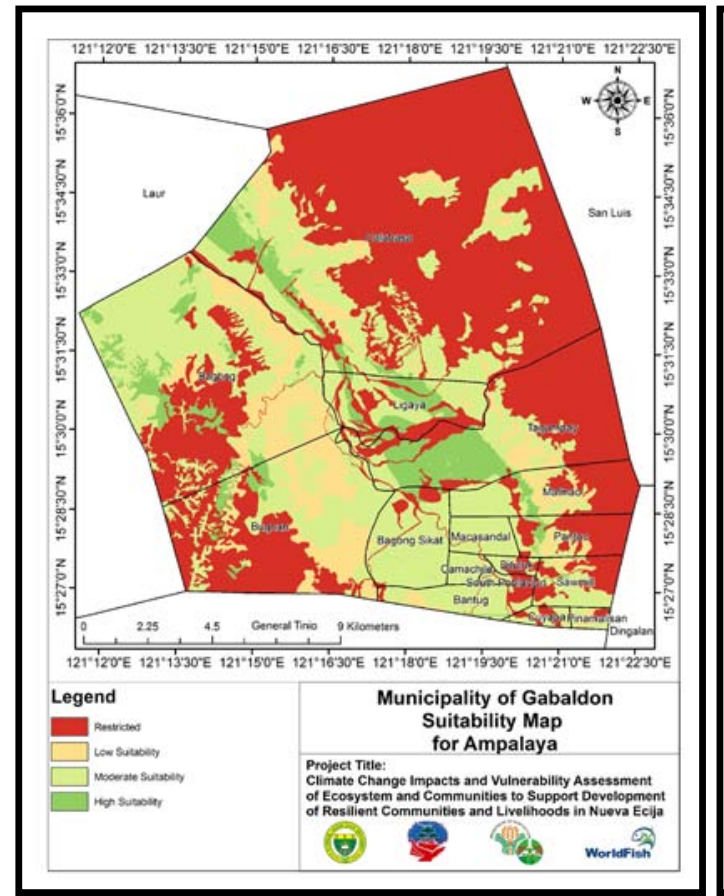

\section{BASELINE}

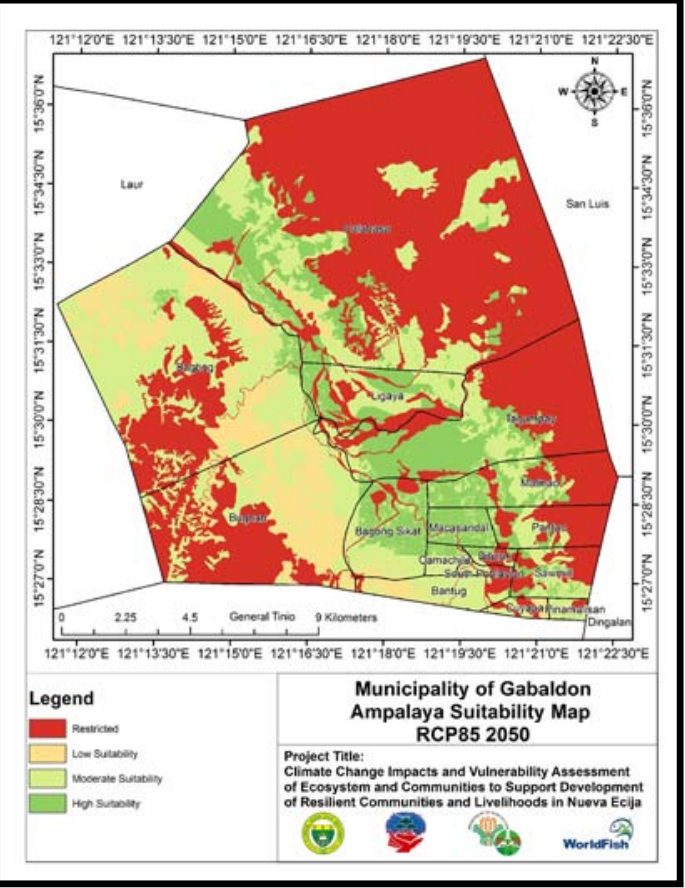

RCP 8.5

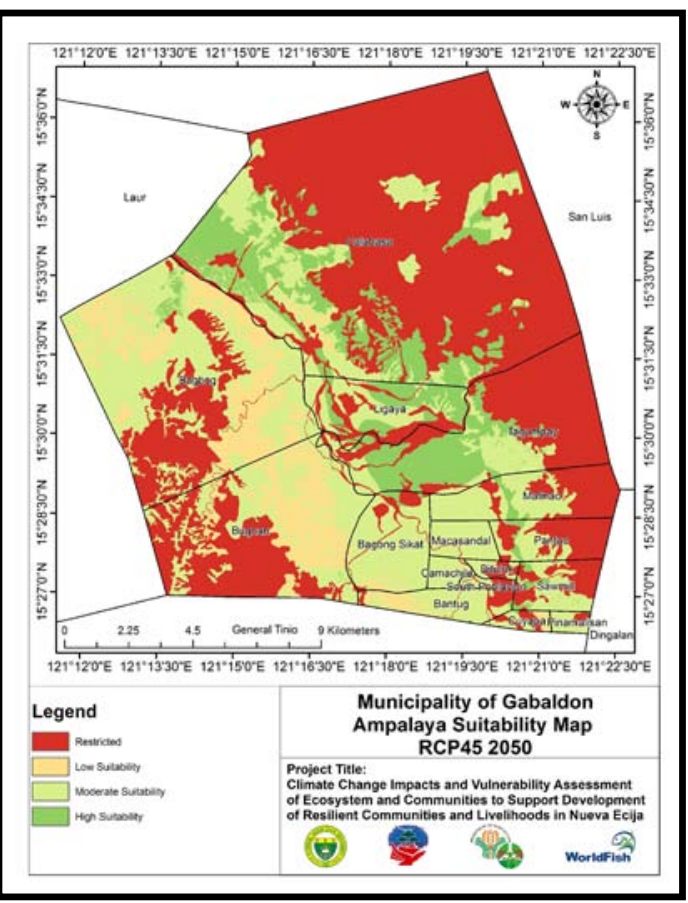

RCP 4.5

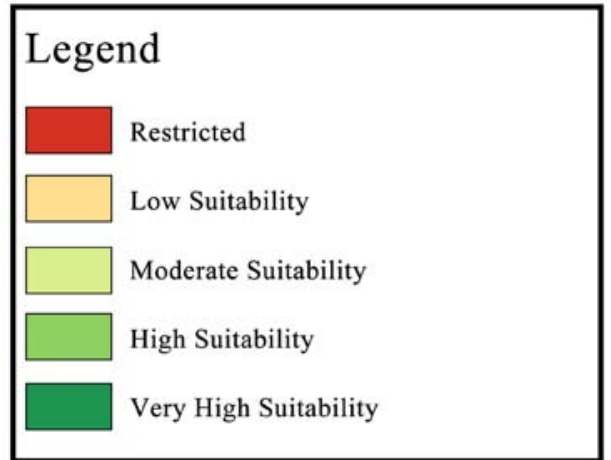

Figure 19. Ampalaya suitability maps in Gabaldon, Nueva Ecija for the 3 conditions.

in RCP 8.5 mainly in Barangays Ligaya, Calabasa, Bagong Sikat, Malinao and Pantoc.

Eggplant was also assessed in terms of its suitability in Gabaldon and results revealed that only small portions of the municipality are favorable in growing eggplants due to frequent flooding and landslide in the area and also due to soil 
type which is not highly favorable to eggplant. Eggplantis low to moderately suitable in some areas but highly suitable for the rest of the barangays in RCP 4.5 scenario while in RCP 8.5 eggplant is highly suitable in almost all barangays except Barangays Bugnan, Bagting and Malinao (Figure 20).

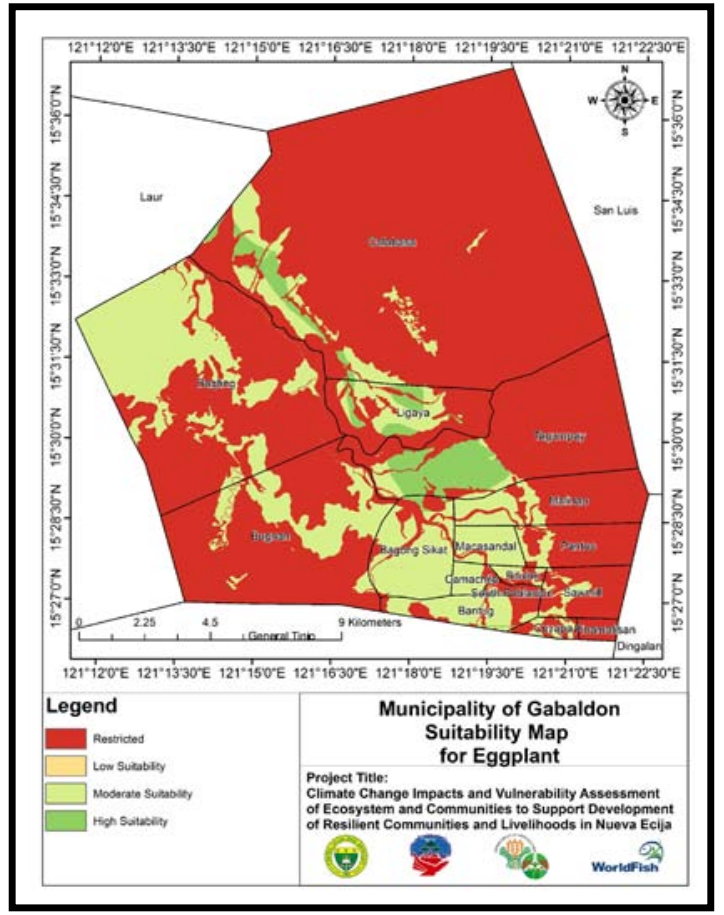

BASELINE

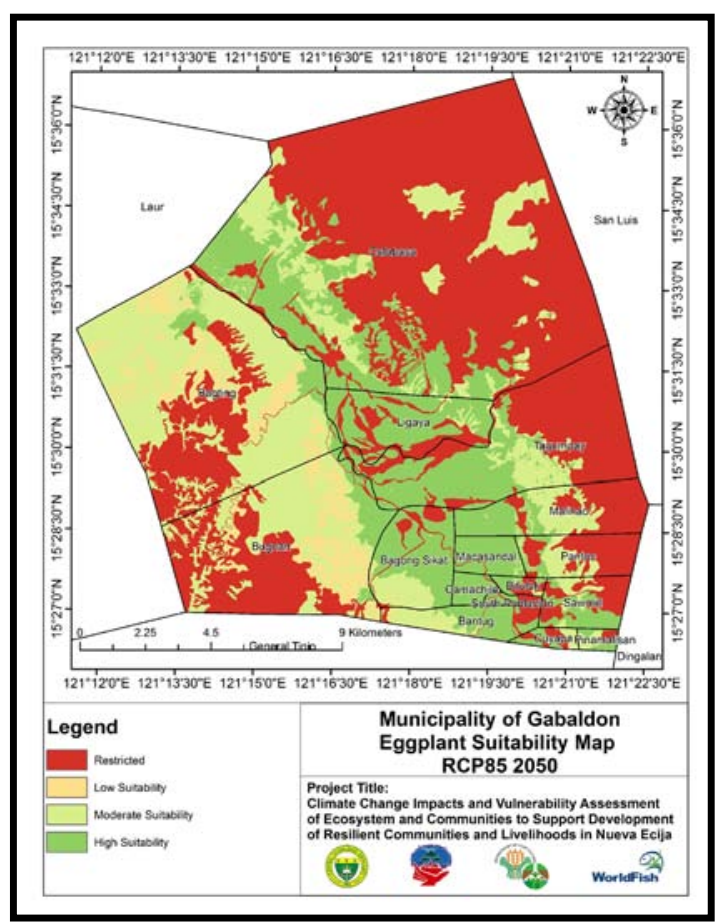

RCP 8.5

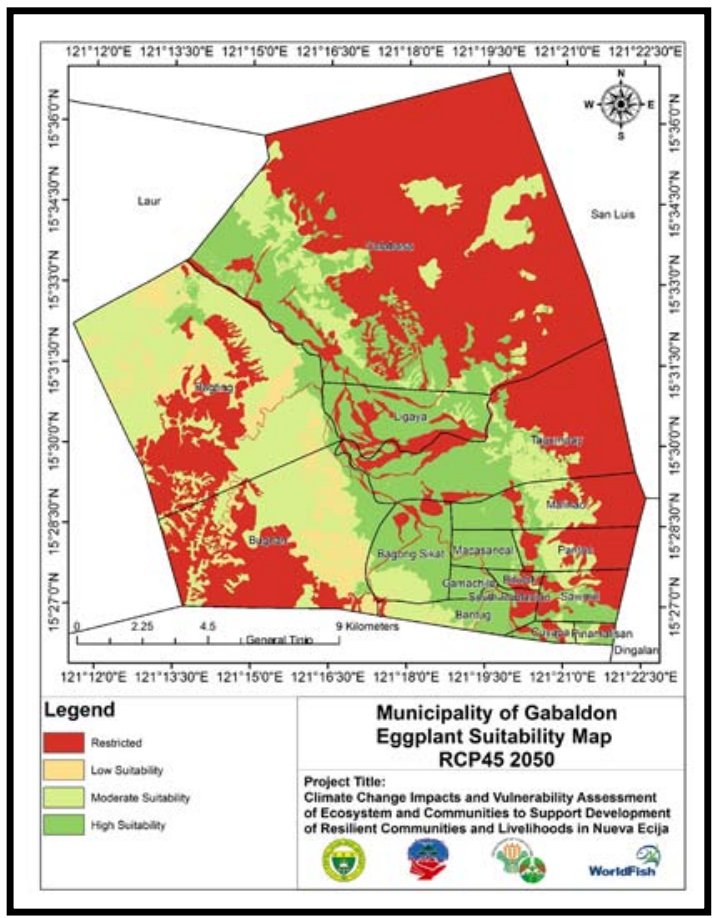

RCP 4.5

\section{Legend}
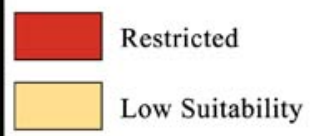

$\square$ Moderate Suitability

High Suitability

$\square$ Very High Suitability

Figure 20. Eggplant suitability maps in Gabaldon, Nueva Ecijafor the 3 conditions. 
Onion is moderately suitable to grow in the baseline situation in Gabaldon but not suitable to grow in Barangays Calabasa, Tagumpay, Malinao, Pantoc, Sawmill, Pinamalisan, Bugnan and Bagting due to the mountain soil type in those areas (Figure 21). The projection of onion suitability for RCP 4.5 in 2050 in Gabaldon was also assessed and results revealed that it is highly suitable for Barangays Ligaya, Bagong Sikat, Tagumpay and Calabasa while only moderately suitable for the rest of the barangays. In RCP 8.5 condition, results revealed that

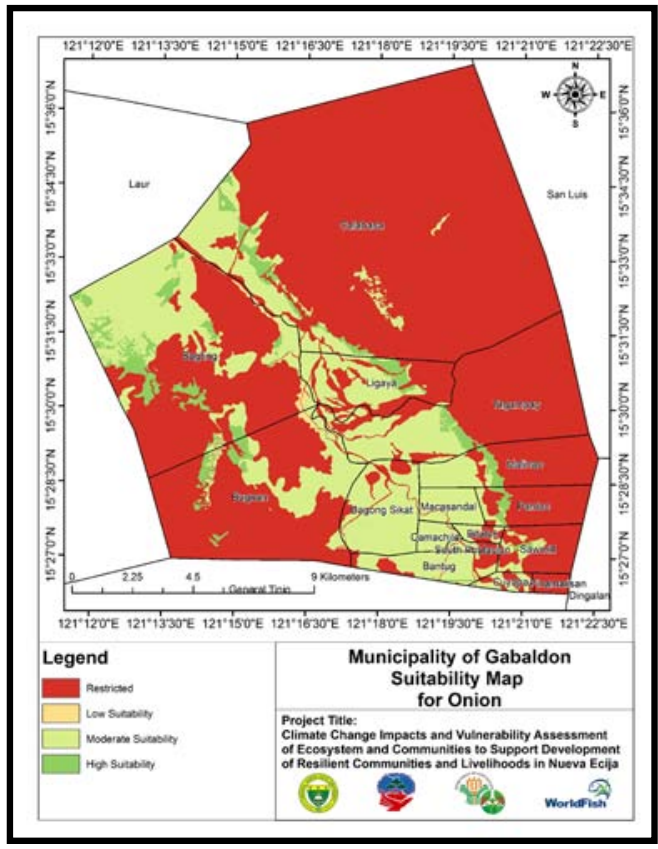

BASELINE

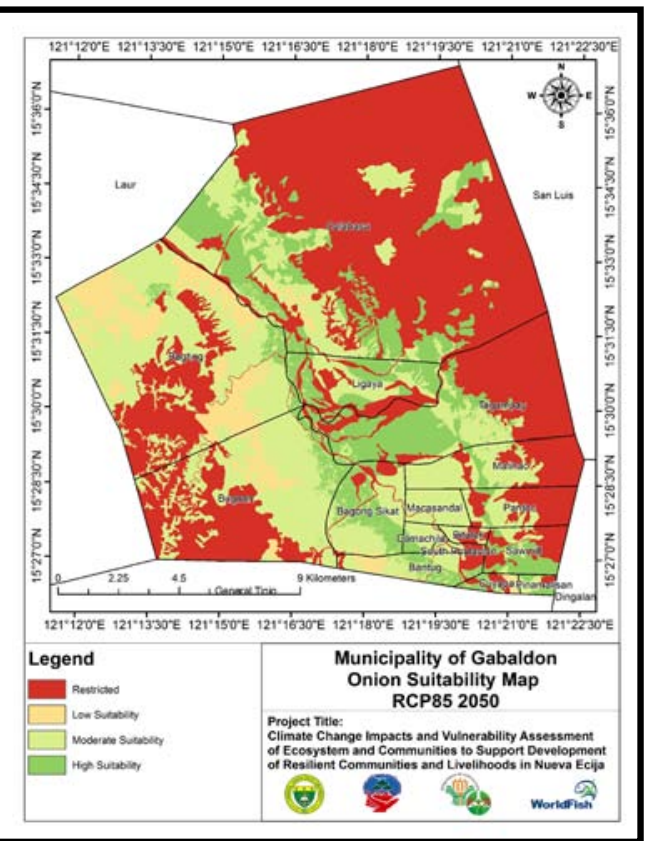

RCP 8.5

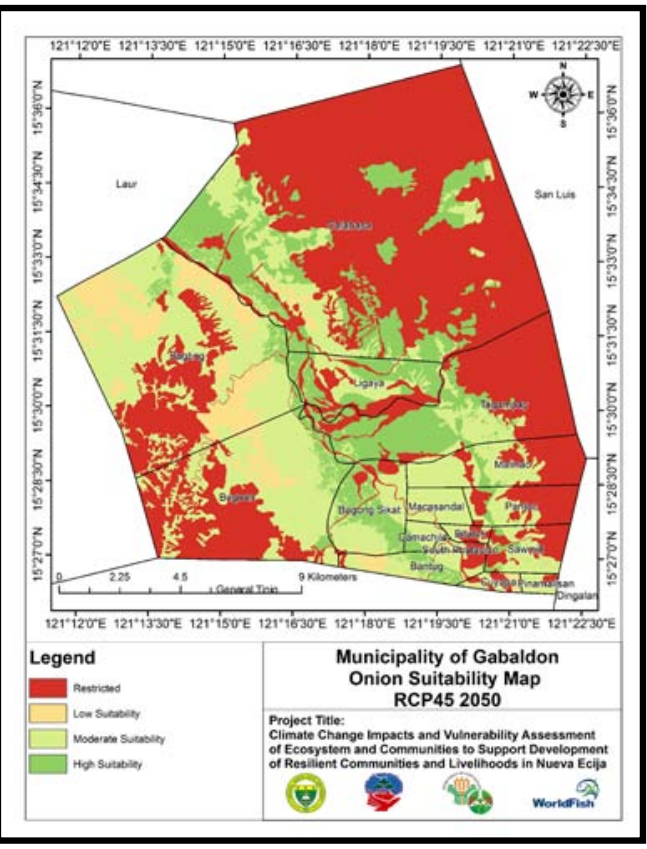

RCP 4.5

\section{Legend}

Restricted

Low Suitability

Moderate Suitability

High Suitability

Very High Suitability

Figure 21. Onion suitability maps in Gabaldon, Nueva Ecija for the 3 conditions. 
onion is no longer suitable in Barangays Calabasa and Ligaya although onion is highly suitable in Pinamalisan, Sawmill and Cuyapa.

String bean (sitao) in the baseline condition is highly suitable only in Barangays Ligaya, Macasandal, Camachile and Bantug and moderately suitable for Barangays Bugnan, Bagting and Calabasa (Figure 22). However, it is not suitable in restricted areas such as the protected forest areas. String bean is highly suitable in RCP 4.5 condition while only a few barangays have high suitability for this crop in RCP 8.5.

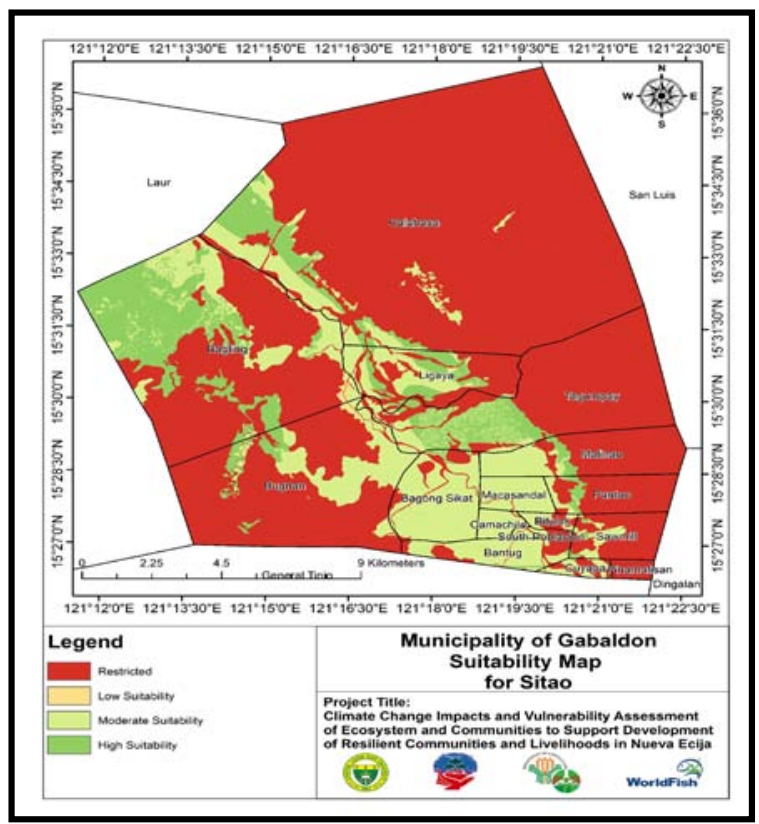

BASELINE

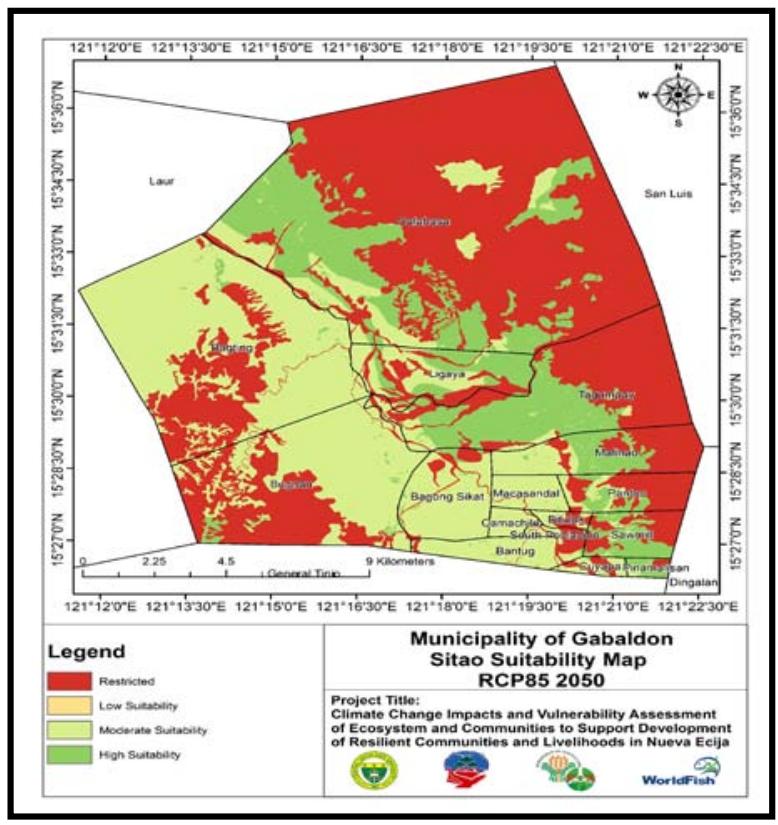

RCP 8.5

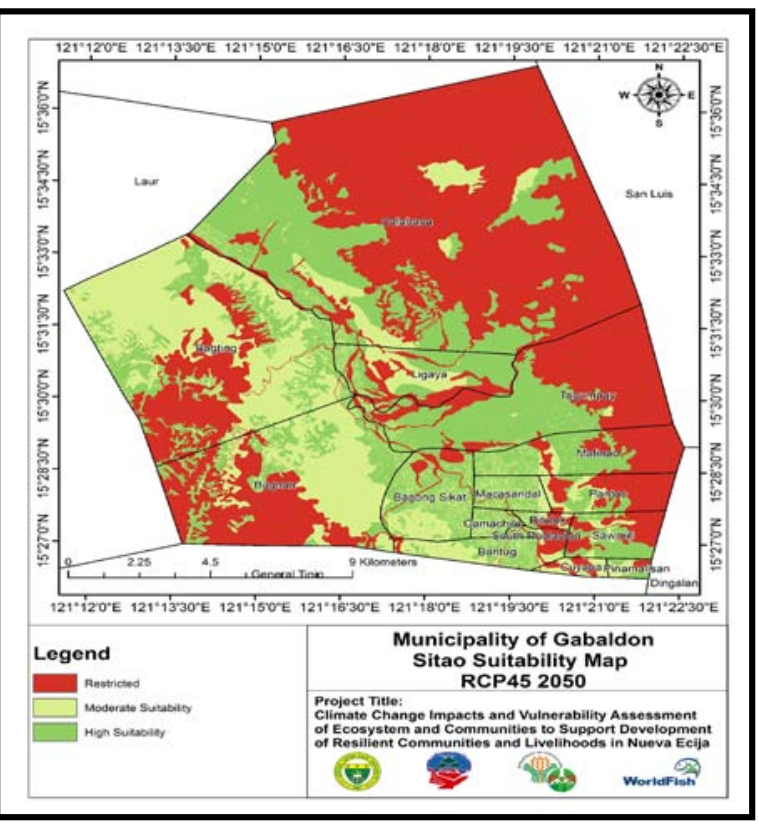

RCP 4.5

\section{Legend}

Restricted

Low Suitability

Moderate Suitability

High Suitability

Very High Suitability

Figure 22. String bean suitability maps in Gabaldon, Nueva Ecijafor the 3 conditions. 
The municipality of Gabaldon is frequently affected by landslide and flooding that cause great damage in crops, and one of these crops is rice which has a very low suitability in Gabaldon for the baseline condition (Figure 23). Rice in RCP 4.5 scenario is highly suitable in many parts of the municipality. Similarly, rice in RCP 8.5 has also high suitability in many areas of the municipality.

The second most widely grown crop in Gabaldon, Nueva Ecija is tomato and

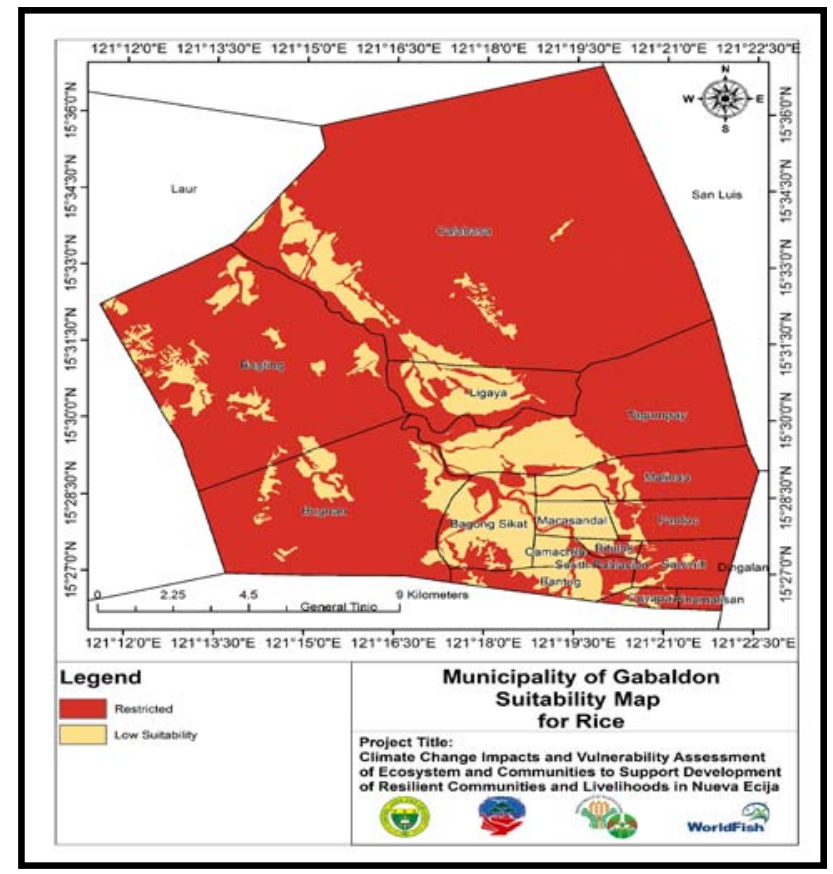

\section{BASELINE}

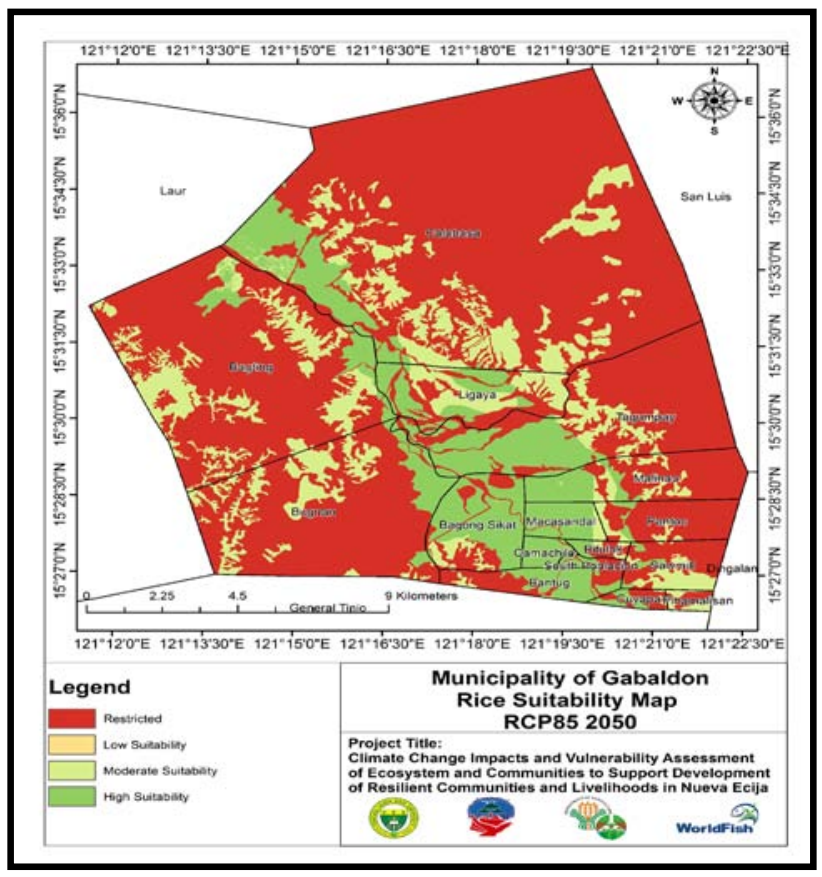

RCP 8.5

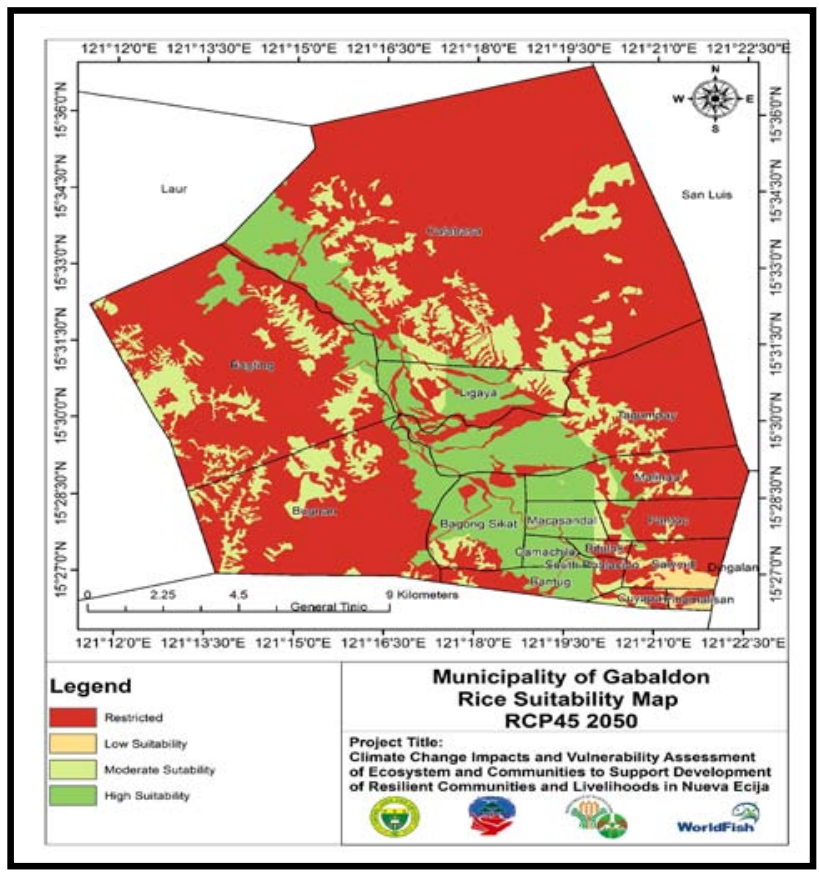

RCP 4.5

\section{Legend}

$\square$ Restricted
$\square$ Low Suitability
$\square$ Moderate Suitability
$\square$ High Suitability
$\square$ Very High Suitability

Figure 23. Rice suitability maps in Gabaldon, Nueva Ecija for the 3 conditions. 
its suitability was also assessed under baseline condition and the other 2 projected scenarios. Tomato is highly suitable in lower parts of the municipality especially in Barangays Ligaya and Tagumpay while it has low to moderate suitability in Barangays Bagong Sikat, Macasandal, Camachile, Bantug, Cuyapa and Sawmill (Figure 24). Tomato in RCP 4.5 is highly suitable while in RCP 8.5 tomato is not suitable anymore in Barangays Calabasa and Bagting but highly highly suitable in many areas of Gabaldon.

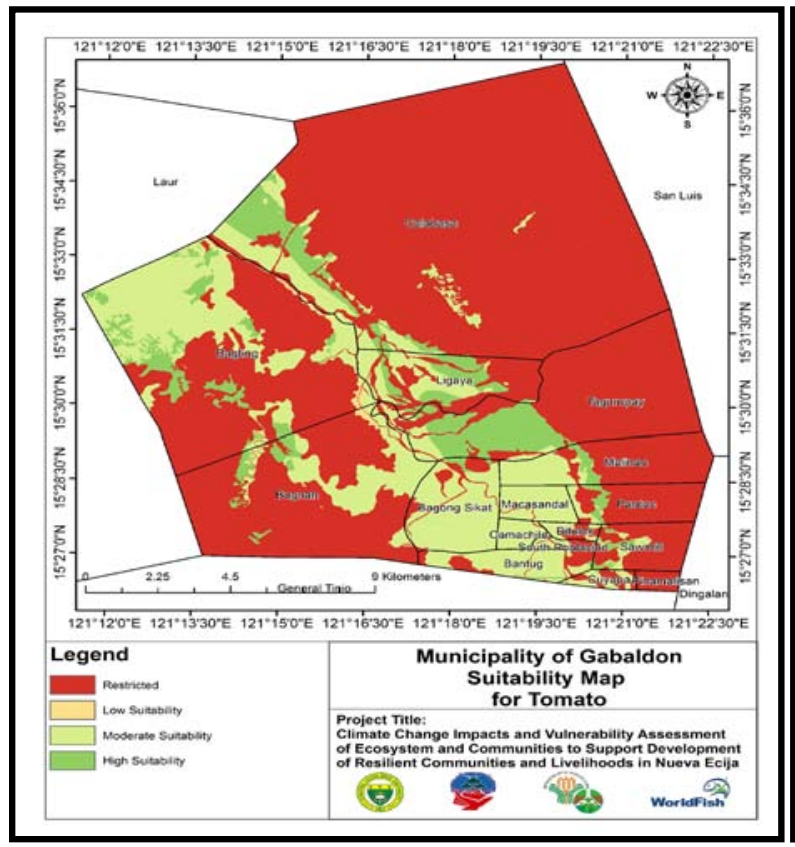

BASELINE

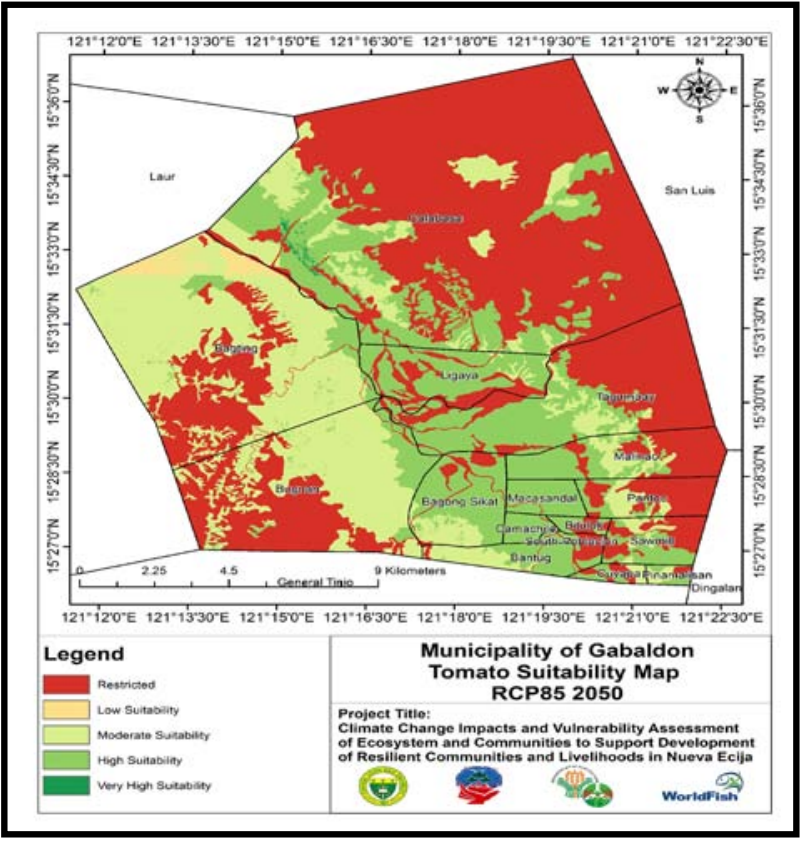

RCP 8.5

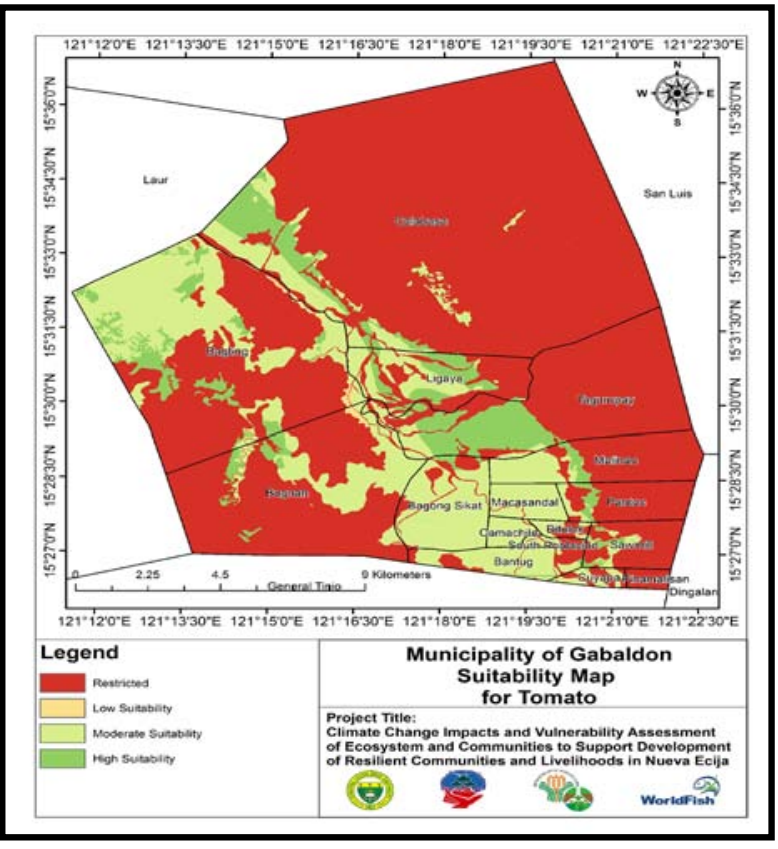

RCP 4.5

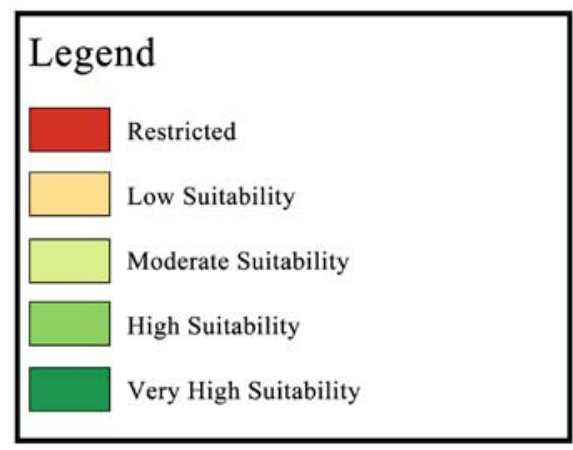

Figure 24. Tomato suitability maps in Gabaldon, Nueva Ecija for the 3 conditions. 
The suitability assessment of chili in the baseline condition revealed that it is moderately suitable only in the town proper while not very suited in some barangays due to the presence of gravelly soil and mountain soil in these areas. In RCP 4.5 , chili is moderately and highly suitable for the majority of barangays in Gabaldon. However, chili has low to moderate suitability in many barangays in RCP 8.5 while it is highly suitable for Barangays Sawmill and Pinamalisan (Figure 25).

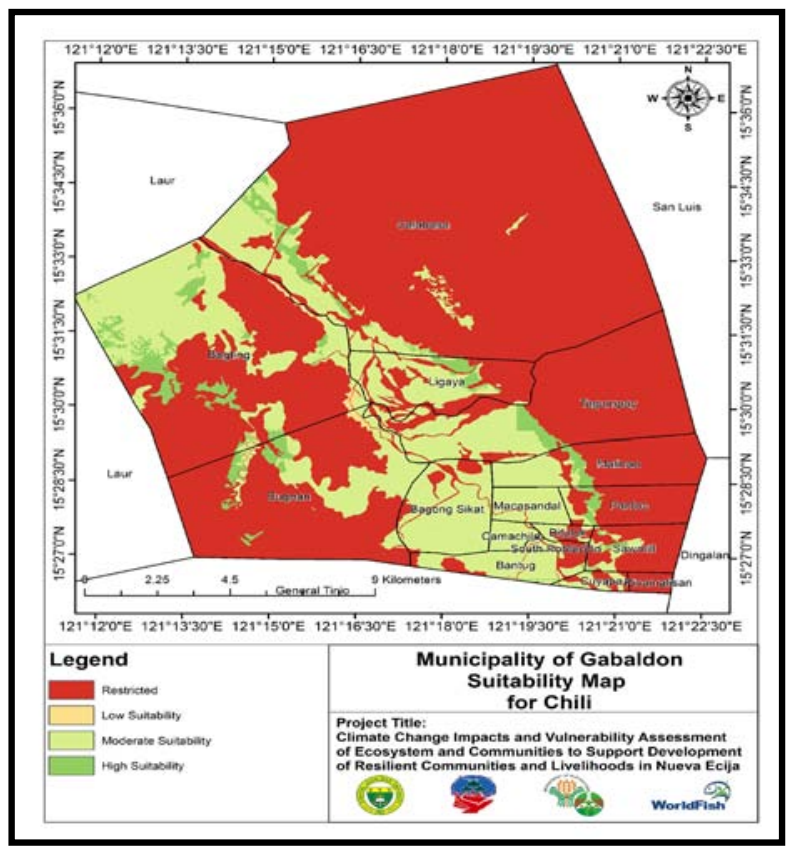

BASELINE

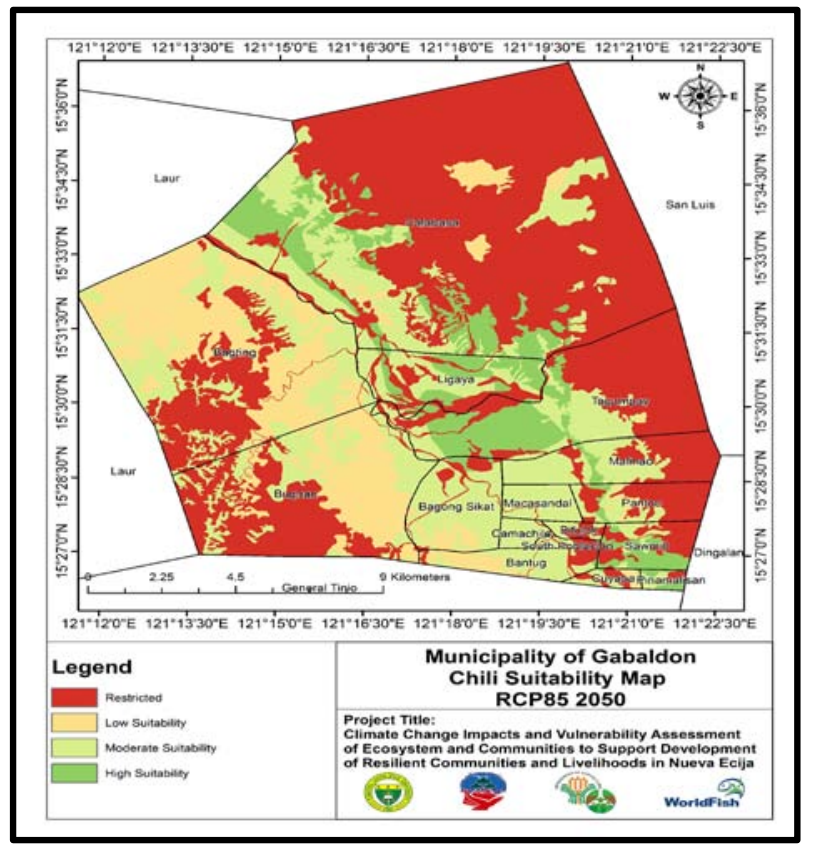

RCP 8.5

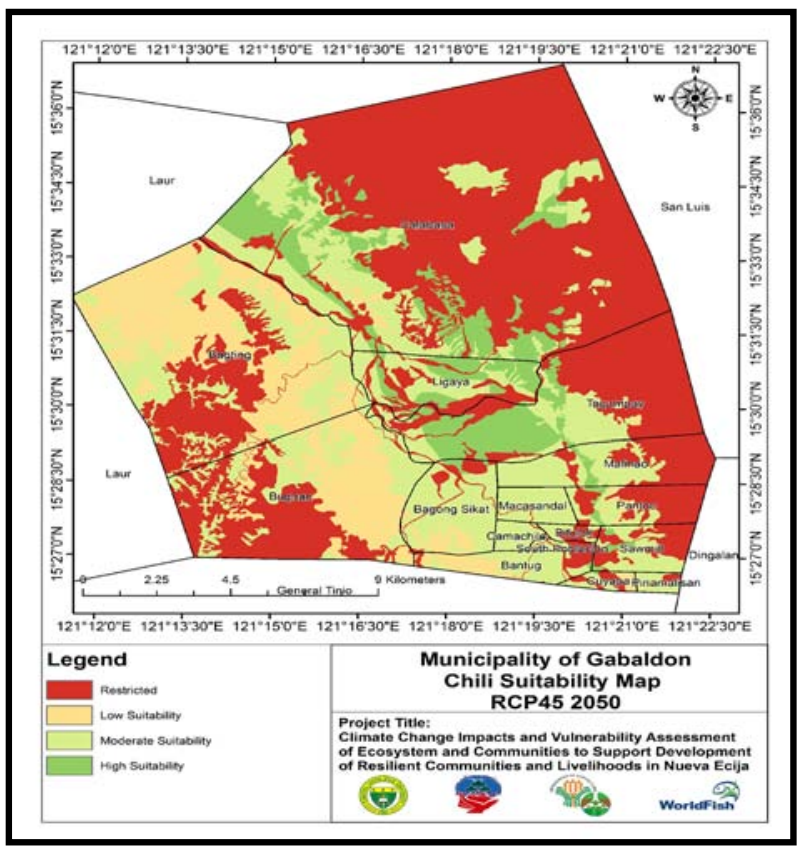

RCP 4.5

\section{Legend}

Restricted

Low Suitability

Moderate Suitability

High Suitability

Very High Suitability

Figure 25. Chili suitability maps in Gabaldon, Nueva Ecijafor the 3 conditions. 
One of the commonly raised animals in Gabaldon is native chicken hence its suitability in the area was assessed. Results revealed that chicken is highly suitable to raise in almost all barangays except in Barangays Calabasa and Tagumpay in the baseline condition (Figure 26). The projected suitability of chicken in RCP 4.5 scenario shows that chicken has low to moderate suitability while chicken in RCP 8.5 condition has high suitability in almost all barangays. Results indicated that native chicken has high suitability in hazardous conditions.

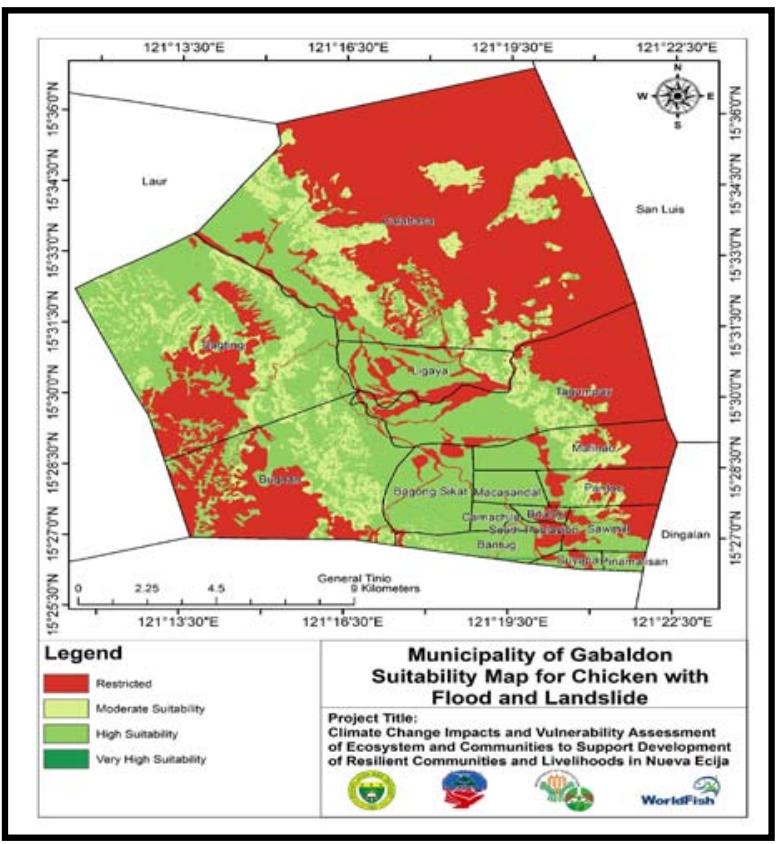

BASELINE

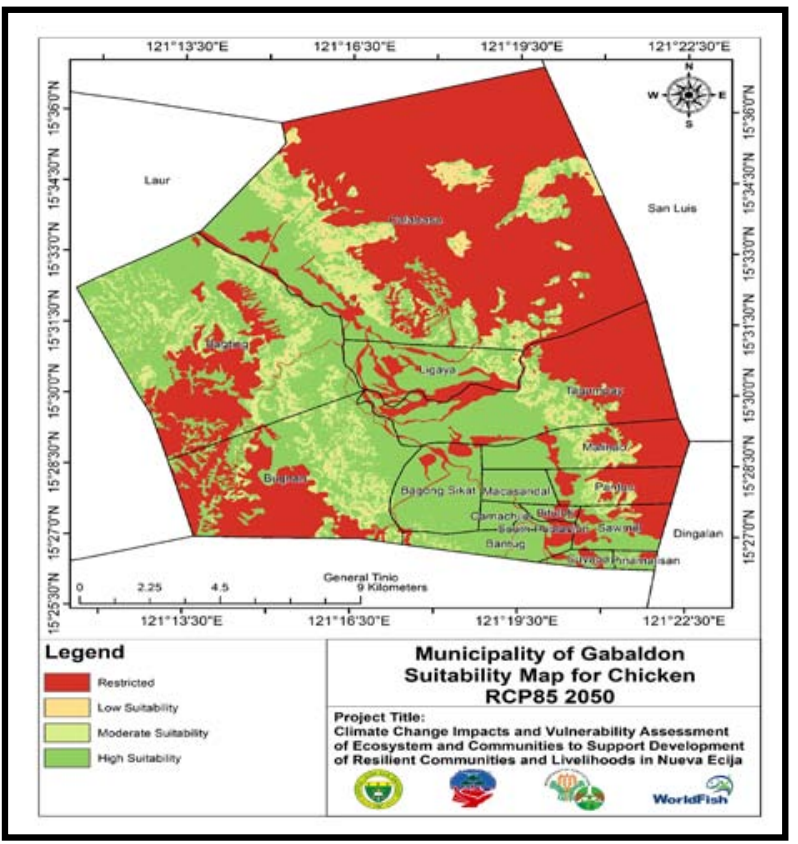

RCP 8.5

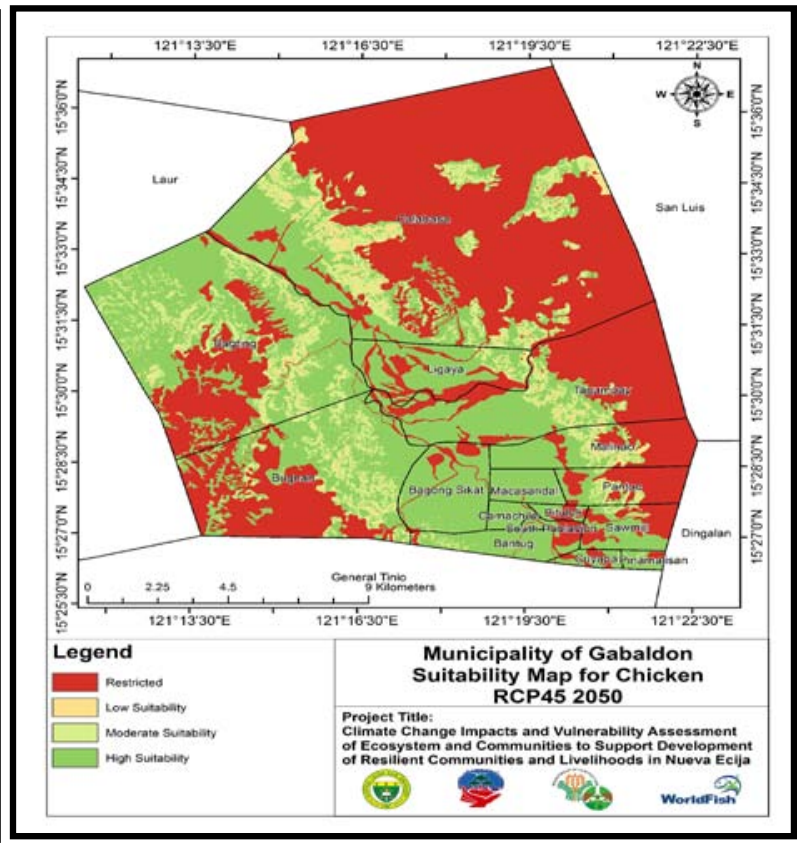

RCP 4.5

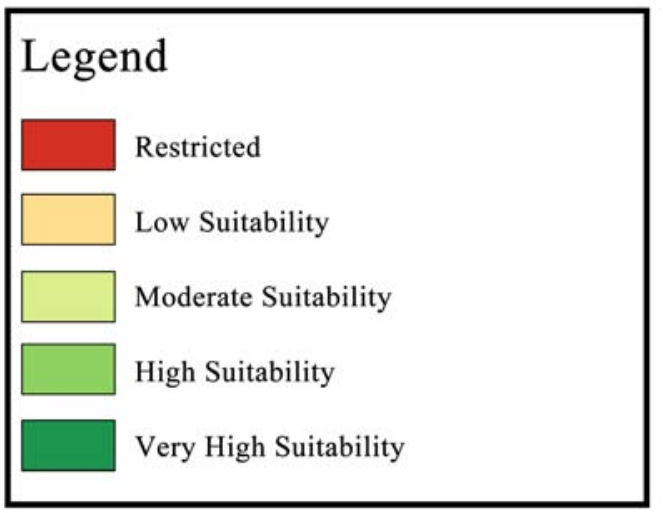

Figure 26. Native chicken suitability maps in Gabaldon, Nueva Ecijafor the 3 conditions. 
Goat suitability in Gabaldon, Nueva Ecija was also assessed and results revealed that it is highly suitable in the current condition and in the future conditions except in the mountainous areas of Gabaldon which means that raising goat is fit to nurture in both good and bad situations and can withstand impacts of climate change based on the indicators and factors considered in the study (Figure 27).

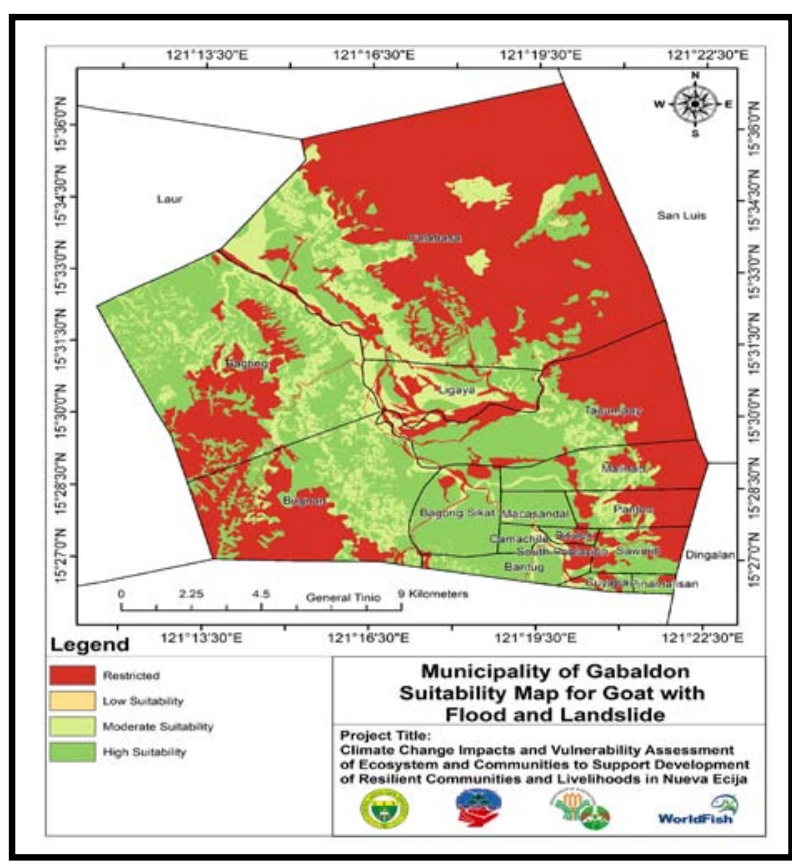

BASELINE

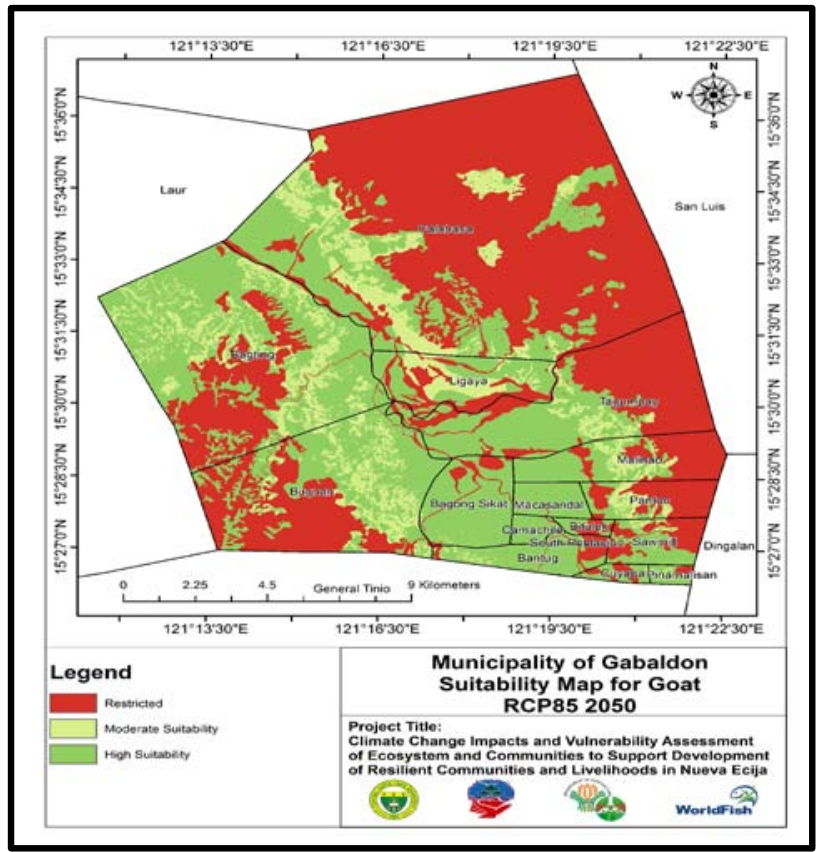

RCP 8.5

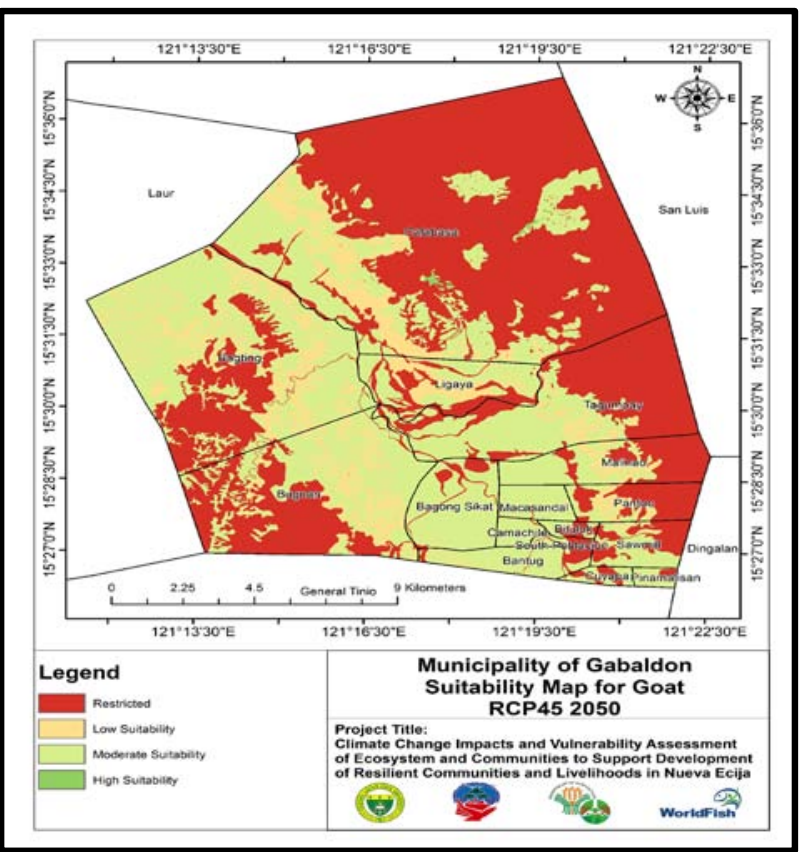

RCP 4.5

\section{Legend}

\begin{tabular}{|l|l}
$\square$ & Restricted \\
$\square$ & Low Suitability \\
$\square$ & Moderate Suitability \\
$\square$ & High Suitability \\
$\square$ & Very High Suitability \\
\hline
\end{tabular}

Figure 27. Goat suitability maps in Gabaldon, Nueva Ecijafor the 3 conditions. 


\subsubsection{Cabanatuan City}

Calamansi is the $4^{\text {th }}$ widely grown crop in Cabanatuan City. Its suitability for the current environmental condition was assessed, and results revealed that it is moderately suitable to grow in the whole city. The suitability of calamansi for 2050 in RCP 4.5 ranged from moderate to highly suitable (Figure 28). However, for RCP 8.5 only a few areas have high suitability for calamansi.

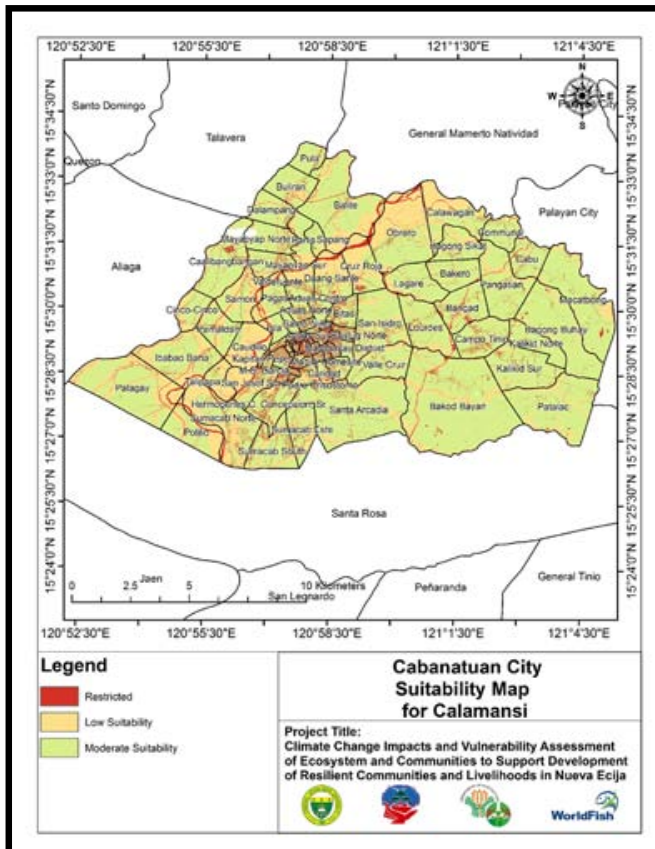

BASELINE

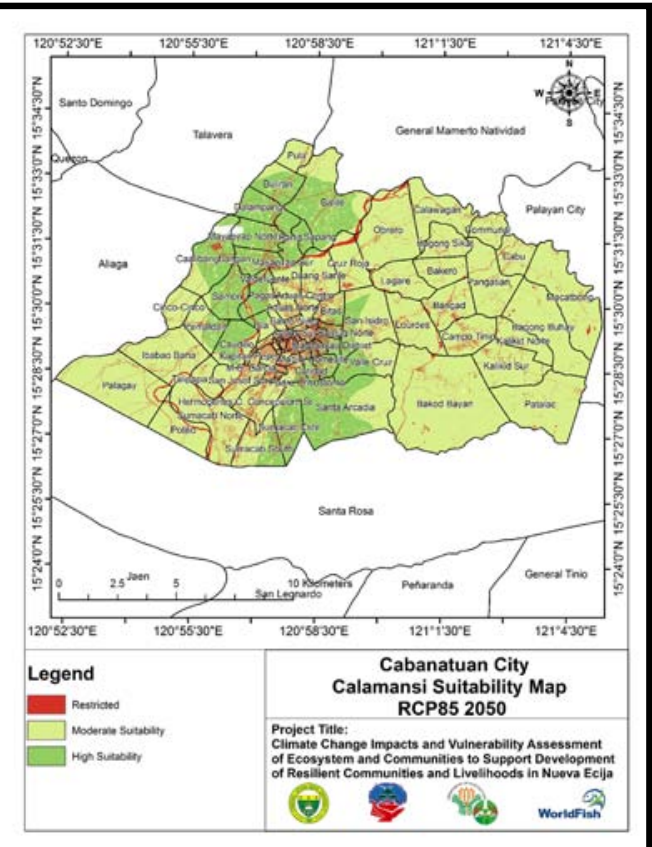

RCP 8.5

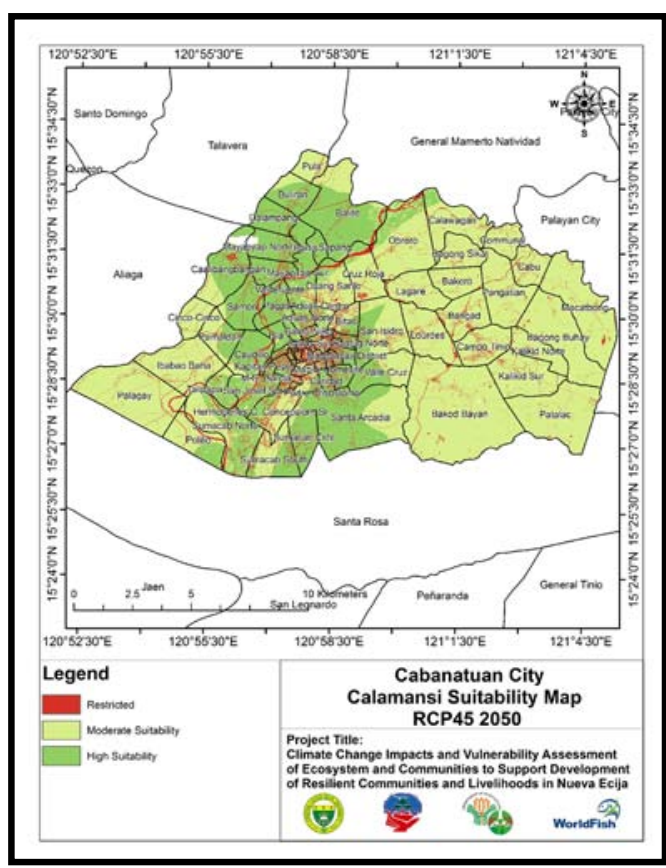

RCP 4.5

\section{Legend}

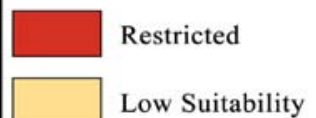

Moderate Suitability

High Suitability

Very High Suitability

Figure 28. Calamansi suitability maps in Cabanatuan City, Nueva Ecija for the 3 conditions. 
Based on the baseline condition suitability assessment for corn in Cabanatuan City, results revealed that it is highly suitable to grow in the city except in areas affected by flood especially Barangays Obrero and Calawagan for they are near the river and streams. Cornhas high suitability in RCP 4.5 while only a few areas in the city have low suitability for corn in RCP 8.5 particularly in Barangays Polilio, Hermogenes C, Obrero, Calawagan, Sapang, Daang Sarile and Pagas (Figure 29).

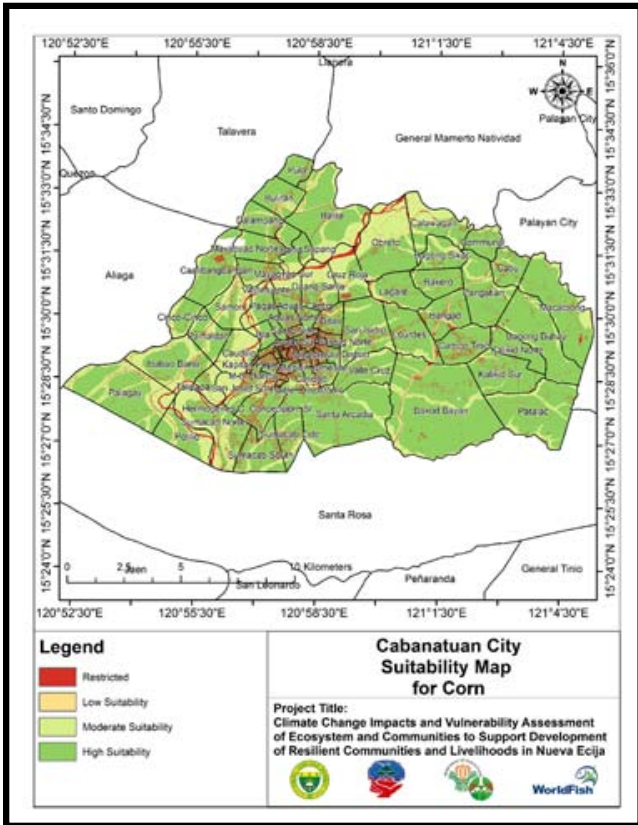

BASELINE

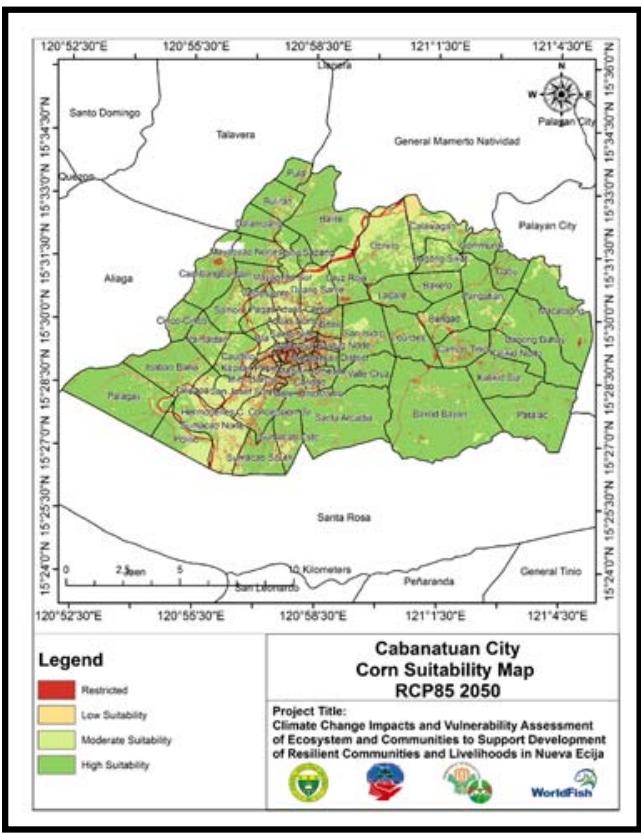

RCP 8.5

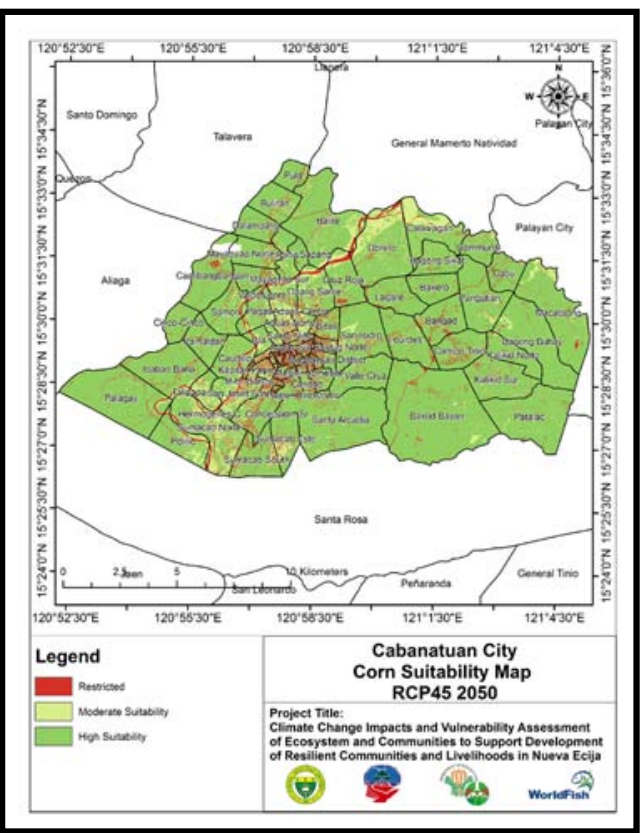

RCP 4.5

\section{Legend \\ Restricted \\ Low Suitability \\ Moderate Suitability \\ High Suitability \\ Very High Suitability}

Figure 29. Corn suitability maps in Cabanatuan City, Nueva Ecijafor the 3 conditions. 
Results of the baseline condition suitability assessment for eggplant in Cabanatuan City revealed that eggplant is highly suitable to grow in the city because of the loam to clay-loam soil type which is best for growing eggplant while it is moderately suitable in areas near rivers and streams due to frequent flooding. Eggplant has high to very high suitability in RCP 4.5 while only a few areas have very high suitability for eggplant in RCP 8.5 (Figure 30). Results indicated that eggplant is very suitable to grow in Cabanatuan City in the future scenarios particularly in the good conditions.

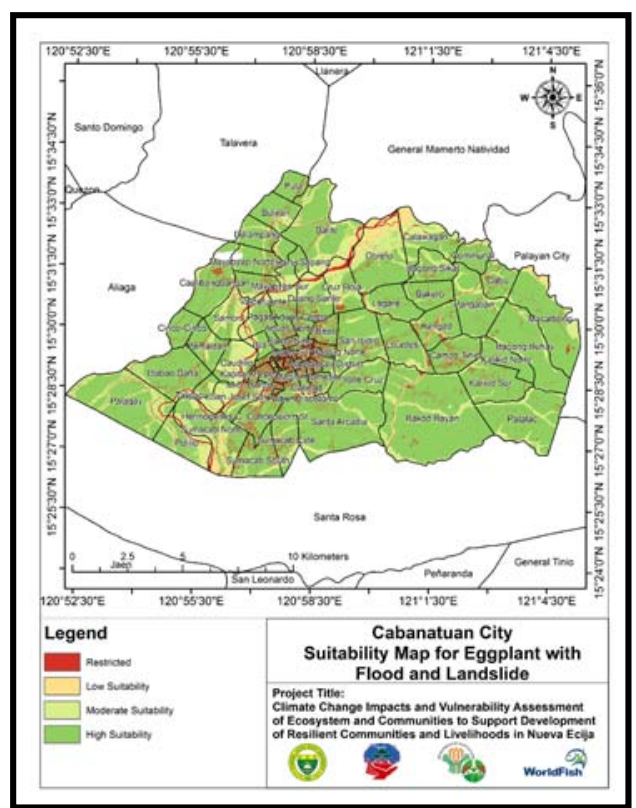

BASELINE

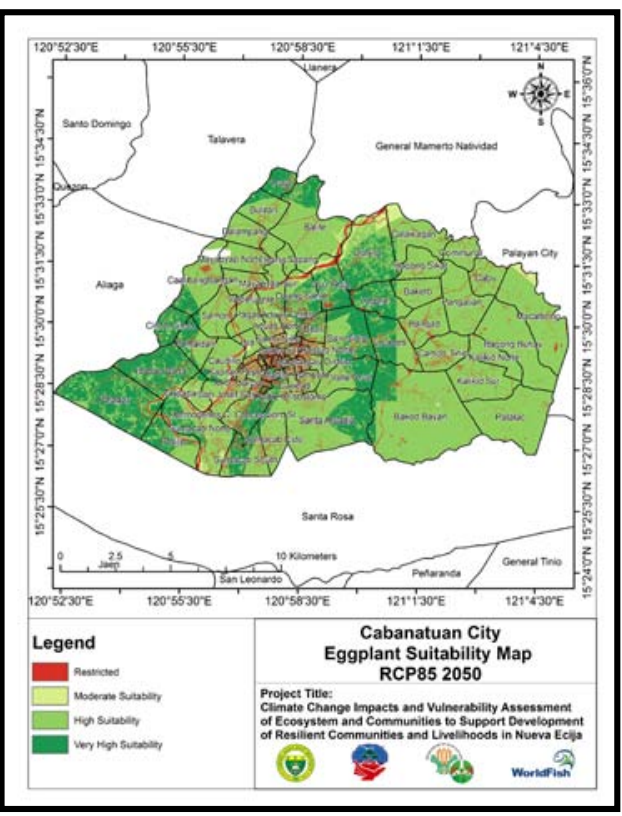

RCP 8.5

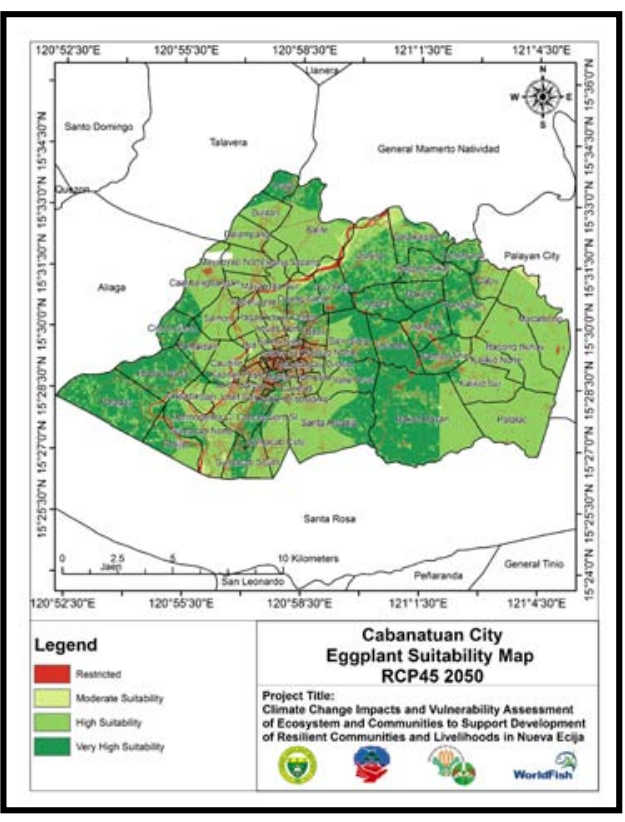

RCP 4.5

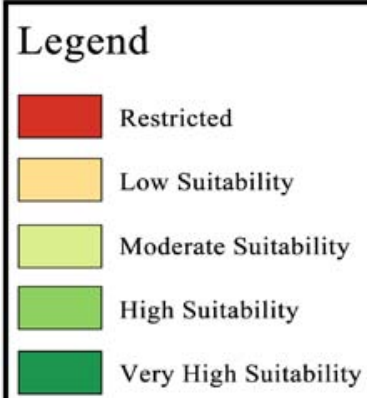

Figure 30. Eggplant suitability maps in Cabanatuan City, Nueva Ecijafor the 3 conditions. 
One of the most widely grown crops in Cabanatuan City is rice which has an estimated 9578 hectares of land for growing rice. The suitability assessment of rice in the current condition shows that rice is highly suitable for Cabanatuan due to its flat terrain farms which are excellent areas for cultivating rice. However, rice is moderately suitable for those areas near the rivers and streams due to frequent flooding in these areas. Rice has high suitability in Cabanatuan City for both RCP 4.5 and RCP 8.5 scenarios (Figure 31 ).

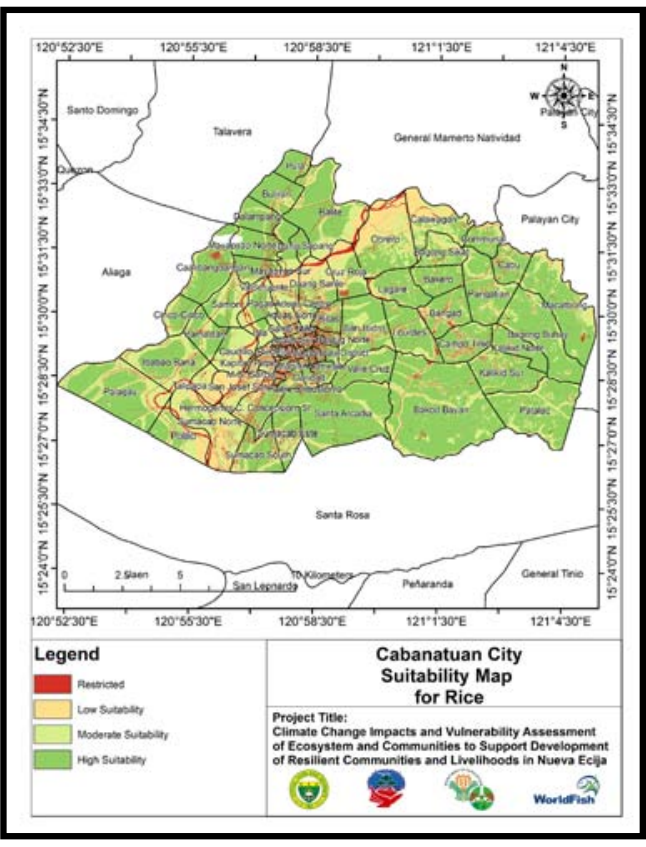

BASELINE

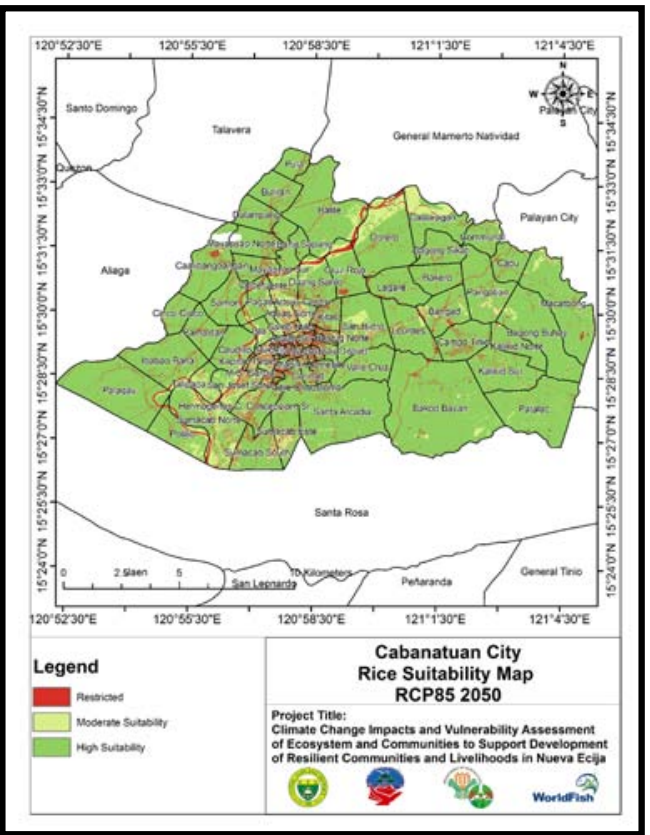

RCP 8.5

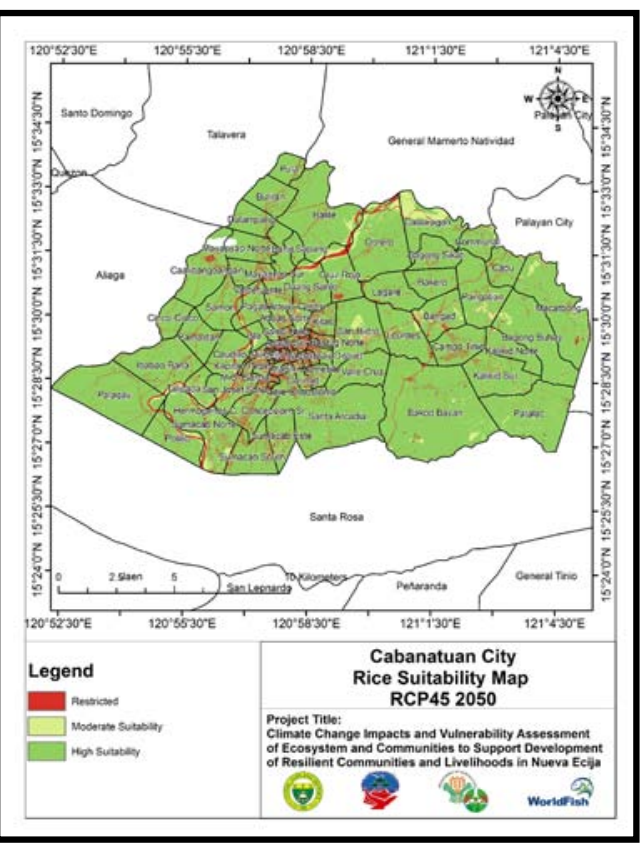

RCP 4.5

\section{Legend}

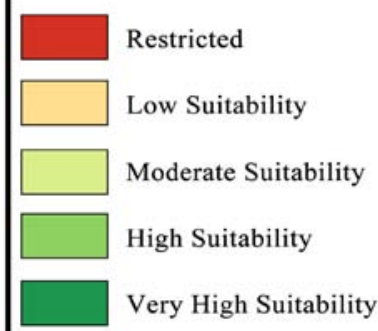

Figure 31. Rice suitability maps in Cabanatuan City, Nueva Ecija for the 3 conditions. 
Onion is not widely grown by farmers in Cabanatuan City, but based on the suitability assessment made, onion is highly suitable to grow in the city in the baseline condition even though the city is affected by frequent flooding in some areas. However, it is not suitable in Barangays Calawagan, Obrero, Cruz Roja and Caudillo because these areas are near the rivers and streams. Onion is highly suitable for RCP 4.5 and RCP 8.5 scenarios (Figure 32 ).

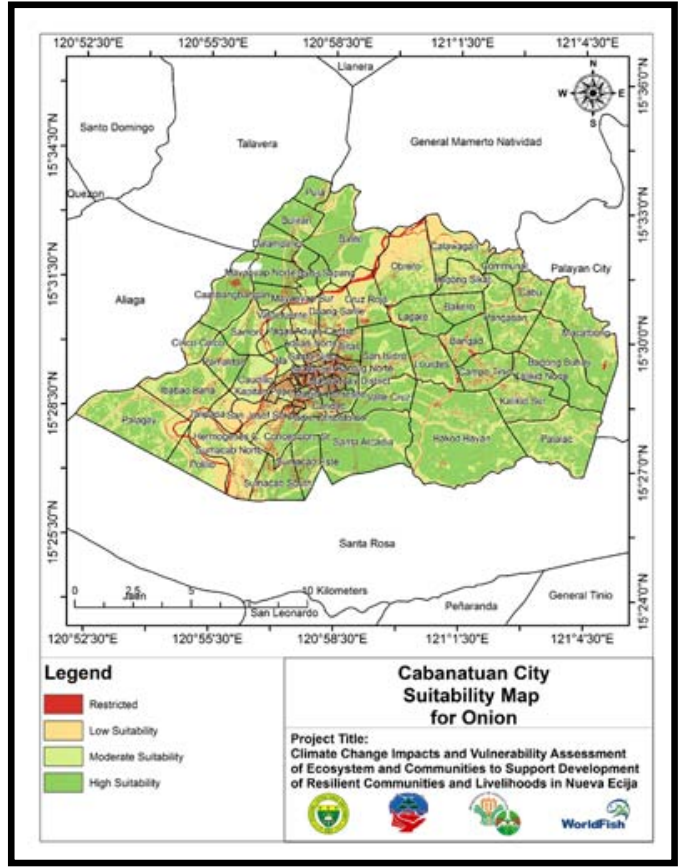

BASELINE

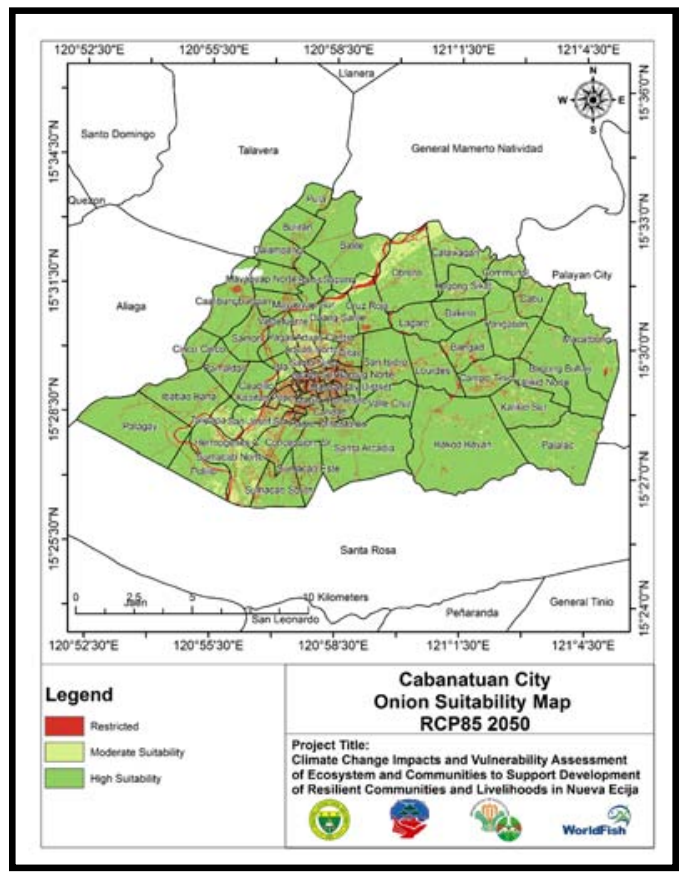

RCP 8.5

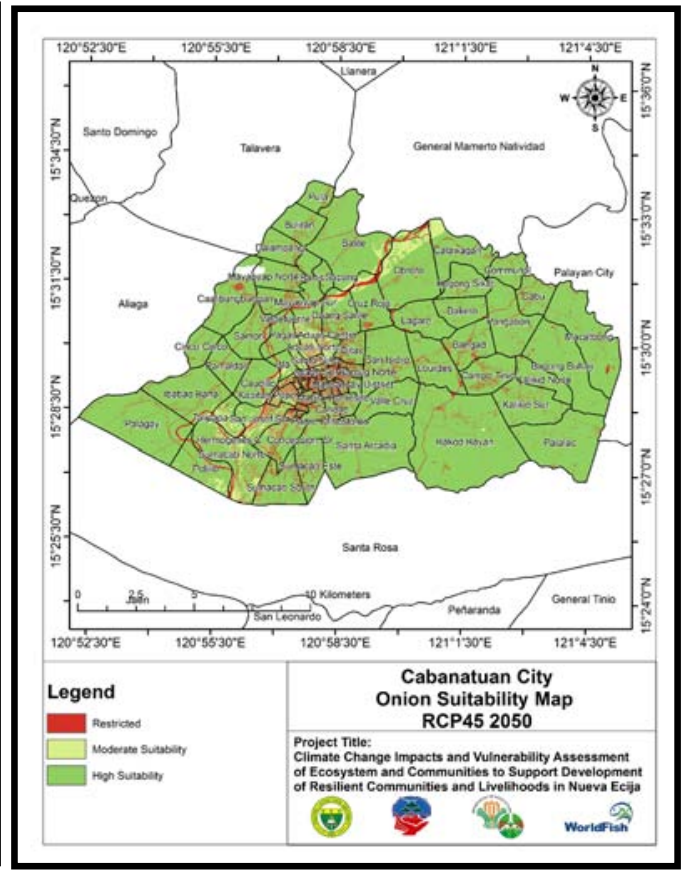

RCP 4.5

\section{Legend}

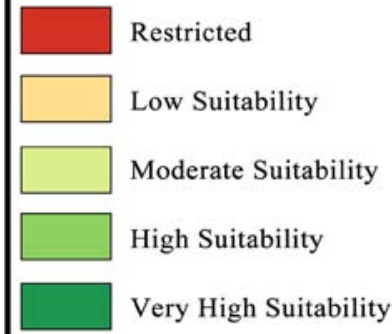

Figure 32. Onion suitability maps in Cabanatuan City, Nueva Ecija for the 3 conditions. 
Native chicken is the most widely raised animal in Cabanatuan City. Results of the suitability assessment for chicken for the baseline condition revealed that it is highly suitable to raise in the city with only a few areas that have low suitability. Native chicken is also highly suitable in RCP 4.5 and RCP 8.5 situations, which means that native chicken is not affected so much by the climate change impacts especially the factors that were considered in the study (Figure 33).

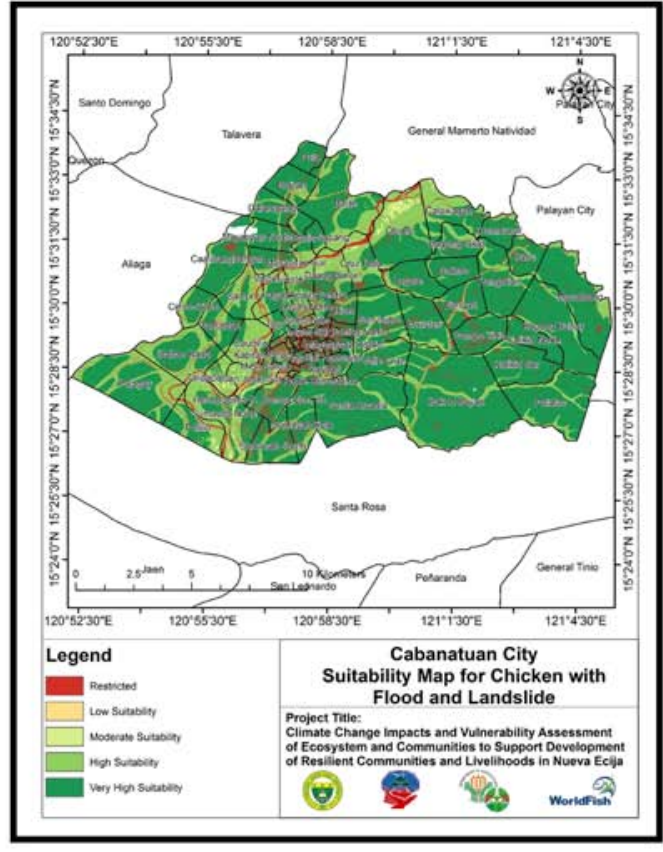

BASELINE

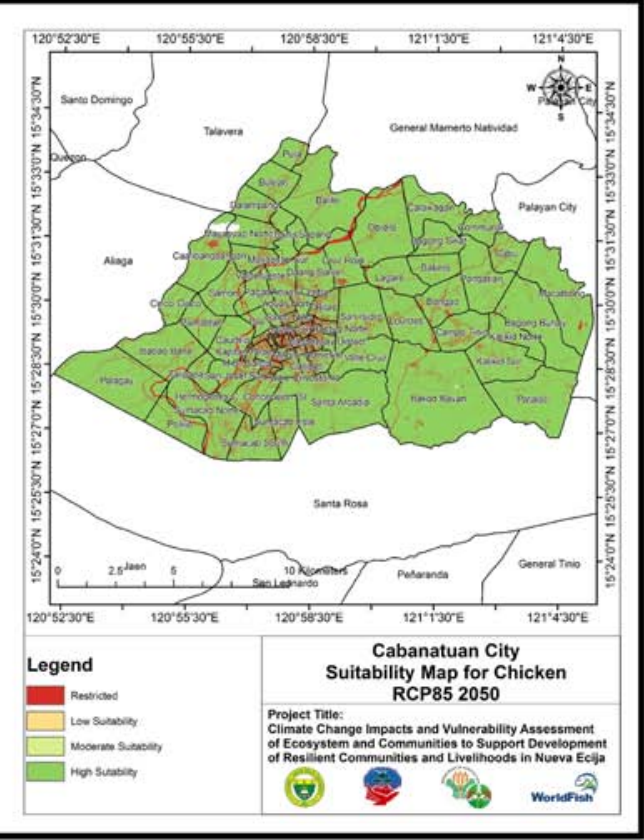

RCP 8.5

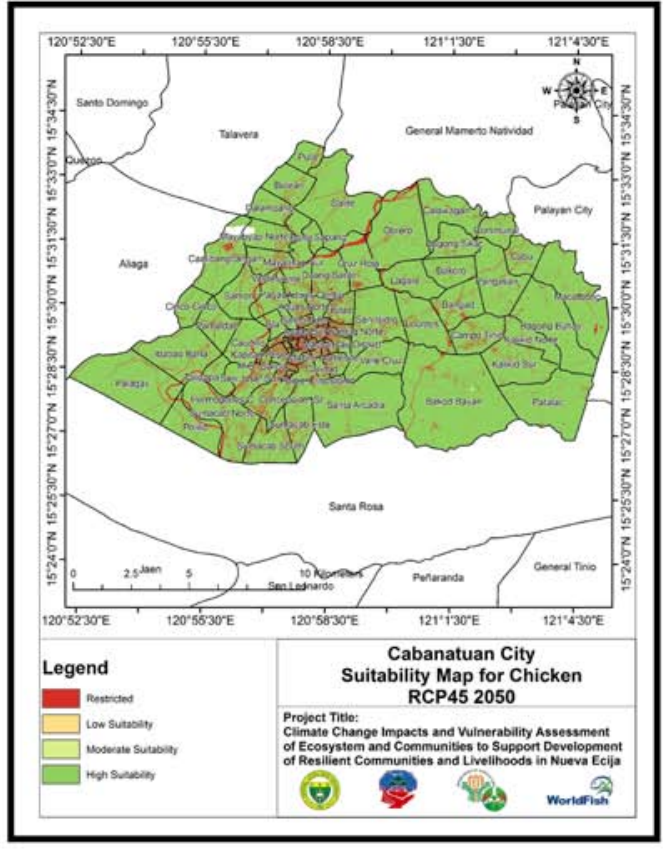

RCP 4.5

\section{Legend}

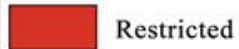

Low Suitability

Moderate Suitability

High Suitability

Very High Suitability

Figure 33. Native chicken suitability maps in Cabanatuan City, Nueva Ecija for the 3 conditions. 
Based on the baseline condition goat is found to be highly suitable in Cabanatuan City especially in Barangays Sumacab Este, San Isidro, Bangad, Pangatian and Bakod Bayan for these areas are composed of farmlands and grasslands which serve as the main source of their food. Results for RCP 4.5 and RCP 8.5 assessment, goat is highly suitable in both scenarios (Figure 34).

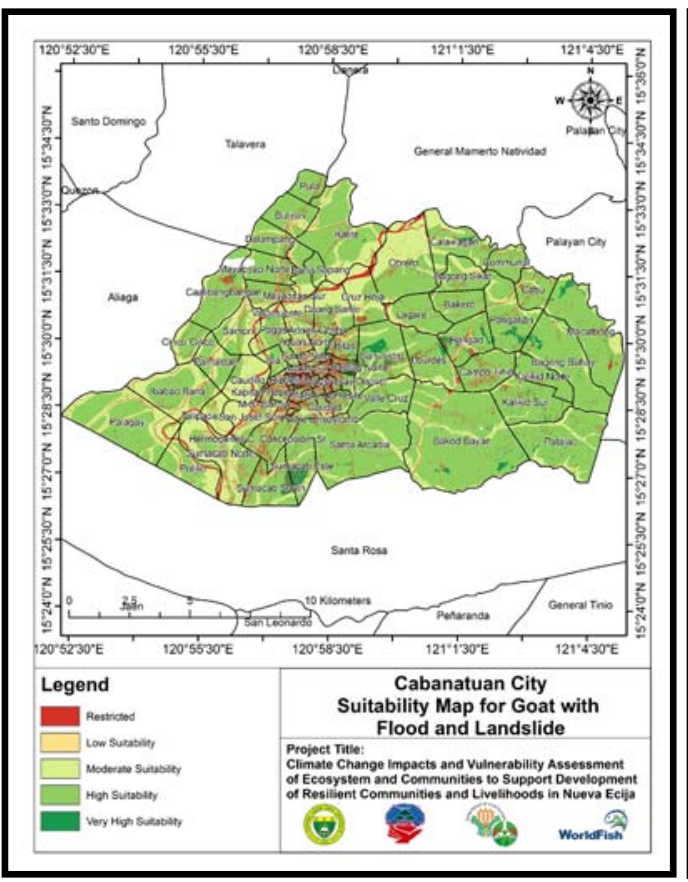

BASELINE

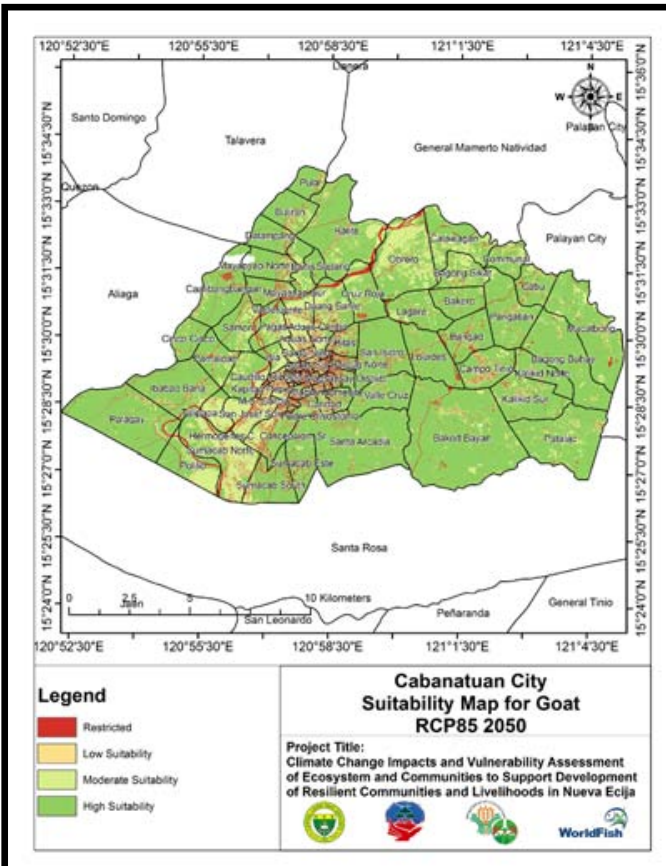

RCP 8.5

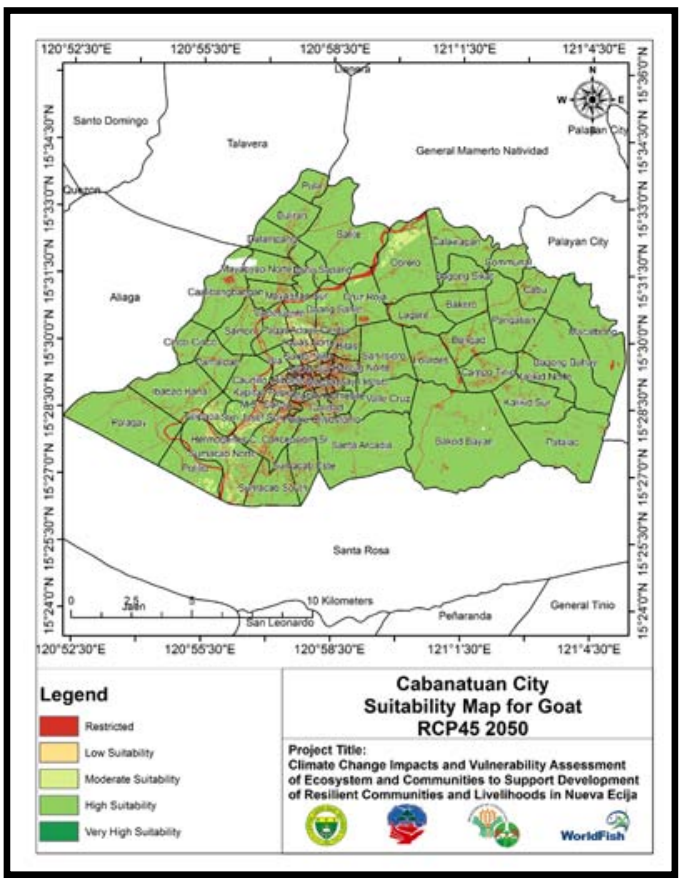

RCP 4.5

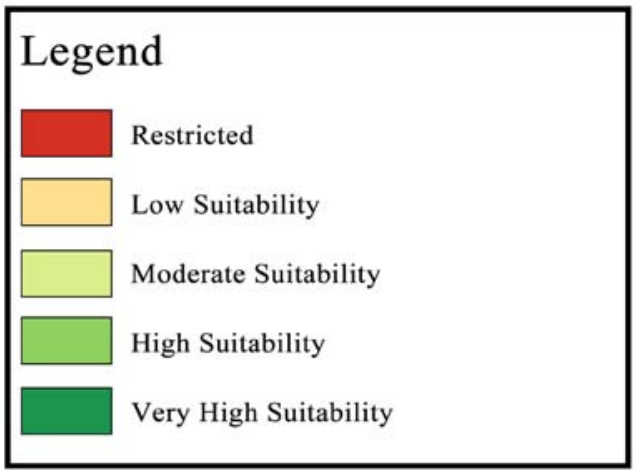

Figure 34. Goat suitability maps in Cabanatuan City, Nueva Ecijafor the 3 conditions. 


\subsection{Farmers Validation Results for Vulnerability Maps and Crops, Chicken and Goat Suitability Maps in Bongabon, Nueva Ecija}

Results of the validation of the vulnerability maps for flood, drought, typhoon and soil erosion in Bongabon by the farmers, LGU personnel and barangay officials showed that the vulnerability maps generated were $100 \%$ accurate. In terms of the validation of the crop suitability maps in the baseline condition, the following are the results of the accuracy of suitability maps: ampalaya (98.42\%), rice $(98.23 \%)$, corn $(100 \%)$, squash $(83.34 \%)$, and onion (96.50\%). Chicken and goat suitability maps obtained $100 \%$ and $95.83 \%$ accuracy, respectively.

\subsection{Farmers Validation Results for Vulnerability Maps and Crops, Chicken and Goat Suitability Maps in Gabaldon, Nueva Ecija}

The vulnerability maps produced for flood, drought, typhoon and soil erosion were rated by the farmers, LGU personnel and barangay officials in Gabaldon as $100 \%$ accurate. The validation of the crop suitability maps for the baseline condition in terms of accuracy in Gabaldon, Nueva Ecija is as follows: ampalaya $(87.50 \%)$, eggplant $(85.71 \%)$, rice $(100 \%)$, chili $(100 \%)$, sitao $(100 \%)$, onion (100\%), and tomato (100\%).

Baseline maps for chicken and goat were also rated $100 \%$ accurate by the farmers and other participants from Gabaldon, Nueva Ecija.

\subsection{Farmers Validation Results for Vulnerability Maps and Crops, Chicken and Goat Suitability Maps in Cabanatuan City, Nueva Ecija}

The vulnerability maps generated for typhoon, flood and drought were rated by the farmers, LGU personnel and barangay officials as $100 \%$ accurate for typhoon, $90.47 \%$ accurate for flood and $95.23 \%$ accurate for drought. The results of validation for crops suitability maps in Cabanatuan City, Nueva Ecija are as follows: ampalaya $(88.89 \%)$, corn $(87.50 \%)$, rice $(93.75 \%)$, onion $(83.65 \%)$, calamansi (100\%), and eggplant (100\%).

The chicken and goat suitability maps were also validated and results indicated that the baseline map for chicken was only $71.67 \%$ accurate while the goat suitability map had $72.60 \%$ accuracy.

\section{Conclusions}

Based on the vulnerability assessment, Bongabon obtained moderate vulnerability to floods and typhoons while low vulnerability to drought and soil erosion whereas Gabaldon had moderate vulnerability to floods, soil erosion and drought while low vulnerability to typhoons. However, Cabanatuan City attained moderate vulnerability to floods and drought while low vulnerability to typhoons.

For the crop suitability assessment, it was found out that the crops suitable to grow in baseline conditions where floods and landslides are included in Bongabon are rice, corn, squash, and onion. However, the crops suitable in the pro- 
jected future scenarios such as RCP 4.5 (good condition) and RCP 8.5 (worst condition) where climate change consequences were involved, are corn, squash, onion, and ampalaya. The crops which are highly suitable to grow in Gabaldon in RCP 4.5 and RCP 8.5 conditions are rice, tomato, and eggplant. The crops suitable to produce in Cabanatuan City for the baseline condition with flood, as well as in RCP 4.5 and RCP 8.5 scenarios, are rice, corn, eggplant, and onion. Native chicken and goat are highly suitable in the 3 conditions for the 3 study sites.

There were 16 vulnerability maps developed and generated in Bongabon, 16 in Gabaldon while only 12 in Cabanatuan City. Furthermore, 21 crop, chicken and goat suitability maps were produced in Bongabon while 27 maps in Gabaldon and 21maps in Cabanatuan City.

Validation of the vulnerability maps obtained $100 \%$ accuracy for typhoon, flood, drought and soil erosion in Bongabon and Gabaldon whereas $100 \%$ accurate for typhoon, $90.47 \%$ accurate for flood and $95.23 \%$ accurate for drought in Cabanatuan City. Overall, validation of the crops, chicken and goat suitability maps in the 3 study sites had high accuracy.

\section{Recommendation}

In order to improve the conduct and analysis of the study, it is therefore recommended that vulnerability and crop suitability assessment and mapping should be conducted for all the municipalities and cities of Nueva Ecija and for the whole Region 3 in order for the local communities to be alert, prepared for and resilient to the impacts of climate change. Moreover, allotment of more time is needed in order to attain all the objectives and expected outputs particularly in the generation of vulnerability maps and crop suitability maps.

\section{Acknowledgements}

Sincere gratitude is being given to the funding agency, the Bureau of Agricultural Research of the Department of Agriculture (DA-BAR) for the provision of financial assistance in order for this study to be conducted and implemented and to WORLDFISH for the technical assistance. Likewise, heartfelt thanks are due to all Local Government Units (LGUs) and local communities of Cabanatuan City, Bongabon and Gabaldon, Nueva Ecija for all the assistance and support they gave and their contribution in the completion of the study.

\section{References}

[1] Paz-Alberto, A.M., Pakaigue, M.A., Bulaong, E.P., Sison, M.J.M. and Lao, R.B. (2016) River Morphology and River Channel Changes in Dagupan River, Pangasinan, Philippines. International Journal of Applied Remote Sensing and GIS, 3, $35-44$.

[2] Paz-Alberto, A.M., Bulaong, E.P., Lao, R.B., Salvador, N.C. and Raneses, E.V. (2017) Remote Sensing in Detection of Geophysical Changes in Talisay River, Bataan, Philippines. Proceedings of SPIE, 10444, 1-10. 
[3] Sajise, A.J., Sombilla, M. and Ancog, R. (2012) Socioeconomic of Climate Change in the Philippines: A Literature Synthesis (1990-2010). SEARCA and PCAARRD, Los Baños, Laguna.

[4] Paz-Alberto, A.M., Sison, M.J.M., Bulaong, E.P. and Pakaigue, M.A. (2016) Remote Sensing Application of the Geophysical Changes in the Coastlines and Rivers of Zambales, Philippines. The International Archives of the Photogrammetry, Remote Sensing and Spatial Information Sciences, XLI-B8, 379-386.

https://doi.org/10.5194/isprsarchives-XLI-B8-379-2016

[5] Paz-Alberto, A.M., Ramos, G.N., Carganilla, H.M.T., Divina, C.C.C. and Barza, J.J.J. (2016) Exposure and Vulnerability Assessment of Buildings Extracted from LiDAR Derived Datasets in the Flood Plains of Santo Tomas River Basin, Zambales, Philippines. International Journal of Applied Remote Sensing and GIS, 3, 1-12.

[6] Paz-Alberto, A.M., Ramos, G.N., Espiritu, J.A., Mapanao, K.M. and Lao, R.B. (2017) Exposure and Vulnerability Assessment of Buildings Extracted From LiDAR Derived Datasets in Bucao River Floodplains, Zambales, Philippines. Proceedings of SPIE, 10444, 1-10.

[7] Mcintyre, B.D., Herren, H.R., Wakhungu, J. and Watson, R.T. (Editors) (2008) Agriculture at a Crossroads: International Assessment of Agricultural Knowledge, Science and Technology for Development (IAASTD) Synthesis Report. Island Press, USA.

[8] Jose, A.M. and Cruz, N.A. (1999) Climate Change Impacts and Responses in the Philippines: Water Resources. Climate Research, 12, 77-84.

http://www.jstor.org/stable/24866001 https://doi.org/10.3354/cr012077

[9] Badjeck, M., Allison, E.H., Halls, A.S. and Dulvy, N.K. (2010) Impacts of Climate Change Variability and Change on Fishery-Based Livelihoods. Marine Policy, 34, 375-383. https://doi.org/10.1016/j.marpol.2009.08.007

[10] Mamauag, S.S., Aliño, P.M., Martinez, R.S., Muallil, R.N., Doctor, M.A., Dizon, E.C. and Cabral, R.B. (2013) A Framework for Vulnerability Assessment of Coastal Fisheries Ecosystems to Climate Change-Tool for Understanding Resilience of Fisheries (VA-TURF). Fisheries Research, 147, 381-393.

https://doi.org/10.1016/j.fishres.2013.07.007

[11] Perez, M.L. and Sajise, A.U. (2013) Economic Analysis of Climate Change Adaptation Strategies in Selected Coastal Areas in Indonesia, Philippines and Vietnam. WordFish, Penang, Malaysia.

https://www.worldfishcenter.org/content/economic-analysis-climate-change-adapta tion-strategies-selected-coastal-areas-indonesia-0

[12] Nzoiwu, C.P., Ezenwaji, E.E. and Okoye, A.C. (2017) A Preliminary Assessment of the Effects of Climate Variability on Agulu Lake, Anambra State, Nigeria. American Journal of Climate Change, 6, 694-170. https://doi.org/10.4236/ajcc.2017.64035

[13] Agba, D.Z., Adewara, S.O., Adama, J.I., Adzer, K.T. and Atoyebi, G.O. (2017) Analysis of the Effects of Climate Change on Crop Output in Nigeria. American Journal of Climate Change, 6, 554-571. https://file.scirp.org/pdf/AJCC_2017092615405249.pdf https://doi.org/10.4236/ajcc.2017.63028

[14] Barry, N.Y., Traore, V.B., Ndiaye, M.L., Isimemen, O., Celestin, H. and Sambou, B. (2017) Assessment of Climate Trends and Land Cover/Use Dynamics within the Somone River Basin, Senegal. American Journal of Climate Change, 6, 513-538. https://doi.org/10.4236/ajcc.2017.63026 